\title{
OBSERVATIONS OF STRESSES AND STRAINS NEAR INTERSECTIONS OF CONICAL AND CYLINDRICAL SHELLS
}

by

Matthew F. Borg

March 1956

Report 911

NS 731.038

This document is PUBLICLY RELEASABLE

Banu Stene

Authorizing Official

Date: $\quad 8.17 .07$

01301 


\section{DISCLAIMER}

This report was prepared as an account of work sponsored by an agency of the United States Government. Neither the United States Government nor any agency Thereof, nor any of their employees, makes any warranty, express or implied, or assumes any legal liability or responsibility for the accuracy, completeness, or usefulness of any information, apparatus, product, or process disclosed, or represents that its use would not infringe privately owned rights. Reference herein to any specific commercial product, process, or service by trade name, trademark, manufacturer, or otherwise does not necessarily constitute or imply its endorsement, recommendation, or favoring by the United States Government or any agency thereof. The views and opinions of authors expressed herein do not necessarily state or reflect those of the United States Government or any agency thereof. 


\section{DISCLAIMER}

Portions of this document may be illegible in electronic image products. Images are produced from the best available original document. 


\section{TABLE OF CONTENTS}

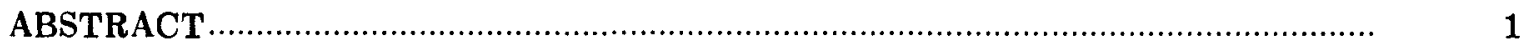

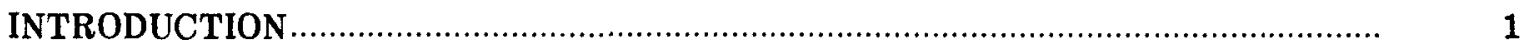

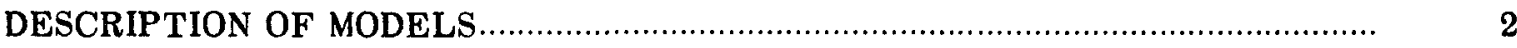

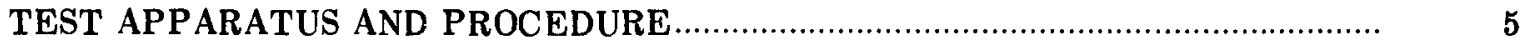

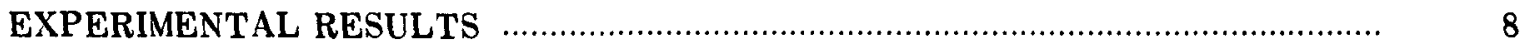

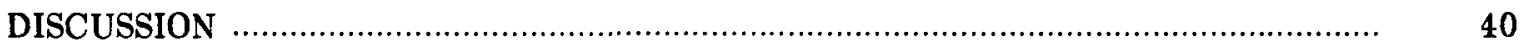

Comparison of Experimental Results with Theory ….......................................... 40

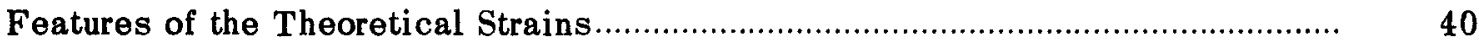

The Experimental Deviations ..................................................................... 42

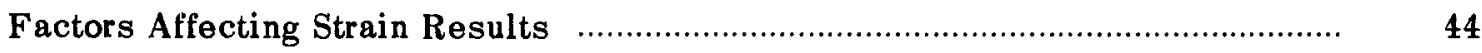

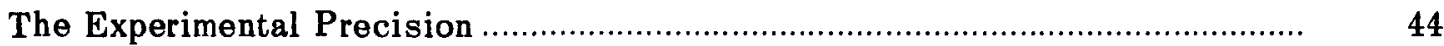

Theoretical Approximations ...................................................................... 44

Effects of Imperfections in the Models .................................................... 45

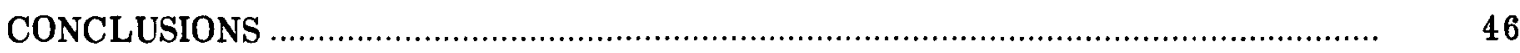

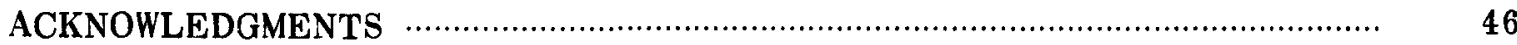

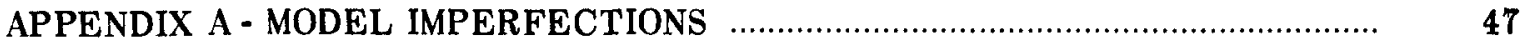

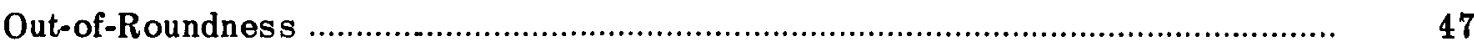

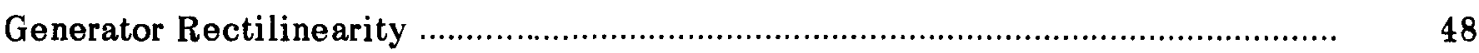

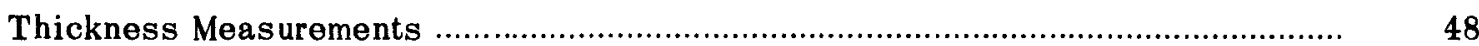

APPENDIX B - THEORETICAL CALCULATIONS ......................................... 60

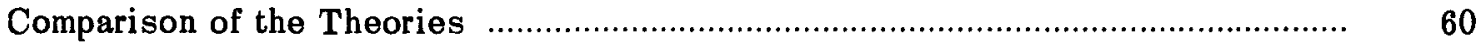

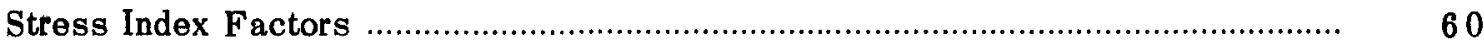

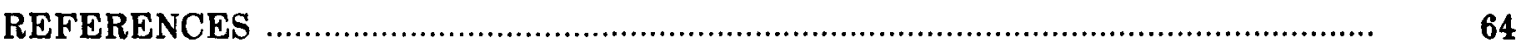




\section{LIST OF ILLUSTRATIONS}

Page

Figure 1 - Nomenclature and Schematic Drawing of Cone-Cylinder Models ............... 3

Figure 2 - Range of Parameters for the Cone-Cylinder Models ............................... 3

Figure 3 - Completed Model Prior to Instrumentation and Testing.......................... 5

Figure 4 - Typical Layout of Strain Gages ......................................................... 6

Figure 5 - Location of Strain Gages on Cone and Cylinder of Models CC-8A, CC-21, and CC-10 in the Second Test ................................................. 7

Figure 6 - Schematic Assembly of Feed-Through Device ........................................ 7

Figure 7 - Typical Test Setup Showing Model CC-21........................................ 7

Figure 8 - Apparatus for Measuring Circularity and Rectilinearity ......................... 7

Figure 9 - Typical Plots of Experimental Pressure versus Strain (Model CC-15) ...... 9

Figure 10 - External Longitudinal Strains in Models CC-8 and CC-8A for Internal Hydrostatic Pressure of 1 psi.............................................. 10

Figure 11 - Internal Longitudinal Strains in Model CC-8A for Internal Hydrostatic Pressure of 1 psi

Figure 12 - Internal and External Circumferential Strains in Models CC-8 and CC-8A for Internal Hydrostatic Pressure of 1 psi

Figure 13 - External Longitudinal Strains in Model CC-9 for Internal Hydrostatic Pressure of 1 psi

Figure 14 - External Circumferential Strains in Model CC-9 for Internal

Hydrostatic Pressure of 1 psi

Figure 15 - External Longitudinal Strains in Model CC-10 for Internal

Hydrostatic Pressure of 1 psi

Figure 16 - Internal Longitudinal Strains in Model CC-10 for Internal Hydrostatic Pressure of 1 psi (Second Test)

Figure 17 - Internal and External Circumferential Strains in Model CC-10 for Internal Hydrostatic Pressure of 1 psi

Figure 18 - External Longitudinal Strains in Model CC-11 for Internal Hydrostatic Pressure of 1 psi

Figure 19 - External Circumferential Strains in Model CC-11 for Internal Hydrostatic Pressure of 1 psi

Figure 20 - External Longitudinal Strains in Model CC-12 for Internal Hydrostatic Pressure of 1 psi

Figure 21 - External Circumferential Strains in Model CC-12 for Internal Hydrostatic Pressure of 1 psi

Figure 22 - External Longitudinal Strains in Model CC-13 for Internal Hydrostatic Pressure of 1 psi.

Figure 23 - External Circumferential Strains in Model CC-13 for Internal Hydrostatic Pressure of 1 psi.

Figure 24 - External Longitudinal Strains in Model CC-14 for Internal Hydrostatic Pressure of 1 psi. 
Figure 25 - External Circumferential Strains in Model CC-14 for Internal

Hydrostatic Pressure of 1 psi

Figure 26 - External Circumferential Strains in Model CC-15 for Internal

Hydrostatic Pressure of 1 psi

Figure 27 - External Longitudinal Strains in Model CC-15 for Internal

Hydrostatic Pressure of 1 psi.

Figure 28 - External Longitudinal Strains in Model CC-16 for Internal Hydrostatic Pressure of 1 psi.

Figure 29 - External Ci.cumferential Strains in Model CC-16 for Internal Hydrostatic Pressure of 1 psi.

Figure 30 - External Longitudinal Strains in Model CC-20 for Internal Hydrostatic Pressure of 1 psi.

Figure 31 - Internal Longitudinal Strains in Model CC-20 for Internal Hydrostatic Pressure of 1 psi

Figure 32 - Internal and External Circumferential Strains in Model CC-20 for Internal Hydrostatic Pressure of 1 psi (First Test)

Figure 83 - Internal and External Circumferential Strains in Model CC-20 for Internal Hydrostatic Pressure of 1 psi (Second Test).

Figure 34 - External Longitudinal Strains in Model CC-21 for Internal Hydrostatic Pressure of 1 psi

Figure 35 - External Circumferential Strains in Model CC-21 for Internal Hydrostatic Pressure of 1 psi

Figure 36 - Schematic Diagram of Purdue University Models 2 and 3.

Figure 37 - Internal Longitudinal Stresses in Purdue University Model 3 for Internal Hydrostatic Pressure of 1 psi

Figure 38 - External Longitudinal Stresses in Purdue University Model 3 for Internal Hydrostatic Pressure of 1 psi

L. úre 39 - Internal Circumferential Stresses in Purdue University Model 3 for Internal Hydrostatic Pressure of 1 psi

* gure 40 - External Circumferential Stresses in Purdue University Model 3 for Internal Hydrostatic Pressure of 1 psi

Figure 41 - Internal Longitudinal Stresses in Purdue University Model 2 for Internal Hydrostatic Pressure of 1 psi

Figure 42 - External Longitudinal Stresses in Purdue University Model 2 for Internal Hydrostatic Pressure of 1 psi

Figure 43 - Internal Circumferential Stresses in Purdue University Model 2 for Internal Hydrostatic Pressure of 1 psi

Figure 44 - External Circumferential Stresses in Purdue University Model 2 for Internal Hydrostatic Pressure of 1 psi

Figure 45 - Circumferential Circularity and Thickness Measurements Compared to Strain Sensicivities at Points $1 / 4$ Inch from the Intersection on the Cone of Model CC-8A.

Figure 46 - Circumferential Circularity and Thickness Measurements Compared to Strain Sensitivities at Points $1 / 4$ Inch from the Intersection on the Cylinder of Model CC-8A. 
Figure 47 - Circumferential Circularity and Thickness Measurements Compared to Strain Sensitivities at Points $1 / 4$ Inch from the Intersection on the Cone of Model CC-10 (Second Test)

Figure 48 - Circumferential Circularity and Thickness Measurements Compared to Strain Sensitivities at Points $1 / 4$ Inch from the Intersection on the Cylinder of Model CC-10 (Second Test).

Figure 49 - Circumferential Circularity Measurements Compared to Strain Sensitivities at Points $3 / 32$ Inch from the Intersection on the Cone of Model CC-21

Figure 50 - Circumferential Circularity Measurements Compared to Strain Sensitivities at Points $3 / 32$ Inch from the Intersection on the Cylinder of Model CC-21

Figure 51 - Longitudinal Profiles of Generators on Cone of Models CC-8 and CC-8A

Figure 52 - Longitudinal Profiles of Generators on Cone of Model CC-10............... 55

Figure 53 - Longitudinal Profiles of Generators on Cylinder of Model CC-10........... 56

Figure 54 - Longitudinal Profiles of Generators on Cone of Model CC-20 (Second Test)

Figure 55 - Longitudinal Profiles of Generators on Cylinder of Model CC-20 (Second Test)

Figure 56 - Thickness Measurements on Generators of Cone of Model CC-10 ............. 57

Figure 57 - Thickness Measurements on Generators of Cylinder of Model CC-10 ........ 58

Figure 58 - Thickness Measurements on Generators of Cone of Model CC-20 (Second Test).

Figure 59 - Thickness Measurements on Generators of Cylinder of Model CC-20 (Second Test)

Figure 60 - Thickness Measurements on 0-Degree Generator of Cone and Cylinder of Model CC-8A

Figure 61 - Maximum Theoretical Circumferential Stress Indexes in Conical and Cylindrical Shell at the Intersection (External Fiber) $h / H=1$

Figure 62 - Maximum Theoretical Longitudinal Stress Indexes in Conical and Cylindrical Shell at the Intersection (External Fiber) $h / H=1$ 


\section{LIST OF TABLES}

Page

Table 1 - Geometric Characteristics of Project Cylicone Models

Table 2 - Maximum Theoretical External Stresses and Strains, for $h / H=1$, per psi of Internal Pressure

Table 3 - Maximum Theoretical External Stresses and Strains, for $h / H \neq 1$, per psi of Internal Pressure.

Table 4 - Average Deviation of Experimental from Theoretical Longitudinal Strain Sensitivities Close by the Intersection

Table 5 - Initial and Allowable Out-of-Roundness of Cone and Cylinder at the Intersection

Table 6 - Comparison of Maximum External Stresses in Cone at Intersection of Models CC-9 and CC- 10

Table 7 - Maximum Theoretical External Strain Sensitivities in Cone of Models CC-9 and CC-10 


\section{ABSTRACT}

To test theory, models of the intersection of a conical and cylindrical shell, having three different apex angles in the cone and three different ratios of thickness to cylinder diameter, were subjected to internal hydrostatic pressure, and the resulting strains at various points were measured. Careful studies were made of the unavoidable imperfections in the models. The results are in substantial agreement with the Wenk-Taylor approximate theory described in TMB Report 826, and with the approximate theory of Geckeler. Comparisons are also made with other theories.

\section{INTRODUCTION}

In the strength analysis of the USS NAUTILUS (SSN 571), of the USS ALBACORE (AGSS 569), and of the 30-ft test tank at the Portsmouth Naval Shipyard, the Bureau of Ships encountered for the first time the task of computing stresses at the intersection of conical and cylindrical components of pressure vessels. In both cases, special strength analyses were developed in collaboration with the David Taylor Model Basin. Experience with these design features has been favorable so that continued omission of shear brackets at such intersections and use of conical transition pieces between cylindrical hull sections of different diameters can be expected. Thus, rather than attack each future problem as a special case, the development of more adequate and general solutions for the strength design of these conical structures was believed warranted. As a consequence, a research program was established at the Taylor Model Basin, designated Project Cylicone, ${ }^{1}$ to evaluate the available knowledge of the subject, to derive new theory or simplify design procedures where necessary, and to validate the analysis by experiment.

The first step, reported in TMB Report $826,{ }^{2}$ was to extract frome basic elastic theory a family of edge coefficients for cones to provide a convenient method of computing strength of pressure vessels which incorporate conical elements. Application was considered to both stiffened and unstiffened intersections. In this report, the proposed theory is confronted by data collected from a series of twelve model tests, which comprise that experimental phase of Project Cylicone dealing with elastic behavior of unstiffened intersections. Additional tests are planned to investigate stiffened intersections. Since it is known that rather high local stresses may develop at intersections without precipitating failure of the structure, additional theoretical and experimental investigations will yet be required to establish what level of elastic stress may be accepted in design. The tests described herein were confined to the elastic range and thus do not throw any light on this question.

\footnotetext{
${ }^{1}$ References are listed on page 64.
} 
The first undertaking in the study of elastic behavior of cones was to examine the existing theory and experiffental work. Several theoretical papers were found, but further refinement was developed because of the unknown accuracy of approximate analyses and because of the impracticability of rigorous ones; this is explained in TMB Reports $826^{2}$ and $981 .^{3}$ On the other hand, collateral experimental work on the equilibrium of intersecting conical and cylindrical shells previous to the last decade was almost totally lacking, probably because experimental techniques were unavailable to measure internal strains of internally loaded pressure vessels. ${ }^{4}$ Within the last few years, however, with the advent of wire-resistance electric strain gages, progress has been rapid. An extensive experimental investigation of steel and plastic pressure vessels having various shapes of heads was conducted at Purdue University under the sponsorship of the Design Division of the Pressure Vessel Research Committee of the Welding Research Council, ${ }^{5-7}$ but the models with conical heads were in a limited range of thickness-to-diameter ratios from approximately 0.013 to 0.04 . The Taylor Model Basin series of tests described in this report utilized models in which the range of thickness-to-diameter ratios was extended downward to include values of greater interest to naval designers. The results from these tests have shown substantial agreement with the approximate theoretical solutions for the differential equations of equilibrium of conical shells developed by Wenk and Taylor. ${ }^{2}$

The data obtained from two models were also compared with theoretical values calculated by the approximate method introduced by J. Geckeler ${ }^{8,9}$ and sometimes called the "equivalent cylinder" method. This method is compared with the results obtained by the theory of TMB Report 826 and by the more rigorous theory of Love-Meissner. ${ }^{10}$ It is concluded that, for the range of geometries studied, there is little difference between the final results of either TMB Report 826, Geckeler, or Love-Meissner, although the maximum stresses computed by the three theories diverge as the apex angle of the conical shell increases.

On the basis of agreement between these three methods of elastic analysis, and their support by experiment, the Model Basin is preparing for early publication, a general evaluation of theory and a simplified procedure by which stresses at cone-cylinder intersections may be rapidly computed.

\section{DESCRIPTION OF MODELS}

Twelve unstiffened models of cone-cylinder intersections were designed so that the effects of three geometric parameters of interest to naval designers could be studied individually. The parameters are $\alpha, h / 2 R$, and $h / H$, where $\alpha$ is the half apex angle of the cone, $h$ is the thickness of the conical shell, $H$ is the thickness of the cylindrical shell, and $R$ is the radius of the cylinder taken to the middle surface; see Figure 1.

Three nominal values of $h / 2 R$ were selected, lying below the range tested at $\mathrm{Purdue}$ University, namely (based on available materials and assumed radii), 0.00391, 0.00617, and 0.01042. For various reasons, the actual values employed were somewhat different. For each nominal value of $h / 2 R$, three models were constructed, with $\alpha$ equal to $5 \mathrm{deg}, 30 \mathrm{deg}$, and $60 \mathrm{deg}$, 


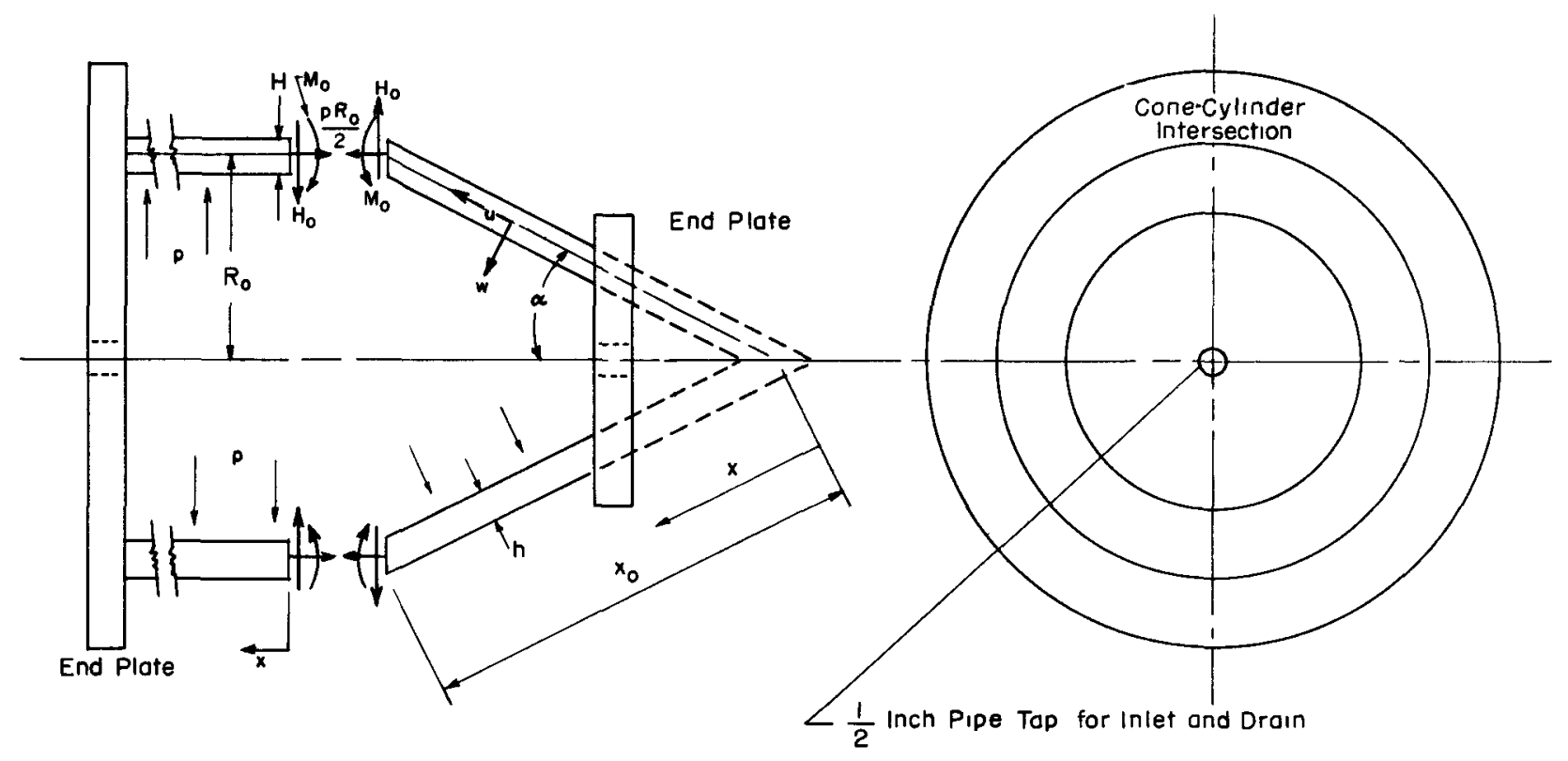

Figure 1 - Nomenclature and Schematic Drawing of Cone-Cylinder Models

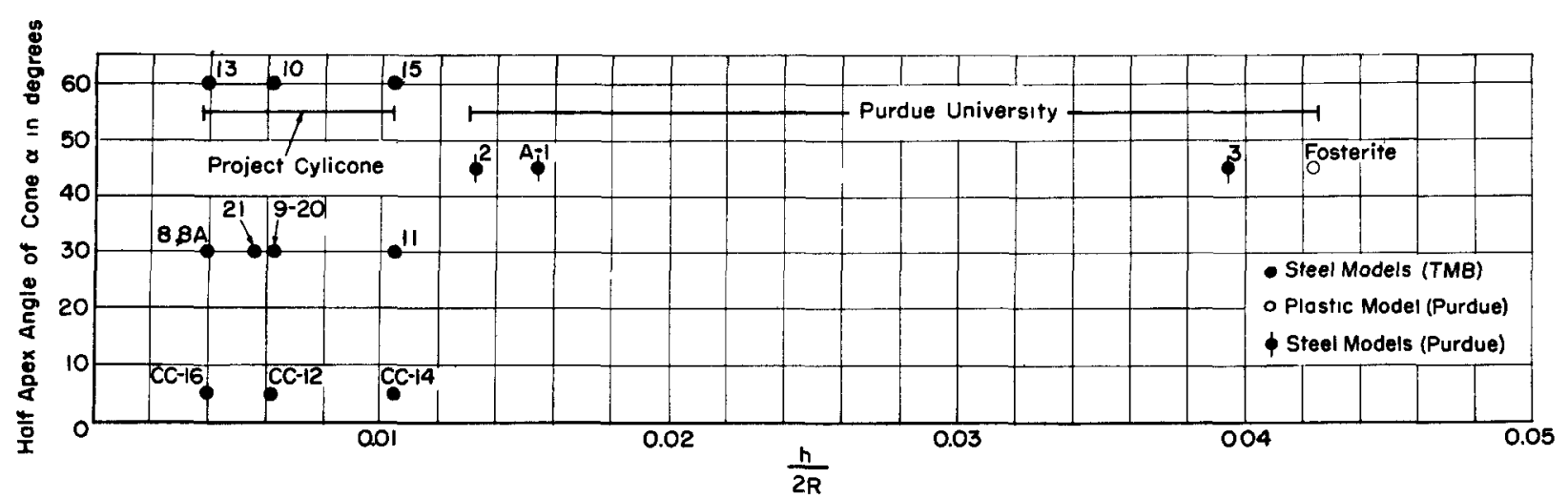

Figure 2 - Range of Parameters for the Cone-Cylinder Models

respectively. For all but two of the models $h=H$; for Model CC-20, $h / H=1.5$, whereas for Model CC-21, $h / H=0.67$. The parameters of these models are listed in Table 1 , together with the yield stress of the material; the values of $\alpha$ and $h / 2 R$ (nominal) are also plotted in Figure 2 , including data for four of the Purdue University models.

Two of the models (Models CC-10 and CC-20) were subsequently reinstrumented and retested, and two models (Models CC-8 and CC-8A) were made as nearly identical as possible in order to determine the consistency and reproducibility of the experimental results.

As the cost of machined models was considered prohibitive, the models were fabricated by rolling and welding together steel sheets. The average variation in thickness of a given steel sheet was \pm 1.0 percent. This low tolerance for steel thickness was deemed essential, as assumptions in the stress distribution theory are based on uniform thickness. However, the fabrication procedure did lead to a variation greater than 1 percent near the intersection, 
TABLE 1

Geometric Characteristics of Project Cylicone Models

\begin{tabular}{|c|c|c|c|c|c|c|c|c|}
\hline \multirow[t]{2}{*}{ Model } & \multirow{2}{*}{$\begin{array}{c}\text { Average } \\
\text { Cone } \\
\text { Thickness } \\
h \\
\text { in. }\end{array}$} & \multirow{2}{*}{$\begin{array}{c}\text { Average } \\
\text { Cylinder } \\
\text { Thickness } \\
H \\
\text { in. }\end{array}$} & \multicolumn{2}{|c|}{$\begin{array}{c}\text { Average Material Yield } \\
\text { Stress, } \sigma_{y^{\prime}} \text { psi }\end{array}$} & \multirow{2}{*}{$\begin{array}{l}\text { Radius } \\
\text { of } \\
\text { Cylinder } \\
R \\
\text { in. }\end{array}$} & \multirow{2}{*}{$\begin{array}{c}\text { Half Apex } \\
\text { Angle of Cone } \\
\alpha \\
\text { deg }\end{array}$} & \multirow{2}{*}{$\begin{array}{l}h / 2 R \\
\text { Actual }\end{array}$} & \multirow{2}{*}{$\begin{array}{r}h / 2 R \\
\text { Nominal }\end{array}$} \\
\hline & & & Cone & Cylinder & & & & \\
\hline CC. 8 & 0.060 & 0.060 & $29,400 *$ & $29,400 *$ & 8.0 & 30 & 0.00375 & 0.00391 \\
\hline CC-8A & 0.060 & 0.060 & $31,350 *$ & $31,350^{*}$ & 8.0 & 30 & 0.00375 & 0.00391 \\
\hline CC-9 & 0.094 & 0.094 & $38,000^{*}$ & $38,000 *$ & 7.6 & 30 & 0.00618 & 0.00617 \\
\hline CC-10 & 0.096 & 0.096 & 39,750 & 39,750 & 7.6 & 60 & 0.00632 & 0.00617 \\
\hline CC-11 & 0.1046 & 0.1046 & 32,600 & 32,600 & 6.0 & 30 & 0.00872 & 0.01042 \\
\hline CC- 12 & 0.0834 & 0.0834 & 30,250 & 30,250 & 7.6 & 5 & 0.00548 & 0.00617 \\
\hline $\mathrm{CC}-13$ & 0.0607 & 0.0607 & 32,300 & 32,300 & 8.0 & 60 & 0.00379 & 0.00391 \\
\hline$C C \cdot 14$ & 0.1034 & 0.1034 & 36,750 & 36,750 & 6.0 & 5 & 0.00862 & 0.01042 \\
\hline CC- 15 & 0.1061 & 0.1061 & 38,400 & 38,400 & 6.0 & 60 & 0.00884 & 0.01042 \\
\hline CC. 16 & 0.0725 & 0.0725 & 32,200 & 32,200 & 8.0 & 5 & 0.00453 & 0.00391 \\
\hline CC-20 & 0.0974 & 0.0607 & 39,900 & 31,850 & 7.6 & 30 & 0.00641 & 0.00617 \\
\hline CC-21 & 0.0607 & 0.0974 & 31,850 & 39,900 & 5.7 & 30 & 0.00532 & \\
\hline
\end{tabular}

but this inconsistency did not materially prejudice the overall comparison of the theoretical and experimental results.

All models were fabricated in a similar way. The cylindrical and conical shells were machine rolled to the desired internal diameters and welded along their longitudinal seams to give two complete individual shells. The longitudinal weld was hand-ground flush with the shell surface. A steel straight edge was placed against each shell, and, if any generator was judged to have excessive peaks or valleys that were difficult to straighten out, the model was rejected.

Thin stiffening plates were tack-welded on the inside of each of the accepted shells at both ends in order to prevent any large distortions at the intersection when the cone and cylinder were welded together. These plates were removed after the two pieces had been joined. The weld at the junction was hand-ground flush with the shell surface. The difficulty at this stage was to produce as constant a thickness around the intersection as could be obtained by hand grinding. Since the shells were not absolutely circular, the excess weld material could not be removed by machining. Guide lines scribed on both shells were used by the machinist in grinding the intersection into a sharp and true line. Thickness measurements 
made at the intersection after the models were completed, as shown in Figures 56 to 60 in Appendix A, gave no observable trend as to overabundance or undercutting of shell materials.

Models CC-20 and CC-21, which had different shell thicknesses for the cone and cylinder, were constructed so that the inside diameters matched; consequently, in addition to the excess weld material, the abutting shell material at the intersection had to be ground off.

End plates were welded on each end of the models. The plate at the cone end was 1 in. thick; that at the cylinder end, 2 in. thick.

A completed model is shown in Figure 3.

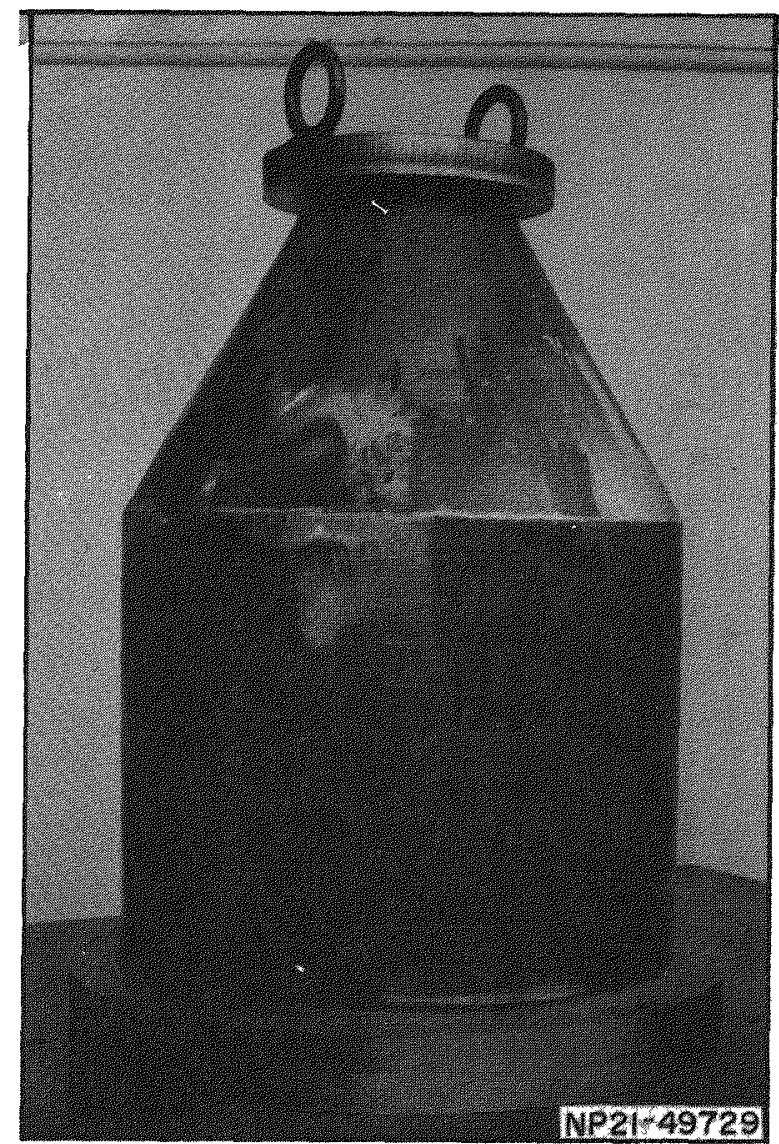

Figure 3 - Completed Model Prior to Instrumentation and Testing

\section{TEST APPARATUS AND PROCEDURE}

The models were instrumented with electric wire-resistance strain gages. Models CC-8 through CC-16 (except for Model CC-8A) and Model CC-21 had gages only on the outer surface of the shells. Models CC-8A, CC-10 for the retest, and CC-20 for both tests were instrumented on both the outer and inner shell surfaces, with gages back to back, to provide data for possible correlation of strain results with variations in thickness and initial departures from circularity at their point of location.

For the high strain gradient near the intersection of the shells, Type A-8, 1/8-in. gage length, SR-4 electric strain gages were oriented as close together as possible in the longitudinal direction. In the circumferential direction, SR-4 Type A-7 gages of 1/4-in. gage length were used, since no variation in strain was expected in that direction. Gages were cemented to the surfaces and dried as recommended by the manufacturer. Gages found to have a resistance to ground of less than 100 megohms were replaced. The distance of the centerline of each gage from the cone-cylinder intersection was measured with a ruler to the nearest $1 / 32 \mathrm{in}$. 


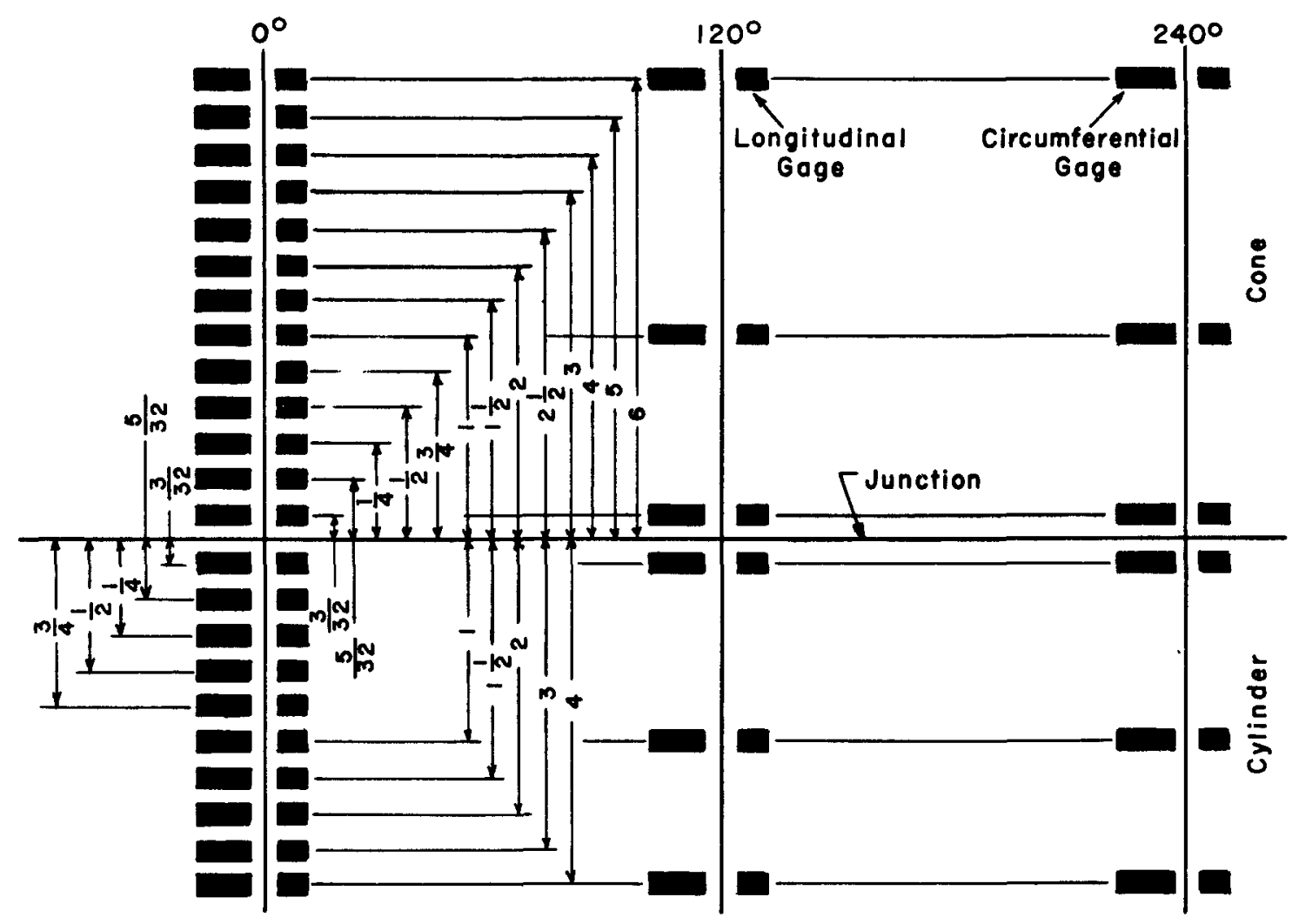

Figure 4 - Typical Layout of Strain Gages

The gages were placed in pairs, one circumferentially, the other longitudinally, from a point $3 / 32$ in. from the intersection to as far as 6 in. away on the conical shell. The gages wer located along generator lines arbitrarily labeled 0, 120, and $240 \mathrm{deg}$. The 0-deg line contained the largest number of gages, while the other two lines were used for spot-checking the data from these gages. A typical layout for the gages is shown in Figure 4. Models instrumented only on the outer surface carried approximately 75 gages. Twice that number were used on models instrumented on both inner and outer surfaces.

Models CC-8A, CC-21, and CC-10 in the second test had a large number of additional gages on the inside or outside of both the conical and cylindrical shells, arranged in bands $3 / 32$ or $1 / 4$ in. from the intersection; see Figure 5. These were installed to investigate possible variability in strains suspected to develop from initial out-of-roundness.

The lead wires from the inside gages were brought out through the large end plate by means of a TMB feed-through device, shown in Figure 6. This feed-through device had 100 holes, for 50 paired lead crom the gages. For the models instrumented on the inside, where more than 50 internal gage were used, common ground leads were employed. A typical test setup is shown in Figure 7.

Prior to the strain gage installation, circumferential and longitudinal circularity, and thickness, were measured along sections and generators on which strain gages were located. 


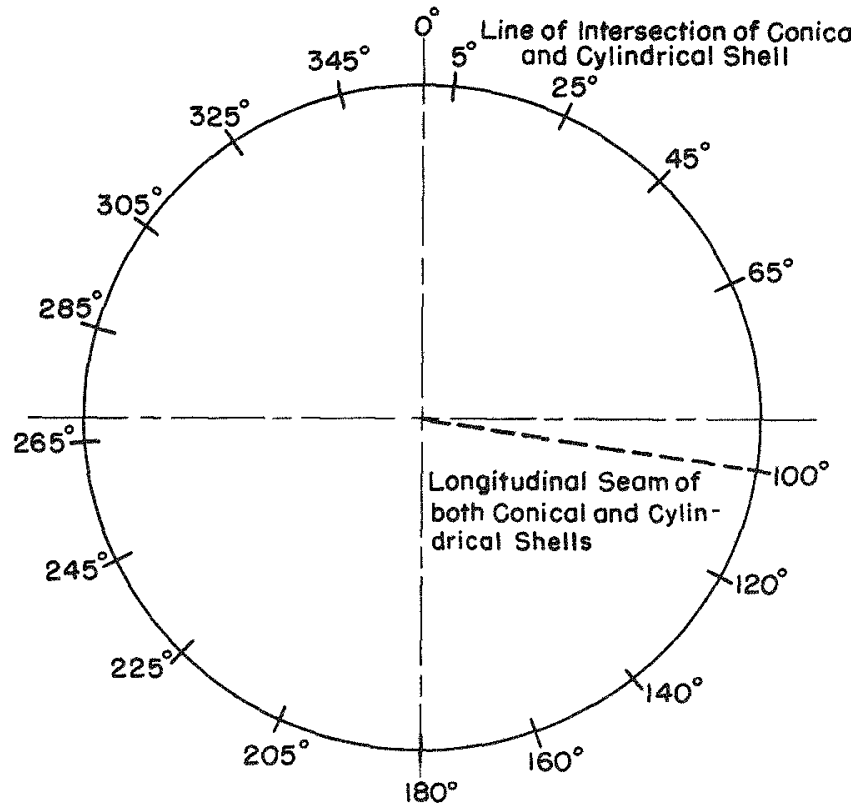

Figure 5 - Location of Strain Gages on Cone and Cylinder of Models CC-8A, CC-21, and CC-10 in the Second Test

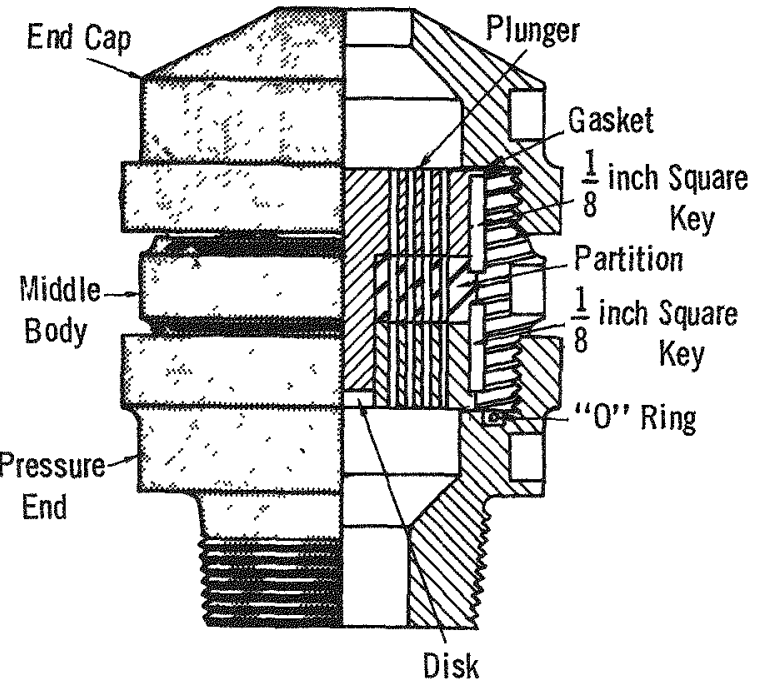

Figure 6 - Schematic Assembly of FeedThrough Device

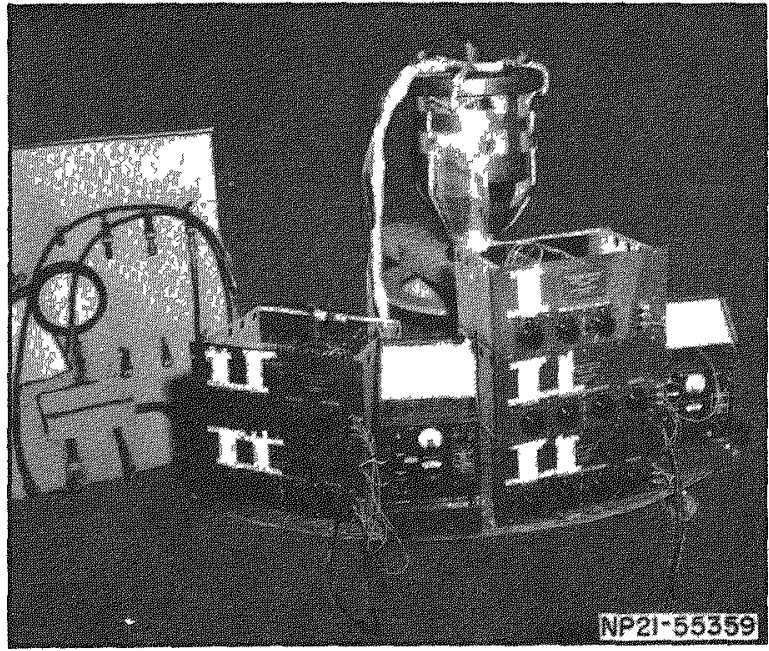

Figure 7 - Typical Test Setup Showing Model CC-21

Switching bozes and strain indicators are in the foreground. Pressure apparatus is to the left.

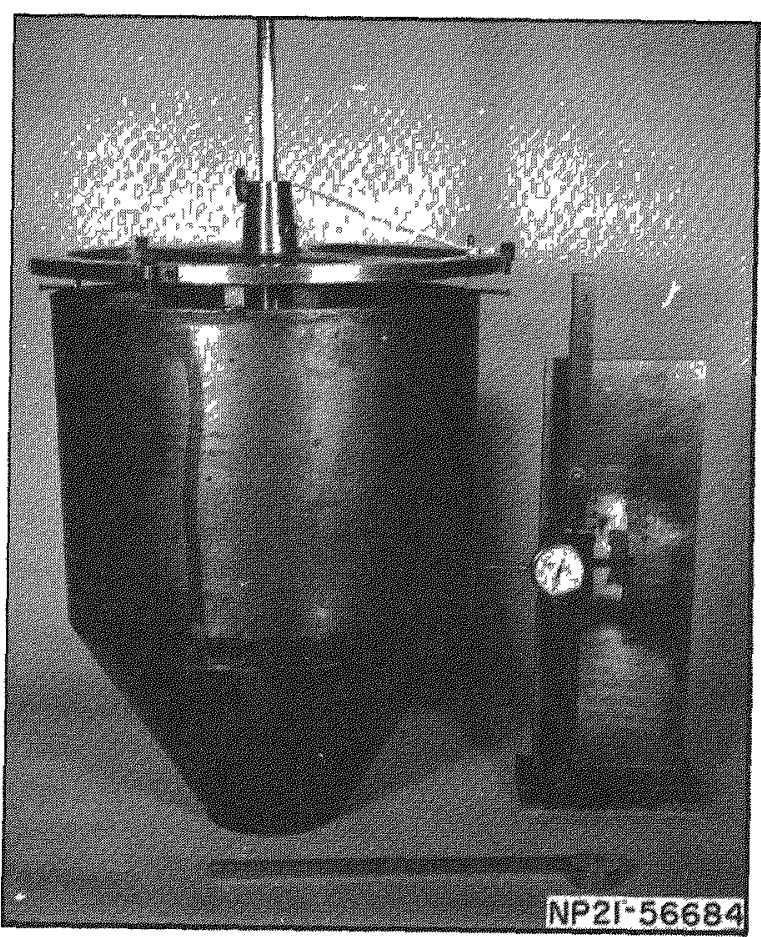

Figure 8 - Apparatus for Measuring Circularity and Rectilinearity

The apparatus inside the shells is for circumferential circularity measurements, and that on the side, for measuring longitudinal profiles. 
Ames dial gages mounted on the shafts of manual deflectometers were used for the circularity measurements; see Figure 8. Circularity and thickness were measured to give (a) an indication of the initial out-of-roundness of the model, (b) an indication of generator rectilinearity, and (c) a possible correlation between initial circularities, measured thickness, and observed strain sensitivities.

Prior to testing, the models were completely submerged in oil for 24 hours. This prevented erratic thermal effects by equalizing the temperature in the model and the dummy blocks on which temperature-compensating gages were mounted. In testing, internal pressure was applied by oil in magnitudes such that the maximum observed strain was about 50 percent below that at which yielding of the model material was first computed to occur.

The strain gage readings were plotted against the applied pressure, and the slope or strain sensitivity in microinches per inch per psi of pressure was obtained for comparison with theoretical calculations. Strain sensitivity was employed in preference to stress because both gages at a point would have to be operative in order to obtain the stress, whereas strain sensitivity could be determined from readings of a single gage. Positive strain or stress indicates tension, and negative strain or stress indicates compression. Strain sensitivities in the cone and cylinder for the 12 models, in microinches per inch per psi, are plotted as a function of the distance from the intersection along the generator.

\section{EXPERIMENTAL RESULTS}

The plot of experimental strain versus applied pressure was essentially linear. Figure 9 is a sample plot. Two pressure runs were usually made, and the slopes of the pressure-strain plots almost always were identical. In all but a small number of gages, the zero shift, after removal of the pressure, was not more than $\pm 10 \mu \mathrm{in} / \mathrm{in}$. Where a gage did not return to its original reading, it was assumed that local yielding had occurred in the shell, probably due to the initial stresses induced by welding at the intersection and the longitudinal seam. All gages had a resistance to ground of at least 100 megohms prior to the tests.

Figures 10 through 35 show the experimentally determined strain sensitivities for all models tested. Theoretical curves are drawn in these figures according to the theory described in TMB Report 826, with the addition of a few curves based on Geckeler's theory. A comparison of the theory with steel models tested at Purdue University ${ }^{5}$ is also of interest. Models 2 and 3, shown schematically in Figure 36, were chosen for this comparison because they were the only models with a sharp transition from cone to cylinder. The experimental results for these models are shown in comparison with theoretical curves in Figures 37 through 44.

The variability of the experimental results was checked by performing the same test on two identical models (CC-8 and CC-8A), and by retesting two models (CC-10 and CC-20) with gages on different generator s.*

\footnotetext{
*Model CC-8, which had been destroyed at the completion of the test, was duplicated because of insufficient strain data. Model CC-10 was reinstrumented because of its extreme cone angle, and in order to obtain additional comparisons with TMB Report 826 and Geckeler approximate theories.
} 
Longitudinal Gages

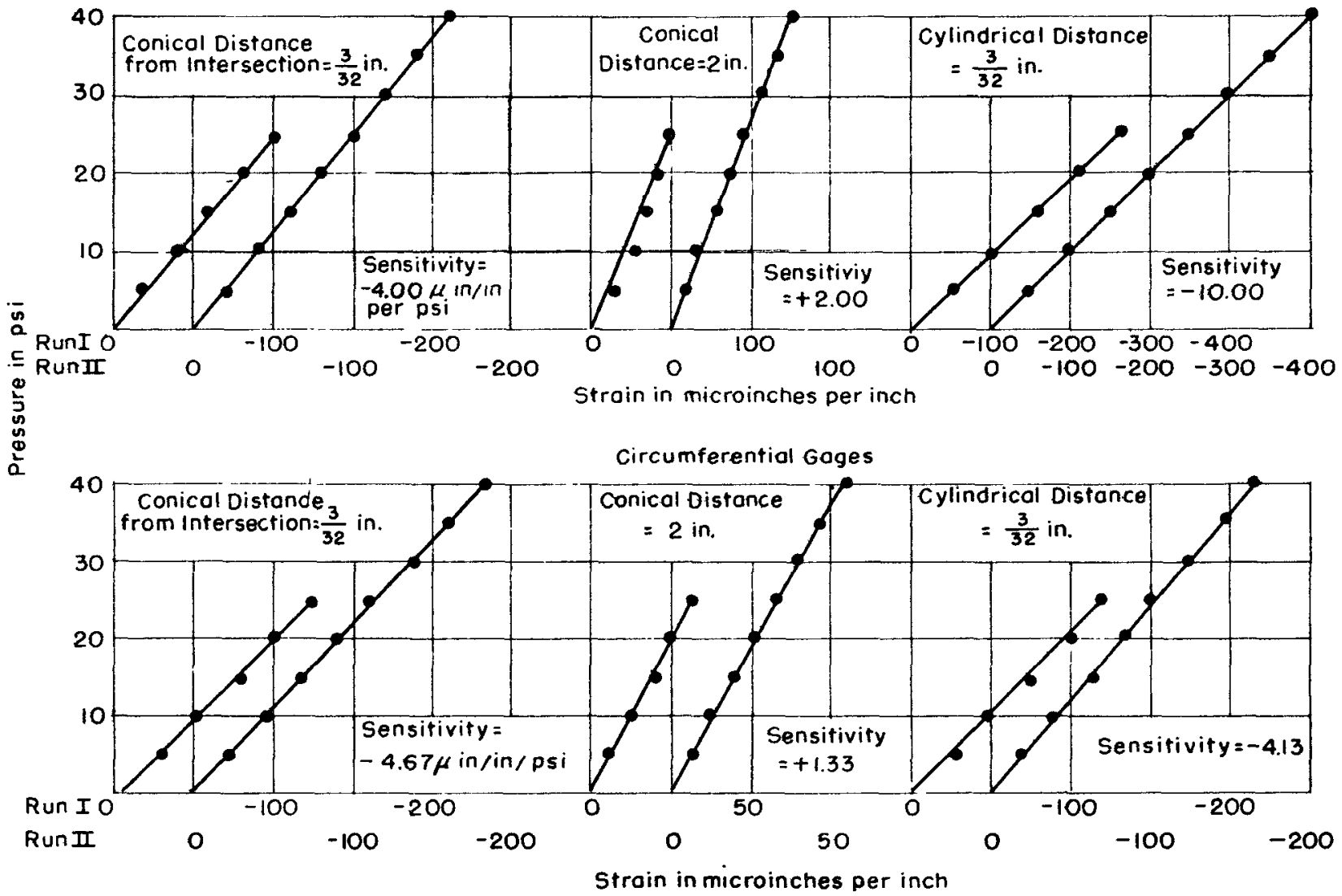

Figure 9 - Typical Plots of Experimental Pressure versus Strain (Model CC-15)

From a comparison of results in Figures 10, 11, 12, 15, 28, and 30-33, consistency between identical tests was considered very good. 


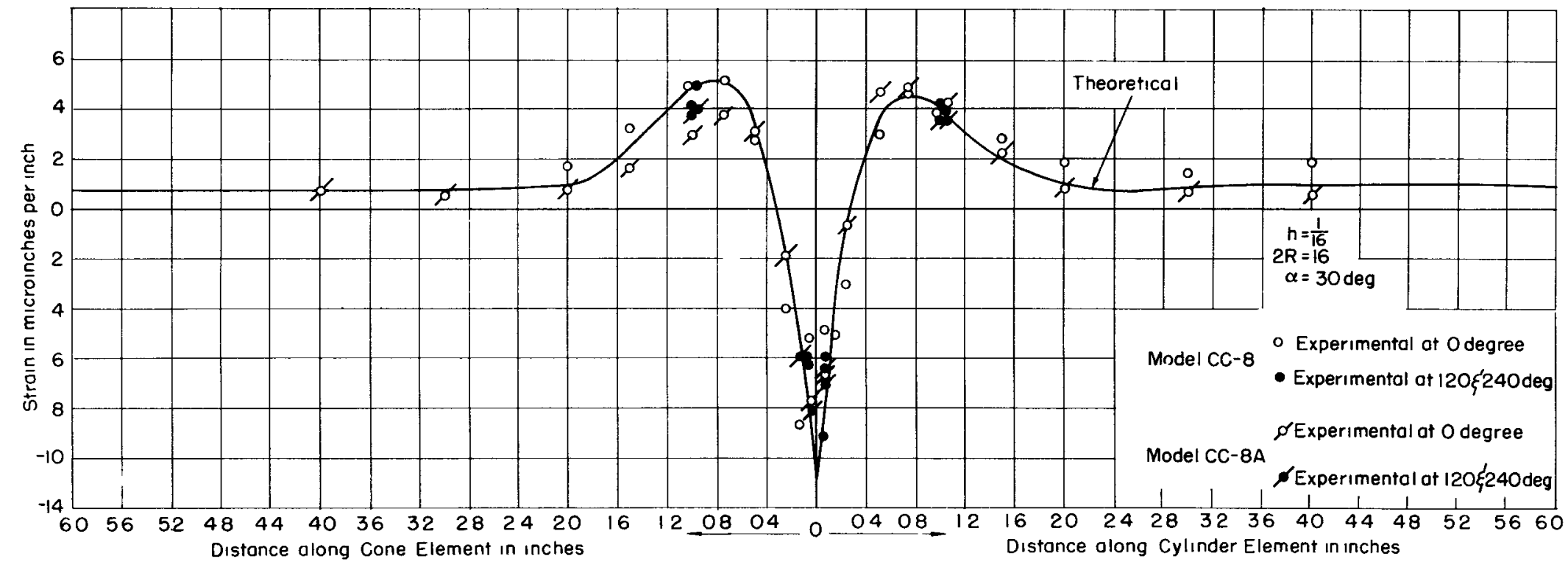

Figure 10 - External Longitudinal Strains in Models CC-8 and CC-8A for Internal Hydrostatic Pressure of 1 psi 


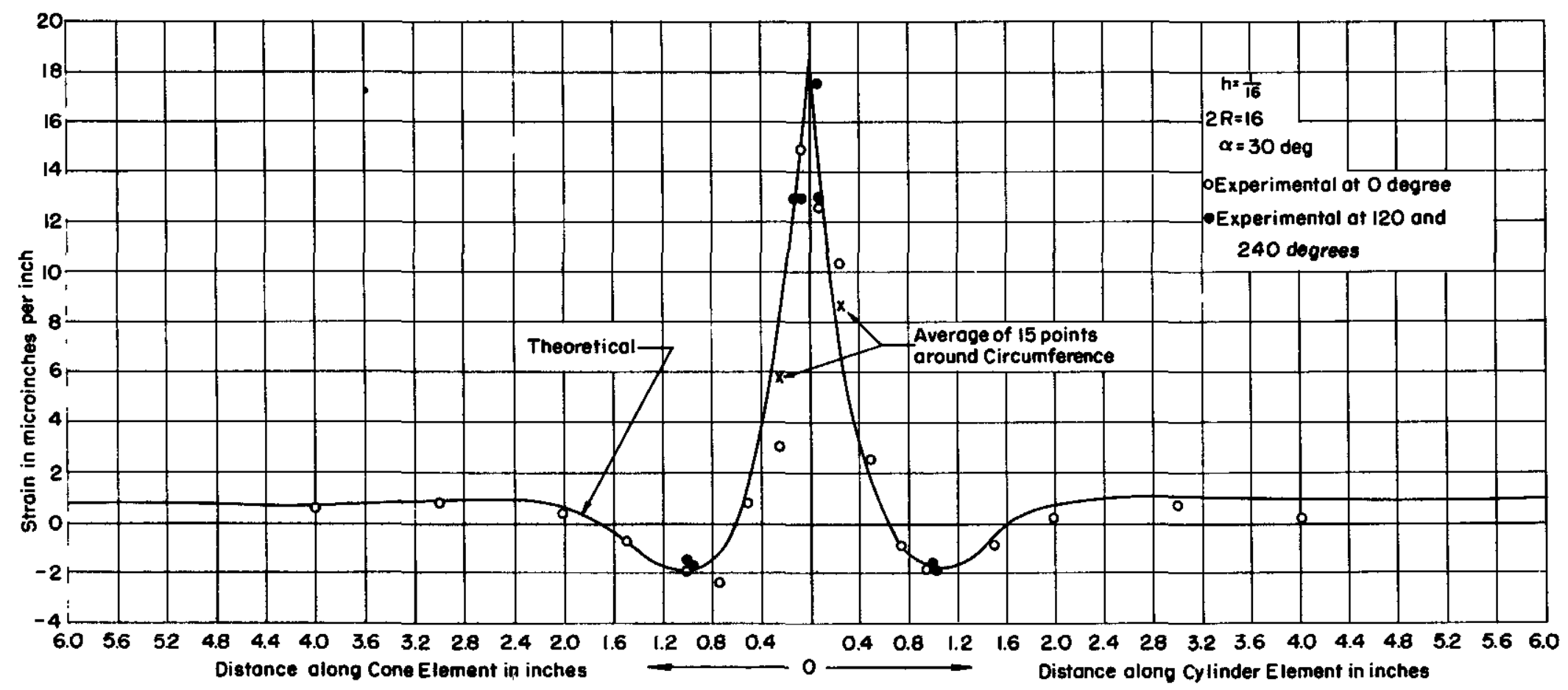

Figure 11 - Internal Longitudinal Strains in Model CC-8A for Internal Hydrostatic Pressure of 1 psi 


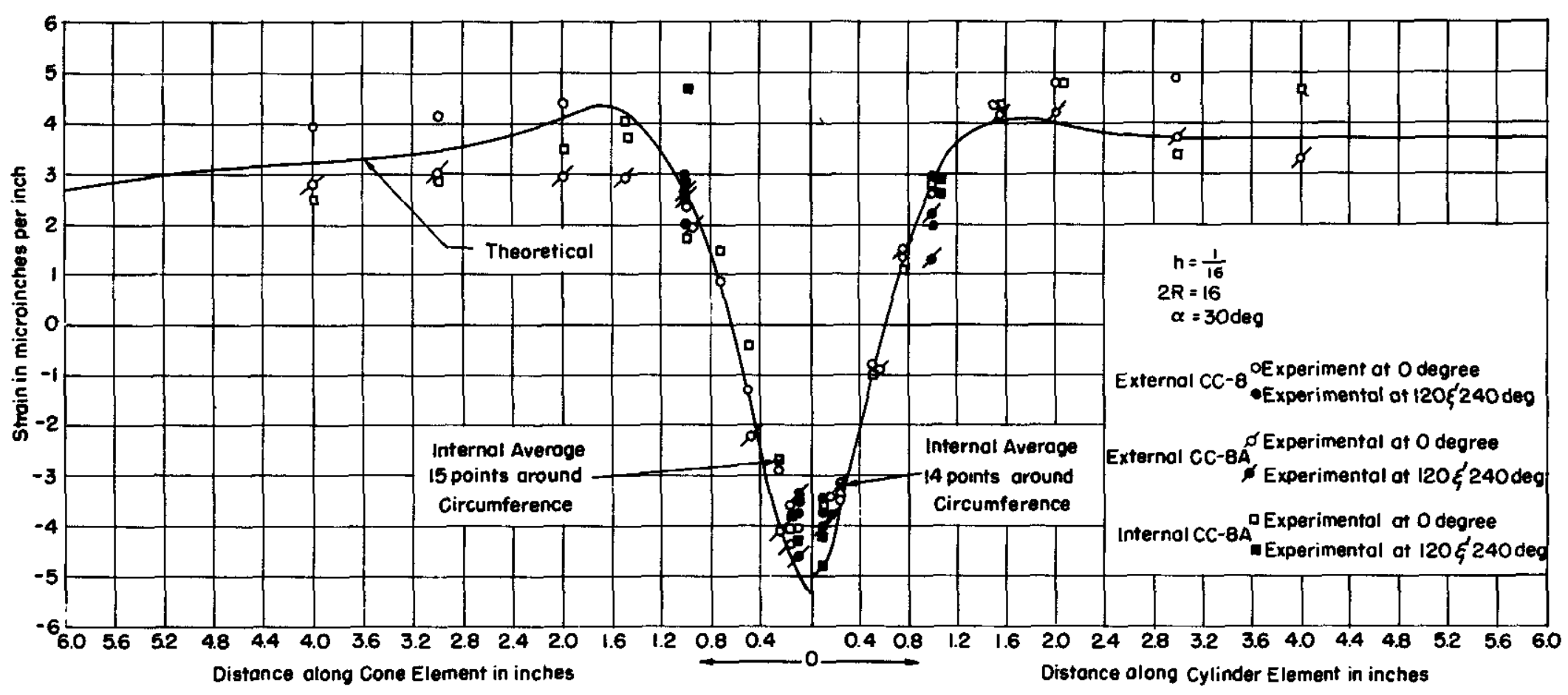

Figure 12 - Internal and External Circumferential Strains in Models CC-8 and CC-8A for Internal Hydrostatic Pressure of 1 psi 


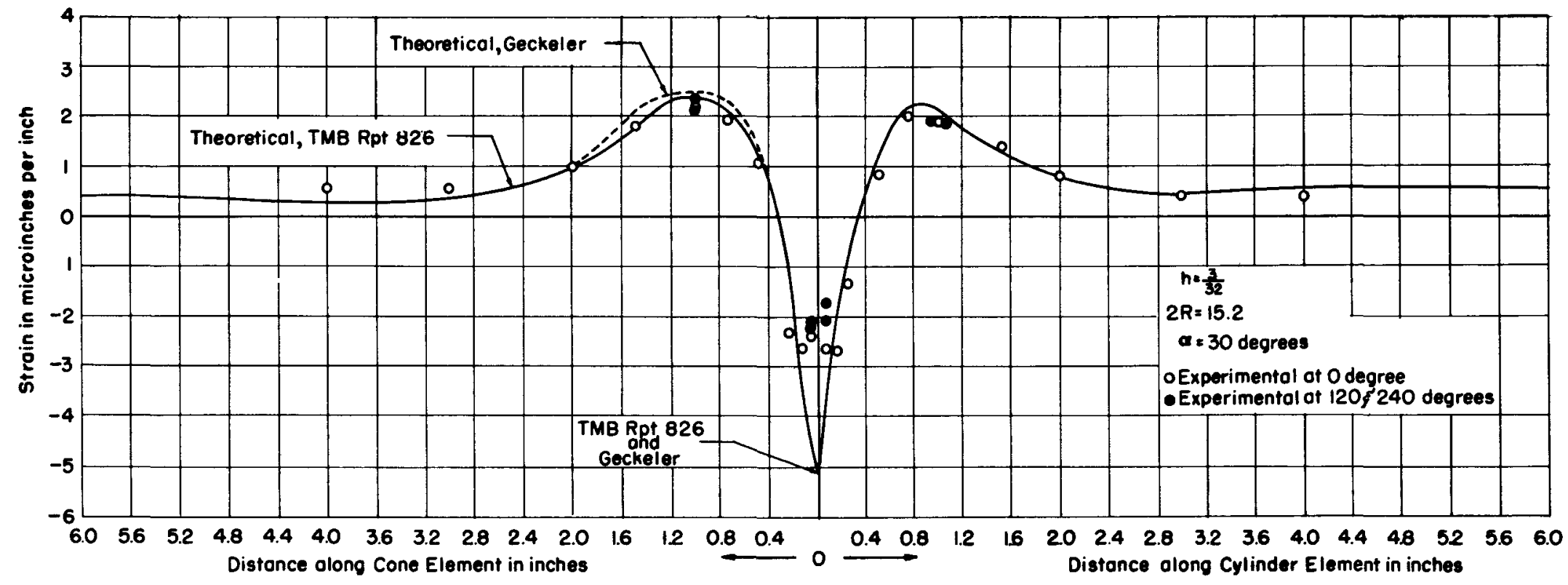

Figure 13 - External Longitudinal Strains in Model CC-9 for Internal Hydrostatic Pressure of 1 psi 


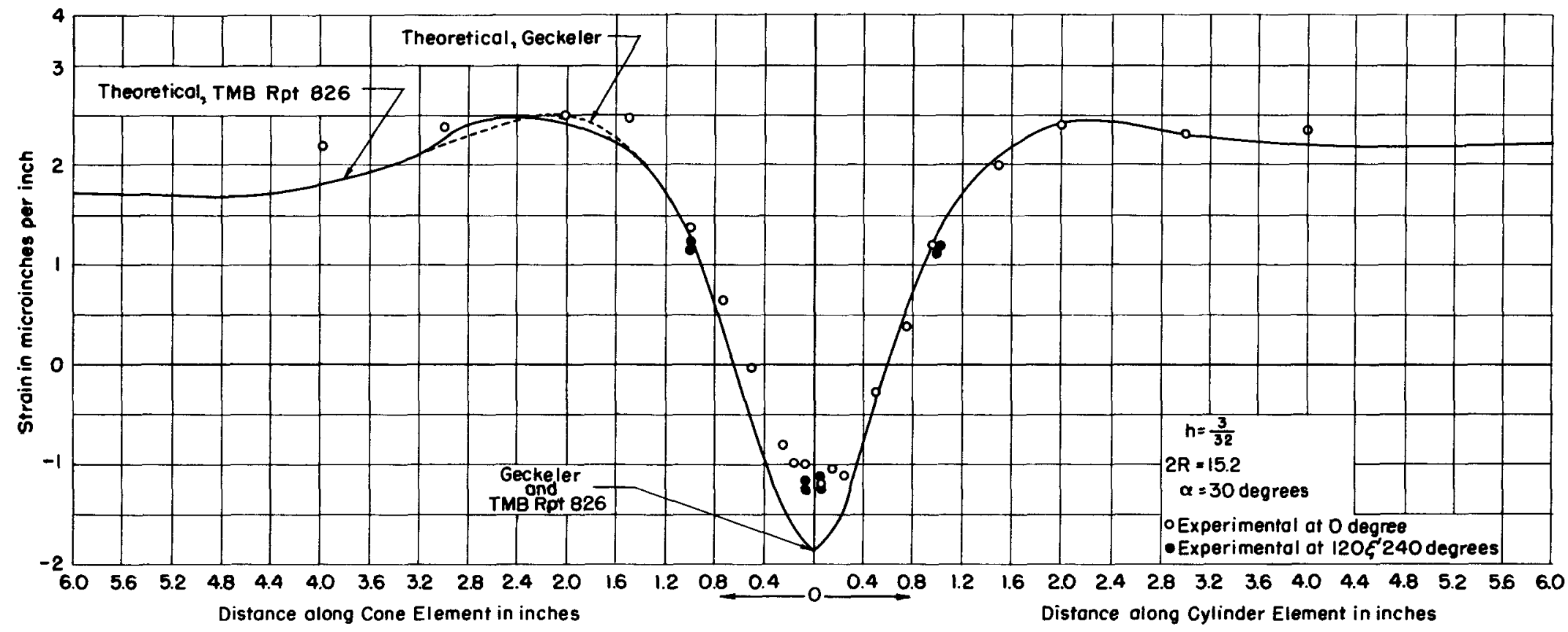

Figure 14 - External Circumferential Strains in Model CC-9 for Internal Hydrostatic Pressure of 1 psi 


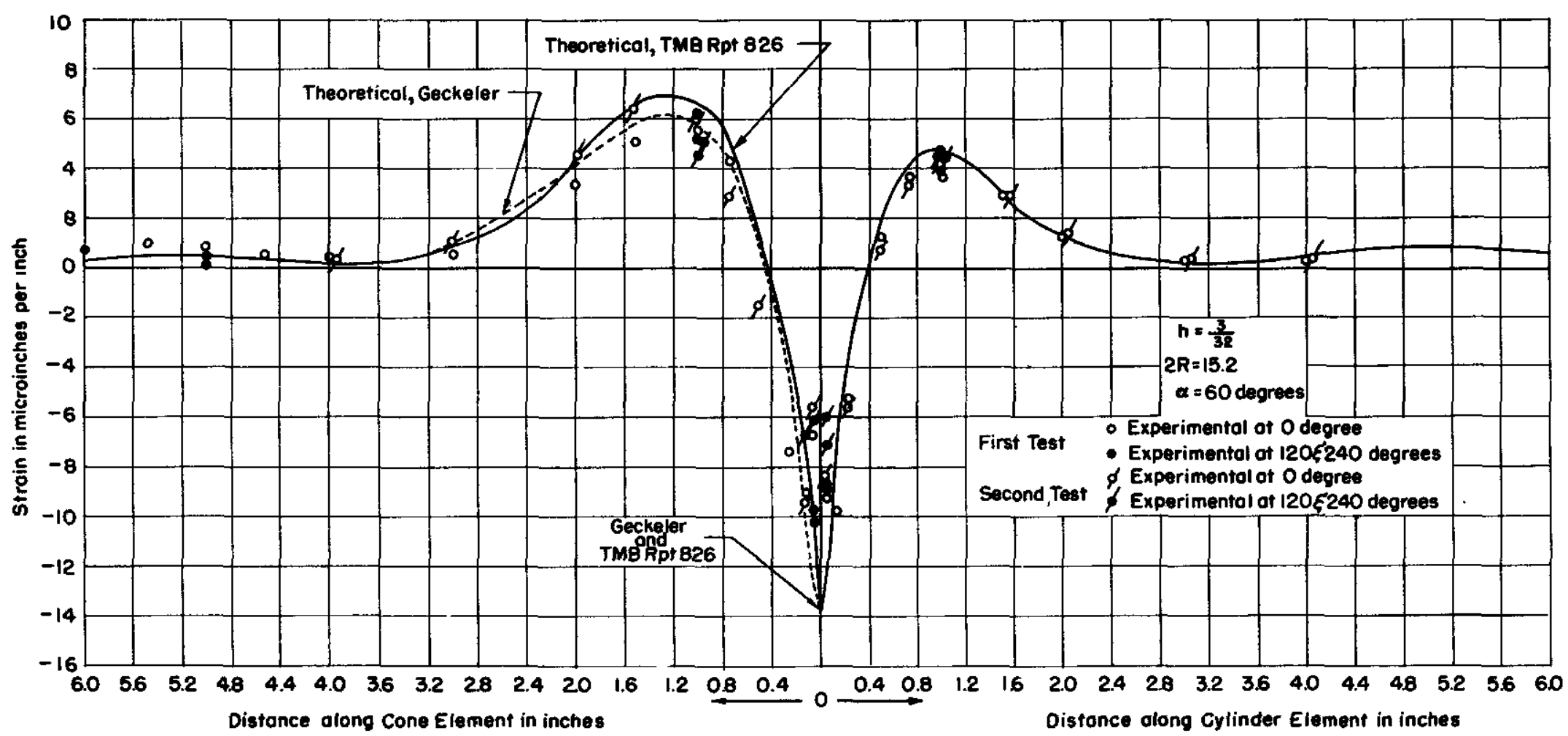

Figure 15 - External Longitudinal Strains in Model CC-10 for Internal Hydrostatic Pressure of 1 psi 


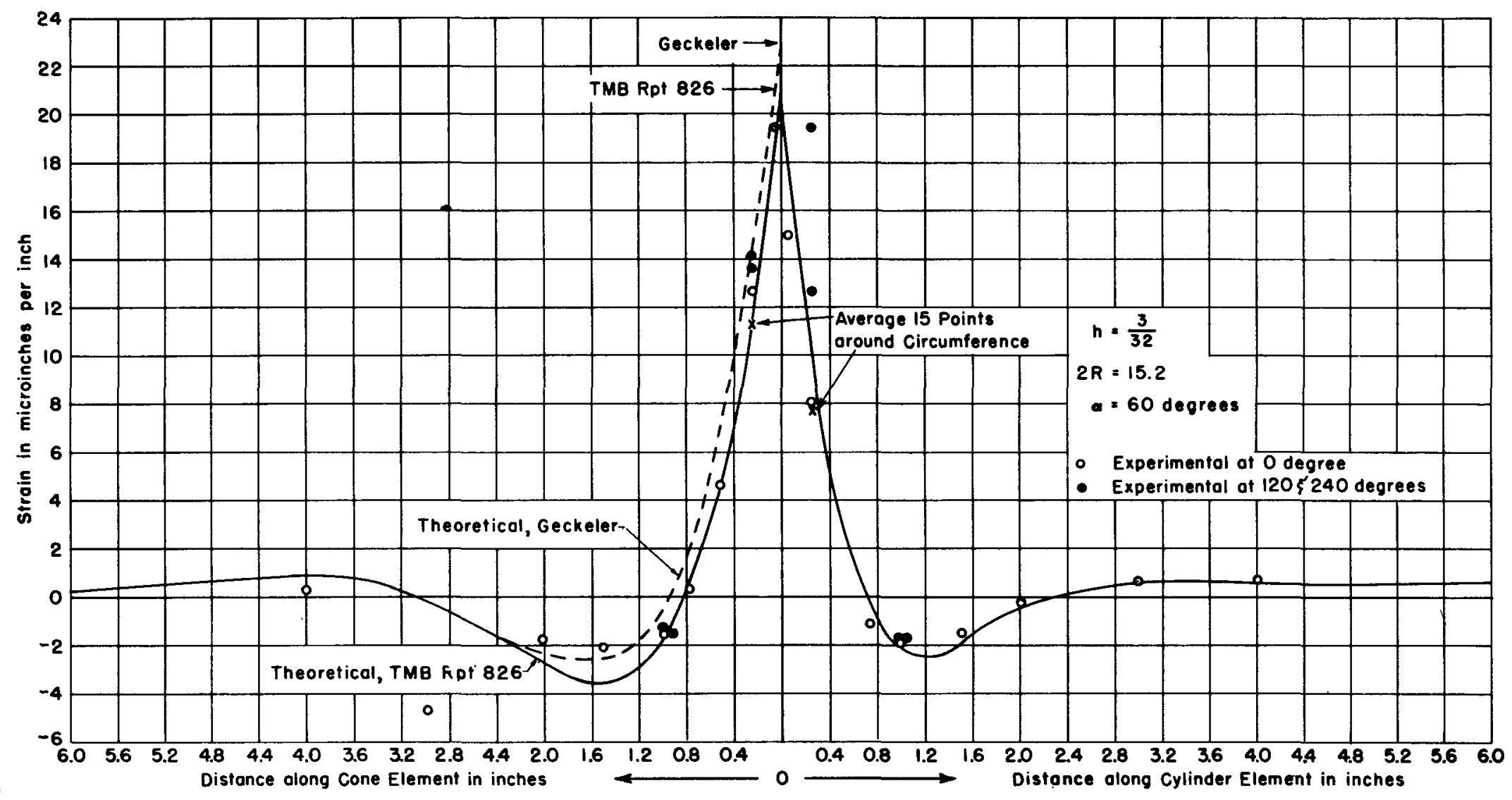

Figure 16 - Internal Longitudinal Strains in Model CC-10 for Internal Hydrostatic Pressure of 1 psi (Second Test) 


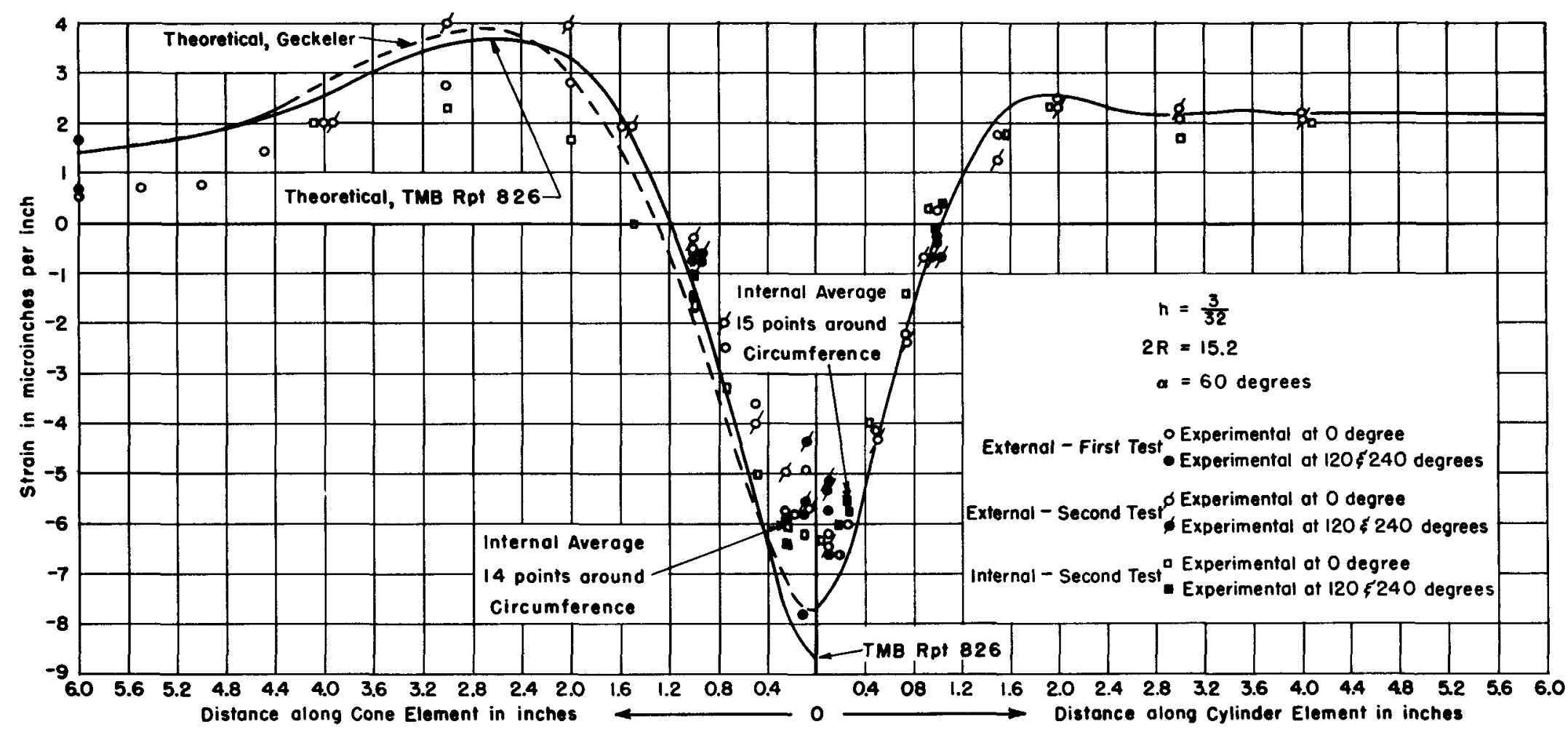

Figure 17 - Internal and External Circumferential Strains in Model CC-10 for Internal Hydrostatic Pressure of 1 psi 


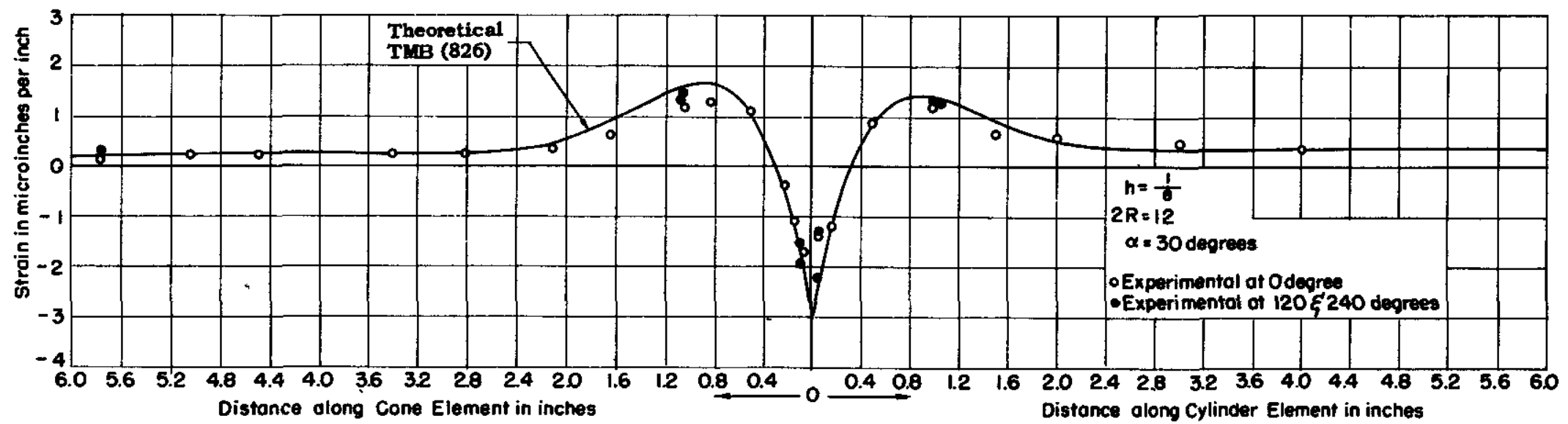

Figure 18 - External Longitudinal Strains in Model CC-11 for Internal Hydrostatic Pressure of 1 psi

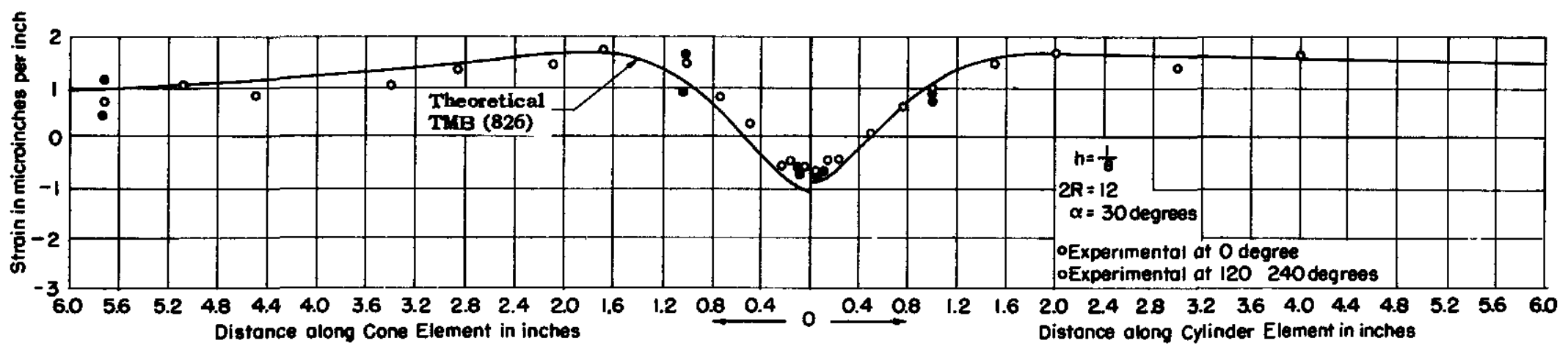

Figure 19 - External Circumferential Strains in Model CC-11 for Internal Hydrostatic Pressure of 1 psi 


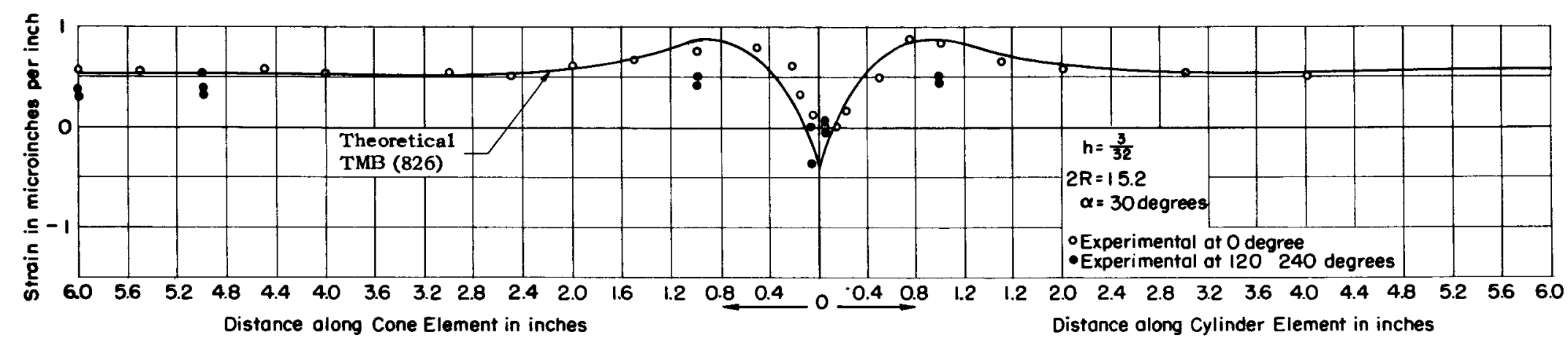

Figure 20 - External Longitudinal Strains in Model CC-12 for Internal Hydrostatic Pressure of 1 psi

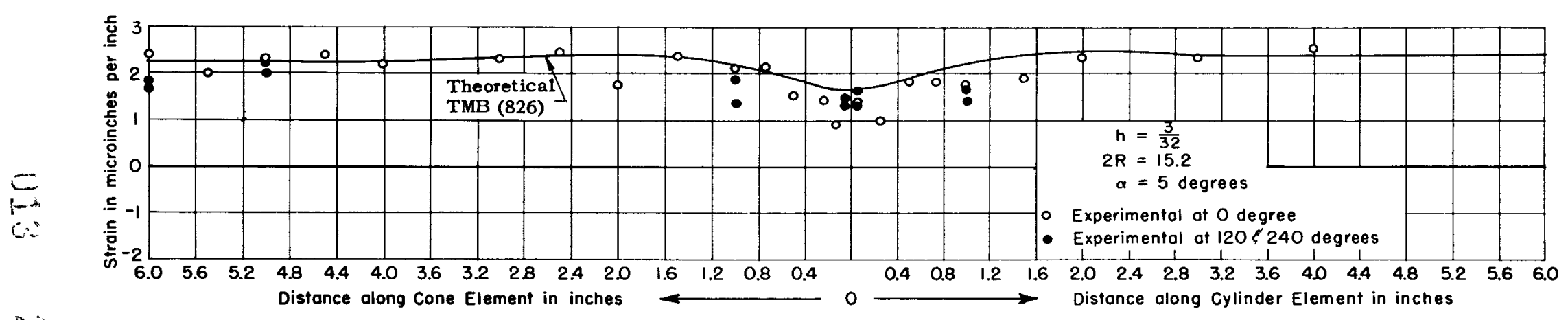

Figure 21 - External Circumferential Strains in Model CC-12 for Internal Hydrostatic Pressure of 1 psi 


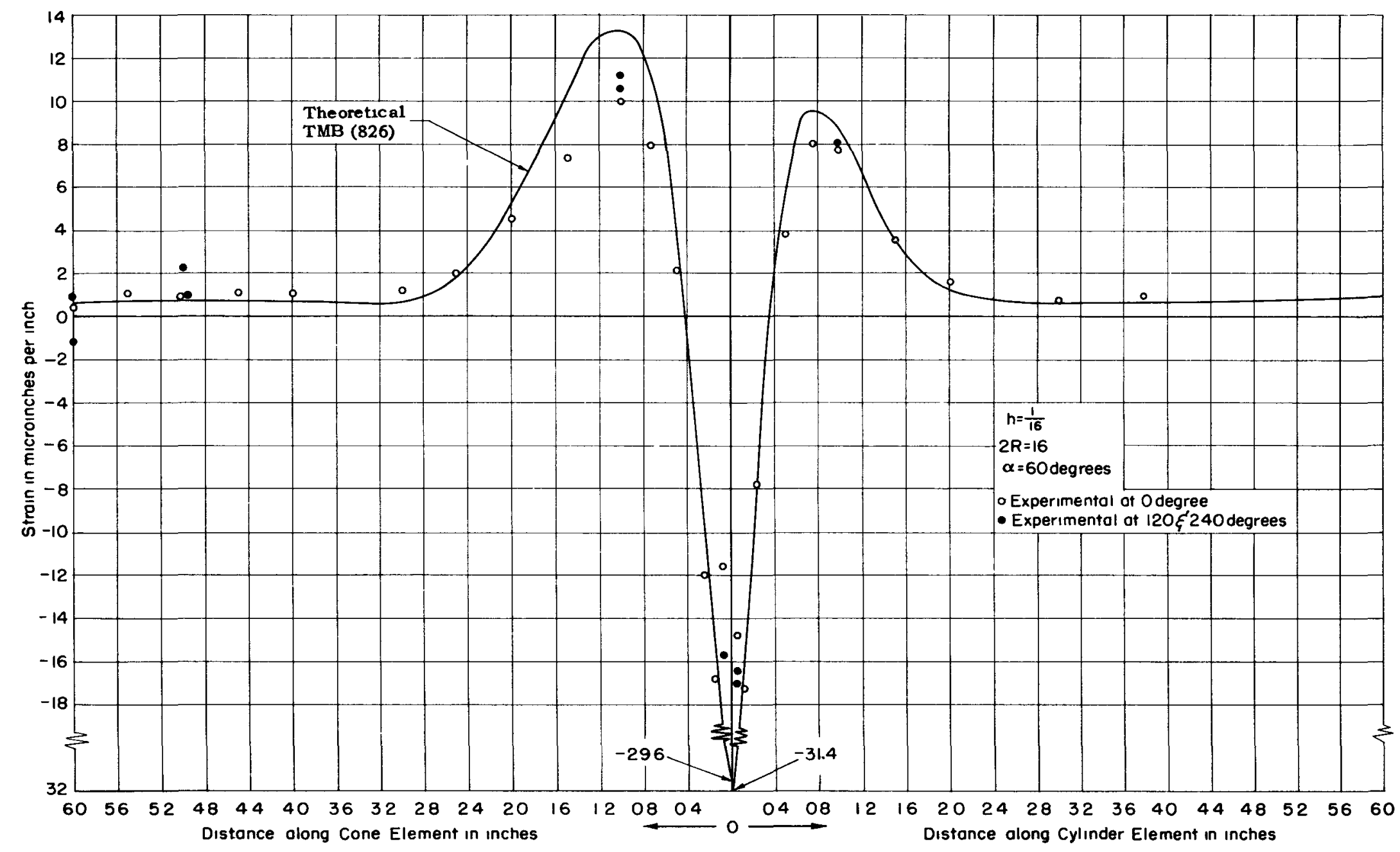

Figure 22 - External Longitudinal Strains in Model CC-13 for Internal Hydrostatic Pressure of 1 psı 


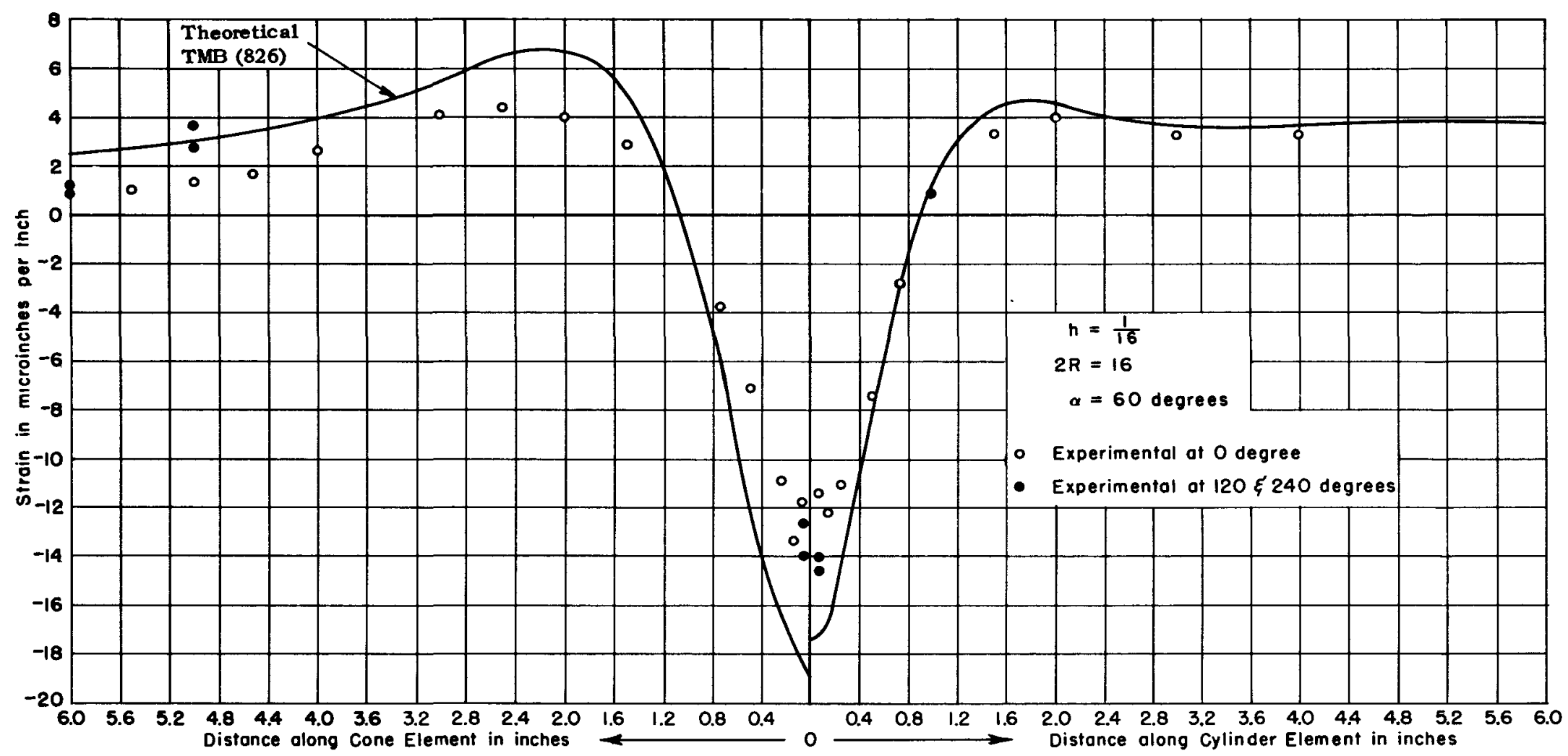

Figure 23 - External Circumferential Strains in Model CC-13 for Internal Hydrostatic Pressure of 1 psi 


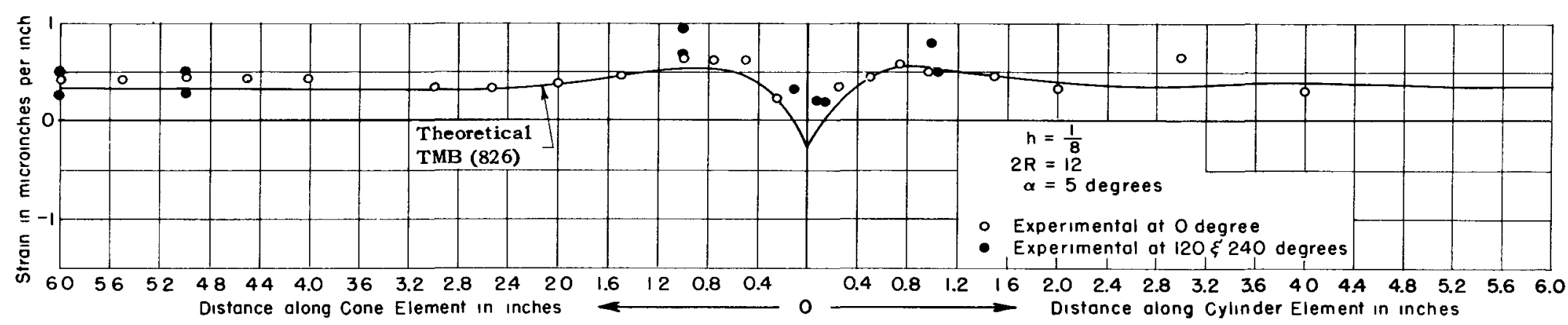

Figure 24 - External Longitudinal Strains in Model CC-14 for Internal Hydrostatic Pressure of 1 psi

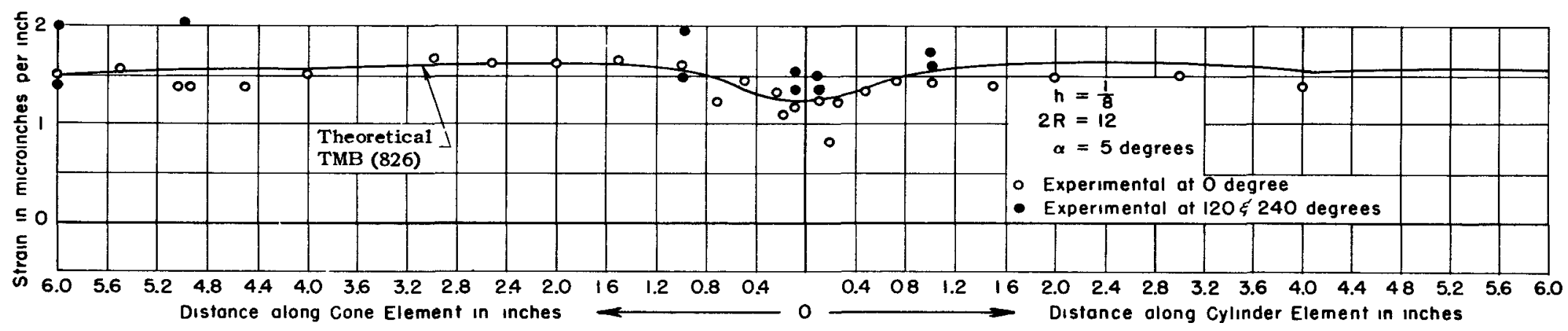




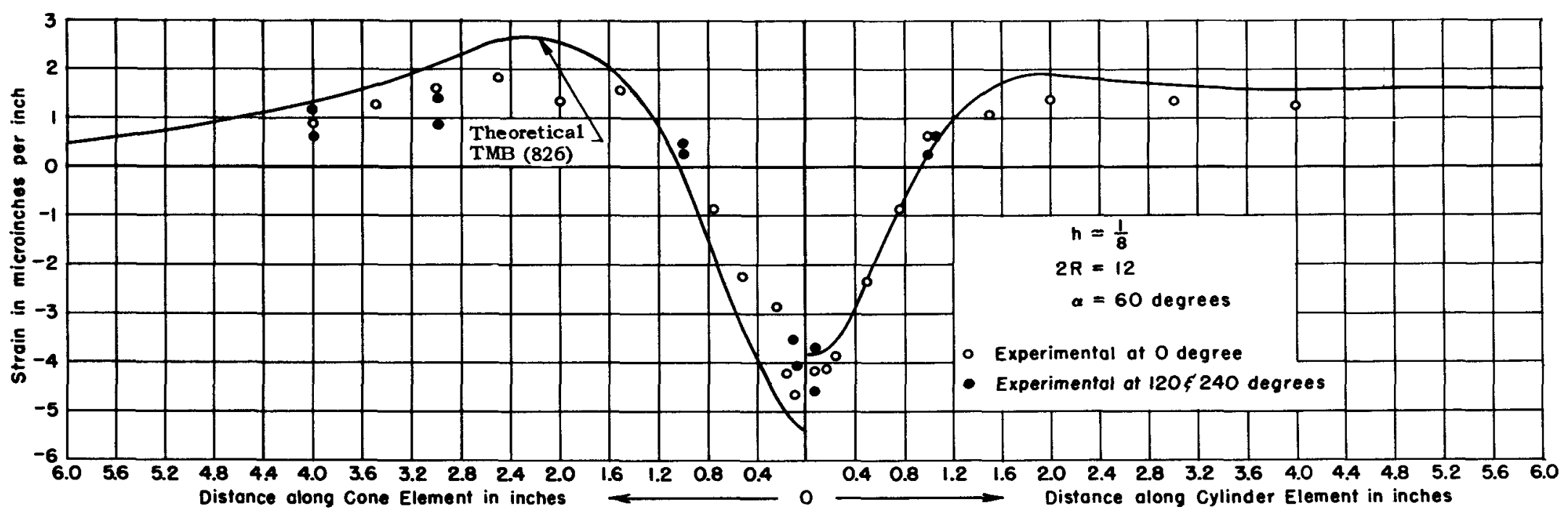

Figure 26 - External Circumferential Strains in Model CC-15 for Internal Hydrostatic Pressure of 1 psi 


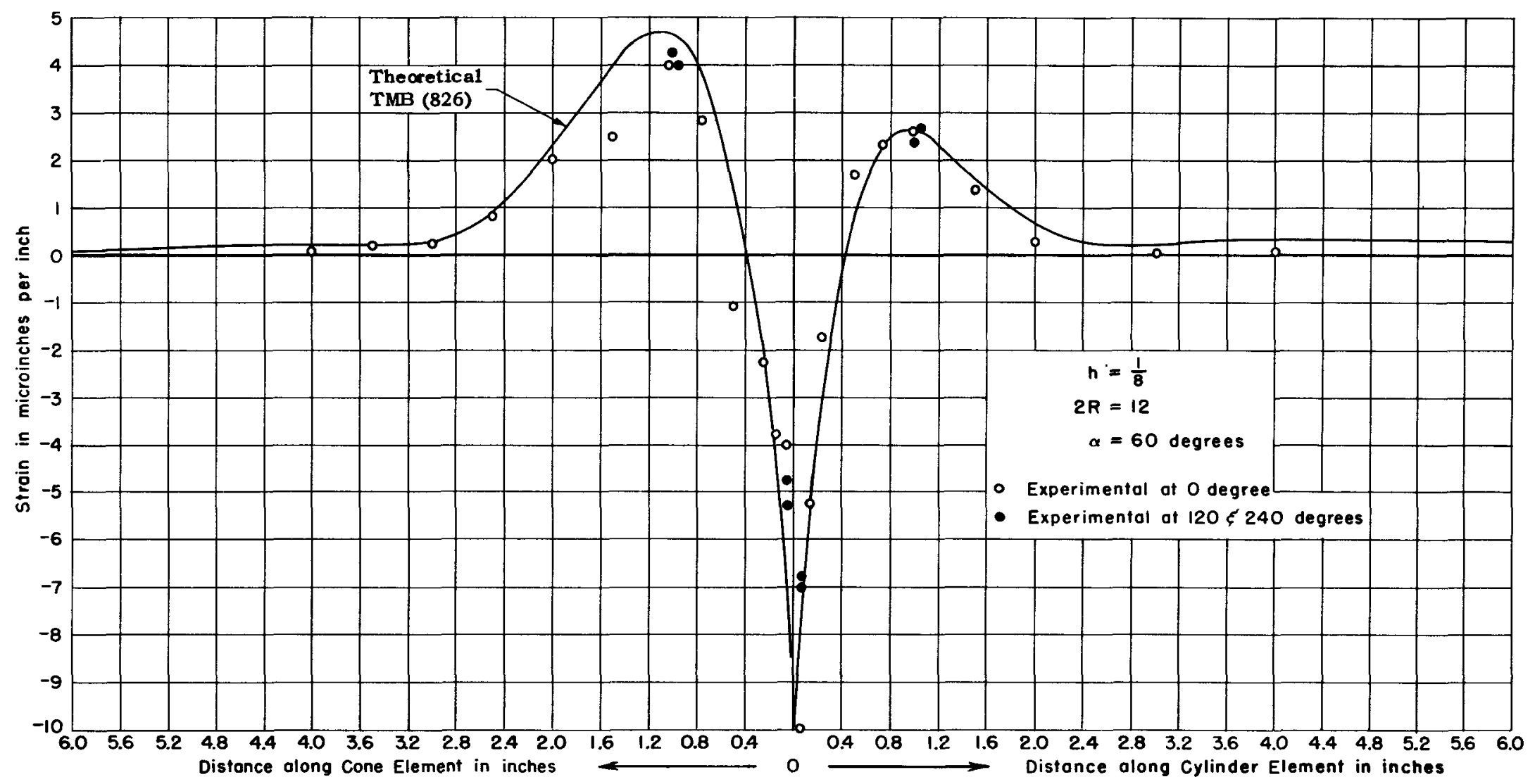

$\theta$

Figure 27 - External Longitudinal Strains in Model CC-15 for Internal Hydrostatic Pressure of 1 psi 


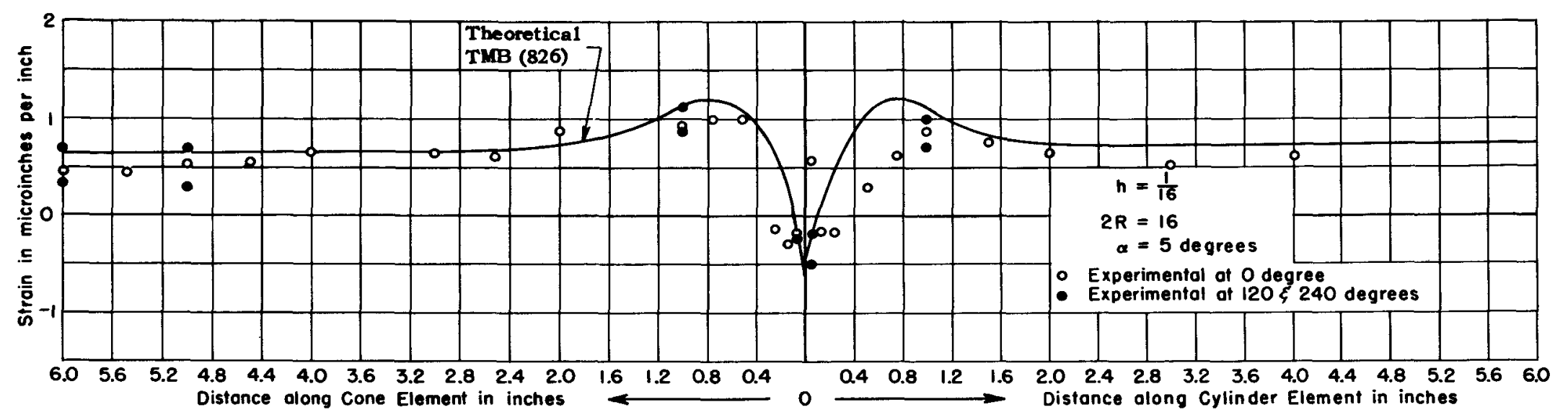

Figure 28 - External Longitudinal Strains in Model CC-16 for Internal Hydrostatic Pressure of 1 psi

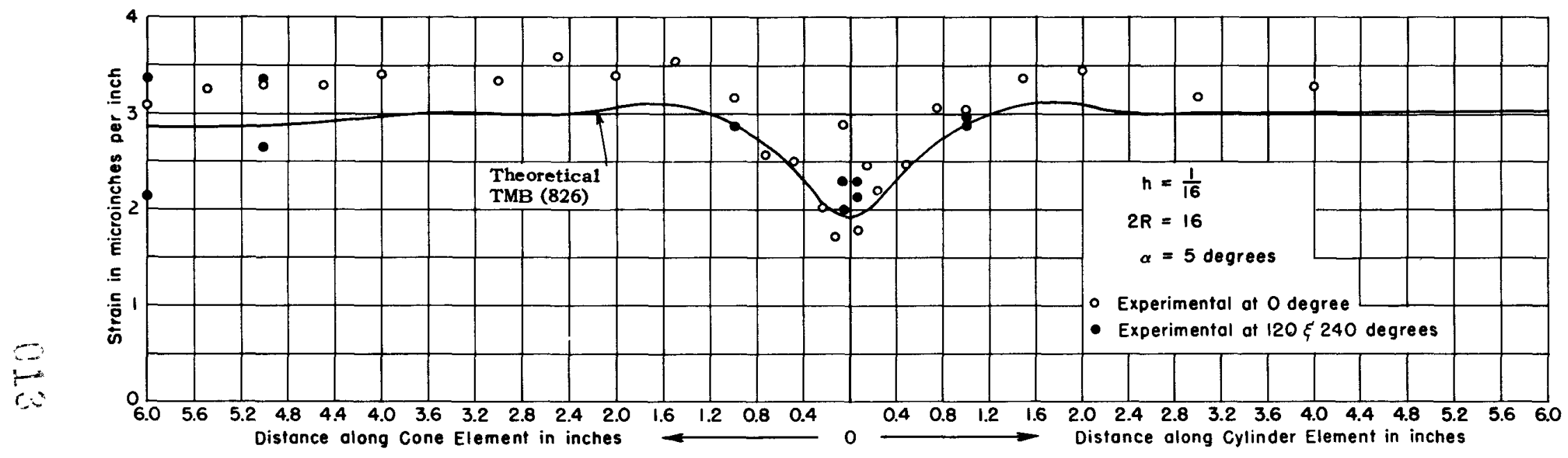

Figure 29 - External Circumferential Strains in Model CC-16 for Internal Hydrostatic Pressure of 1 psi 


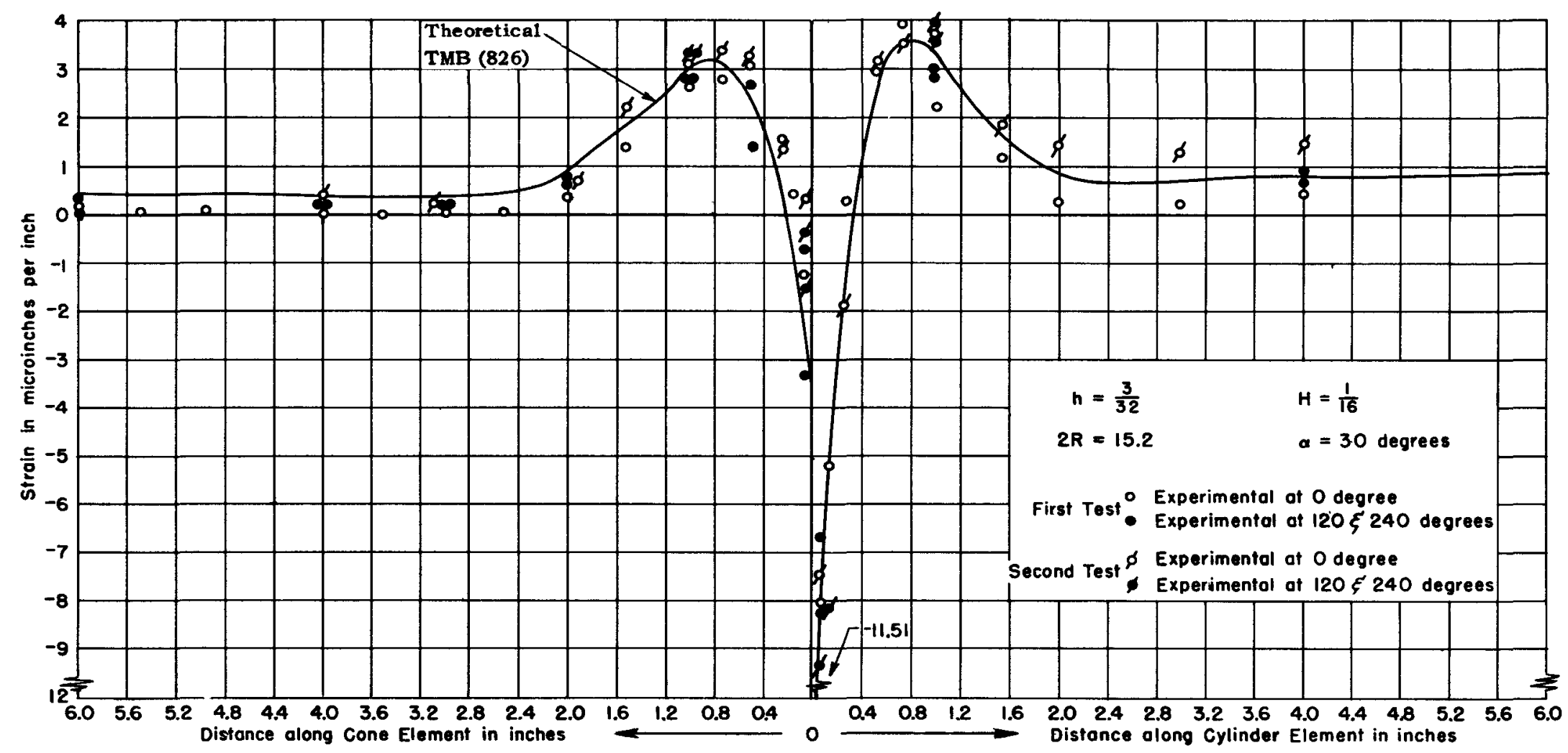

Figure 30 - External Longitudinal Strains in Model CC-20 for Internal Hydrostatic Pressure of 1 psi 


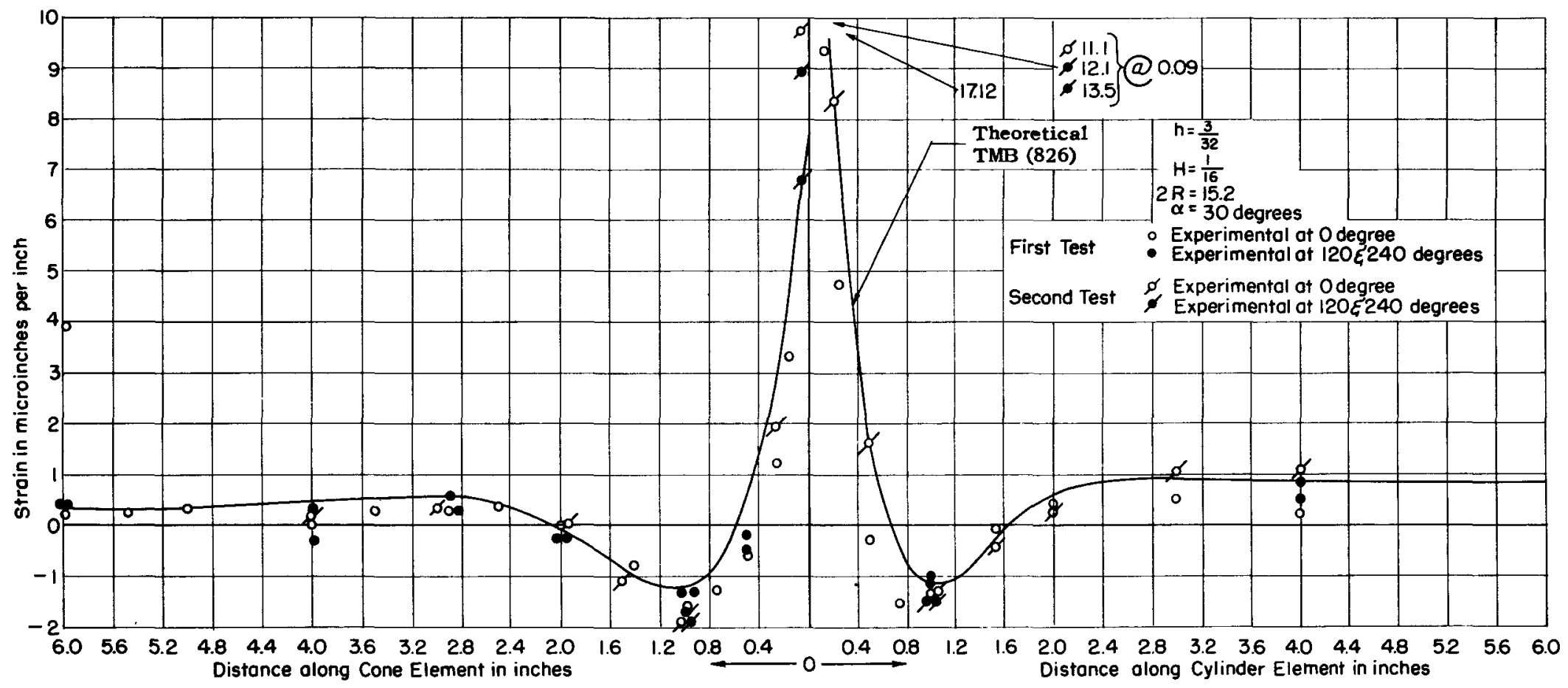




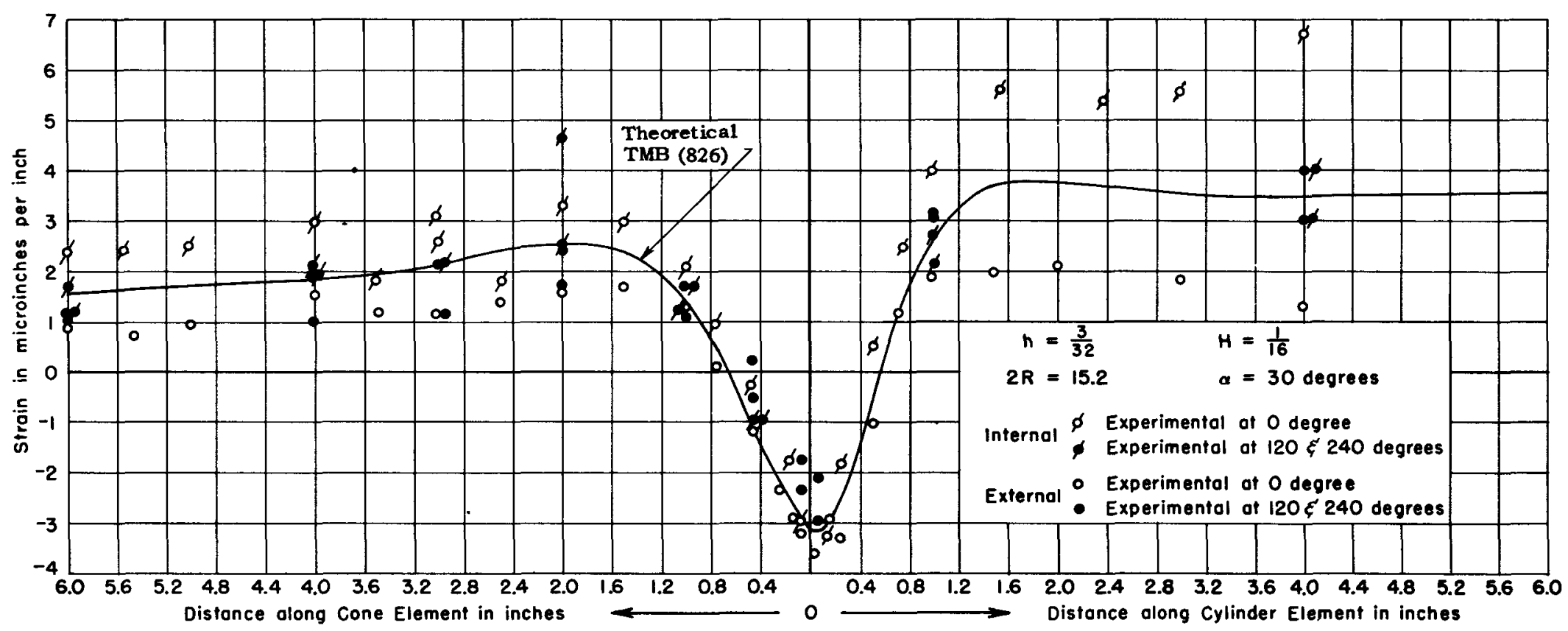

Figure 32 - Internal and External Circumferential Strains in Model CC-20 for Internal Hydrostatic Pressure of 1 psi (First Test)

0
0
0 


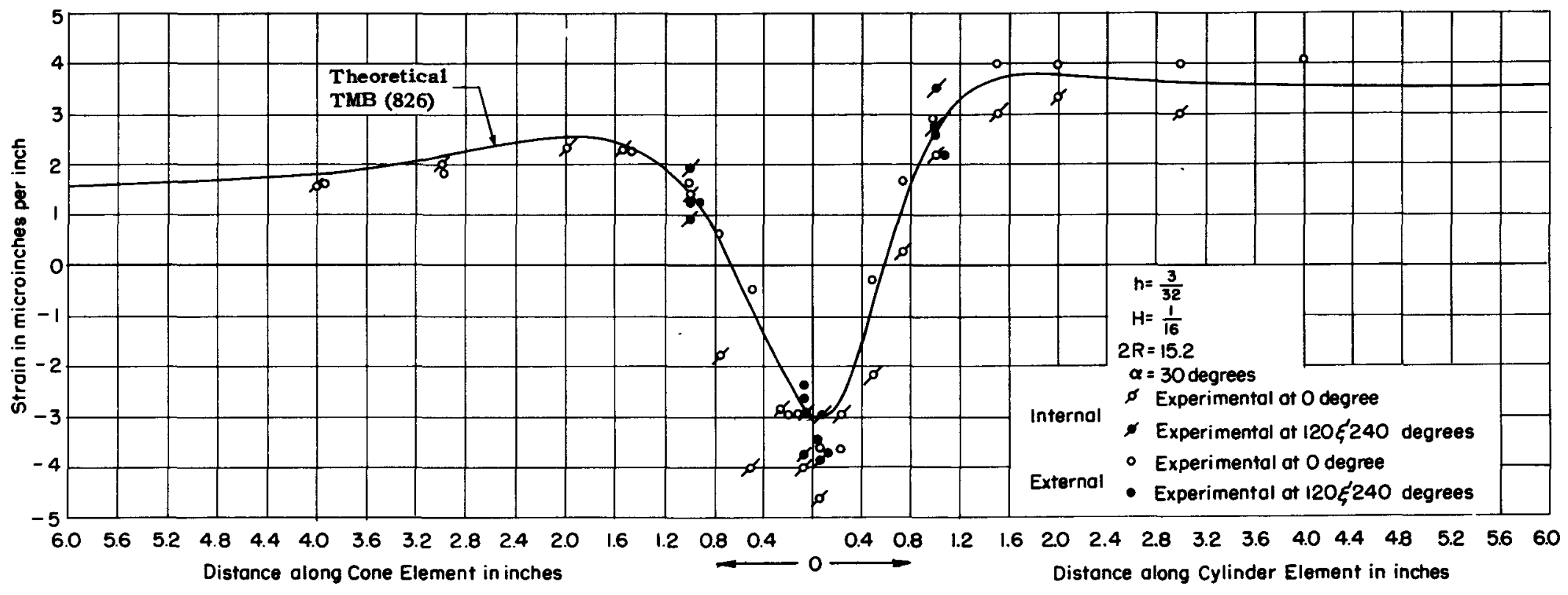

Figure 33 - Internal and External Circumferential Strains in Model CC-20 for Internal Hydrostatic Pressure of 1 psi (Second Test) 


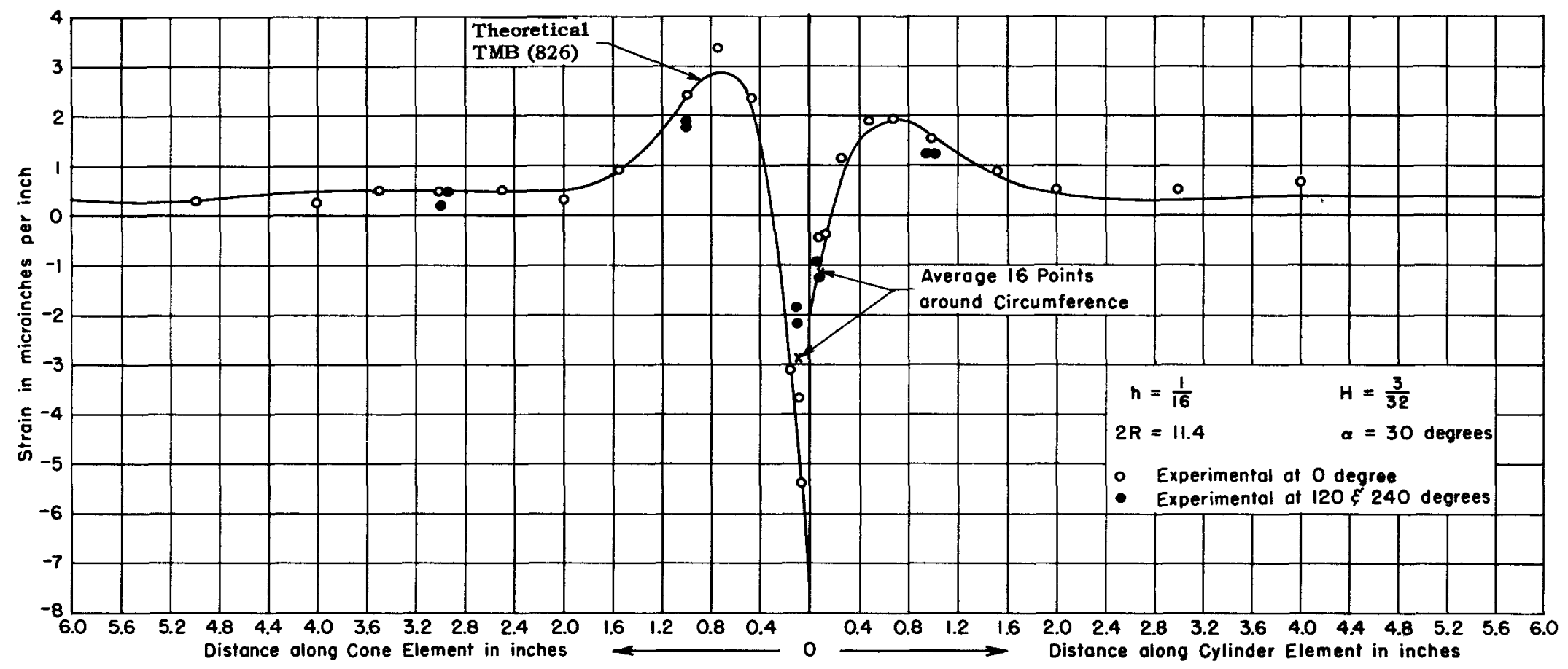

0
$\omega$
0

Figure 34 - External Longitudinal Strains in Model CC-21 for Internal Hydrostatic Pressure of 1 psi 


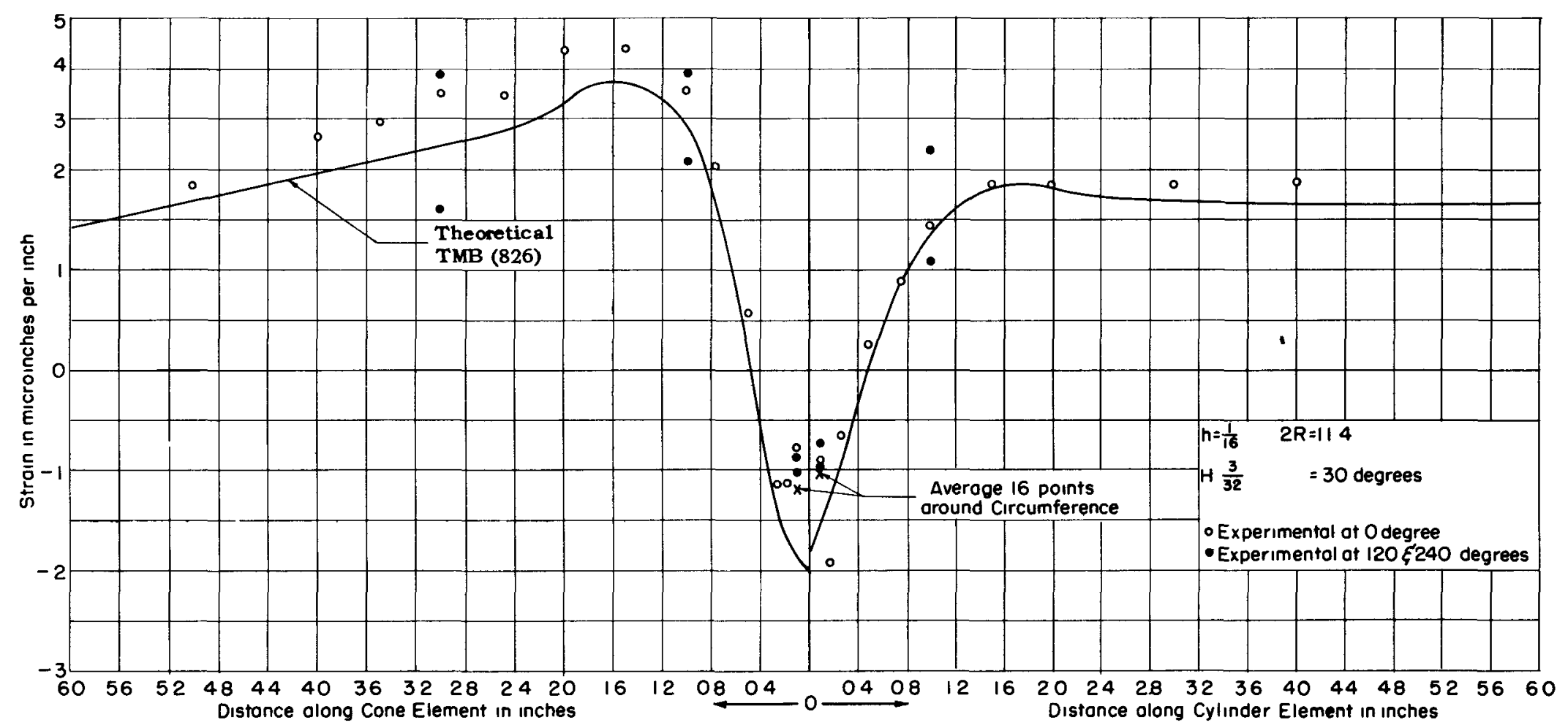

Figure 35 - External Circumferential Strains in Model CC-21 for Internal Hydrostatic Pressure of 1 psi 


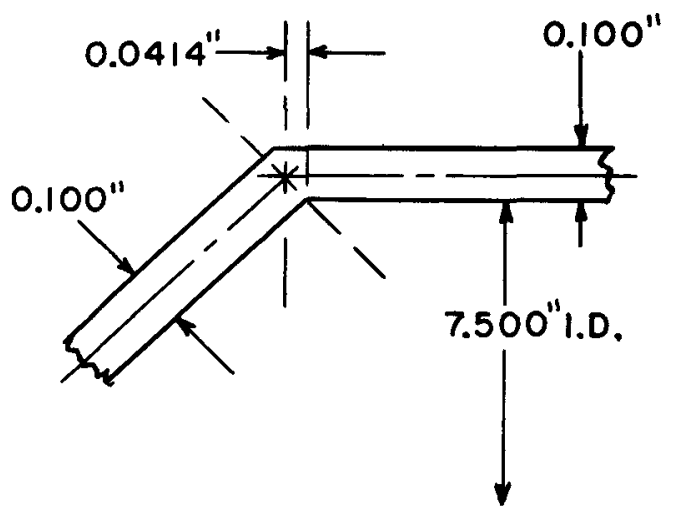

Figure 36a - Model 2

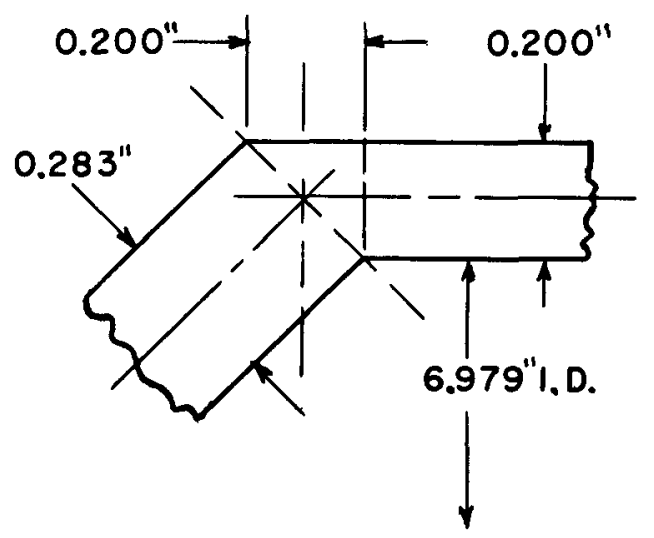

Figure 36b - Mode1 3

Figure 36 - Details of Intersections of Purdue University Models 2 and 3. 


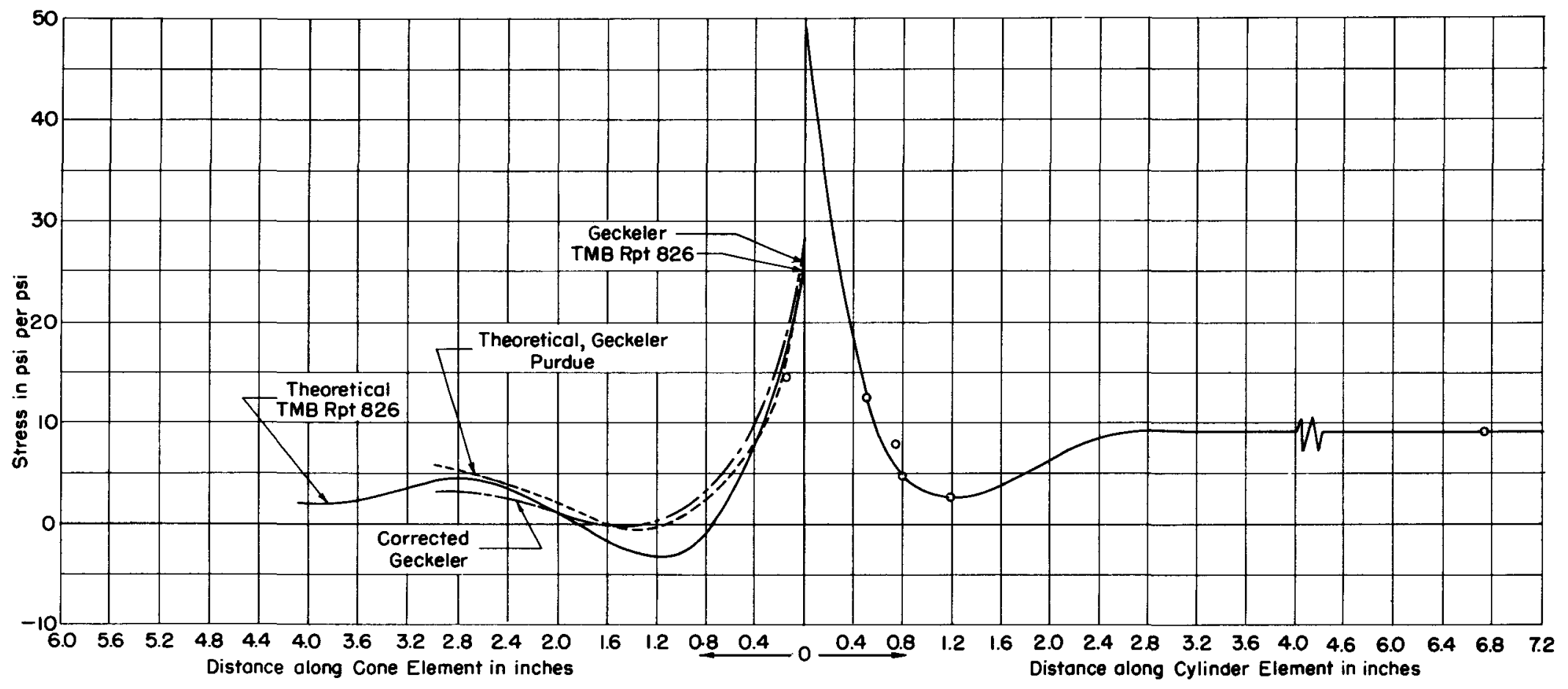

Figure 37 - Internal Longitudinal Stresses in Purdue University Model 3 for Internal Hydrostatic Pressure of 1 psi

Inadvertently, a cylindrical membrane term was used in the Geckeler curves computed by Purdue University. The corrected Geckeler curves contain a conical membrane term. 


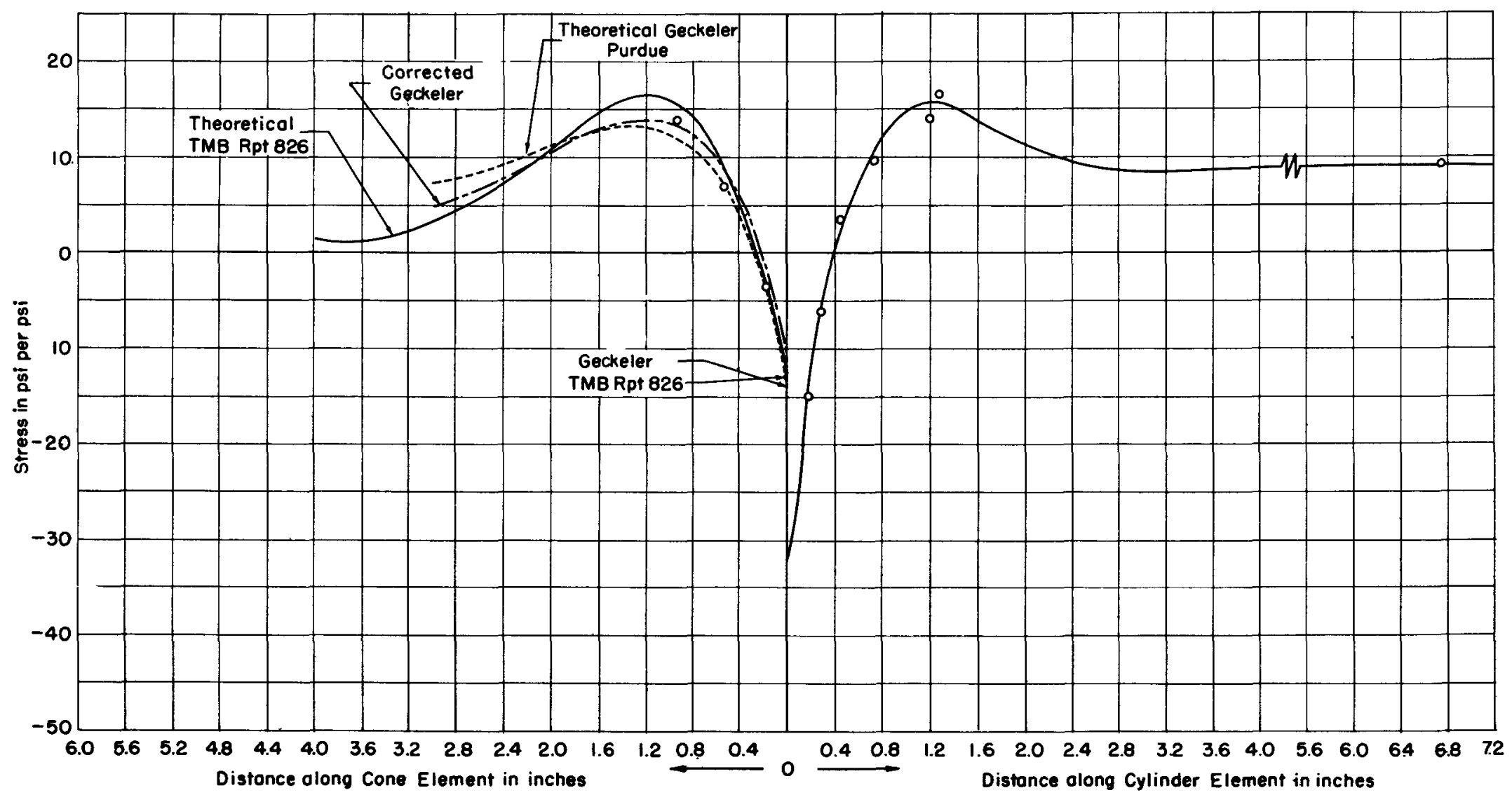

Figure 38 - External Longitudinal Stresses in Purdue University Model 3 for Internal Hydrostatic Pressure of 1 psi Inadvertently, a cylindrical membrane term was used in the Geckeler curves computed by Purdue University. The corrected Geckeler curves contain a conical membrane term. 


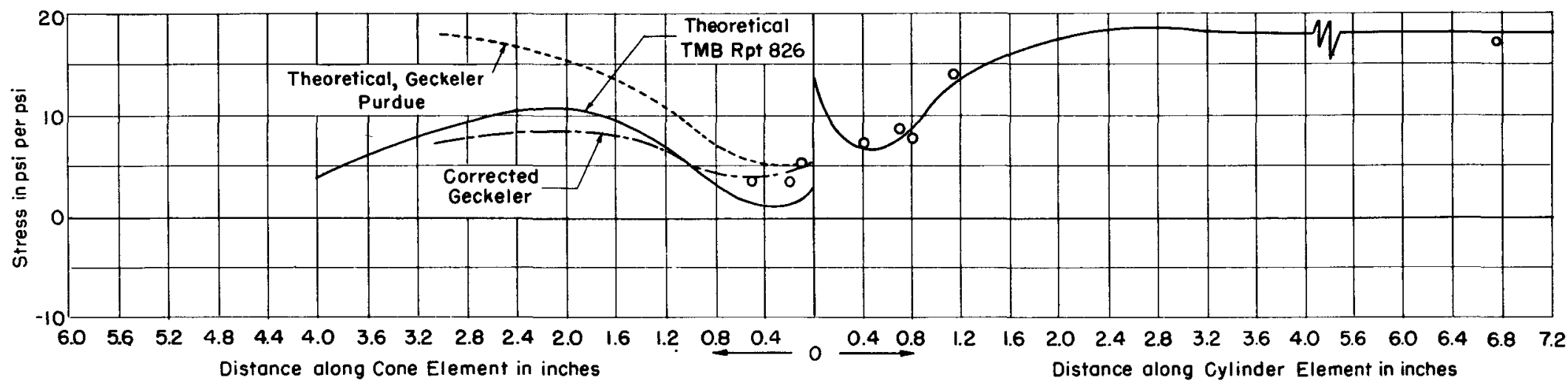

Figure 39 - Internal Circumferential Stresses in Purdue University Model 3 for Internal Hydrostatic Pressure of 1 psi

Inadvertently, a cylindrical membrane term was used in the Geckeler curves computed by Purdue University. The corrected Geckeler curves contain a conical membrane term.

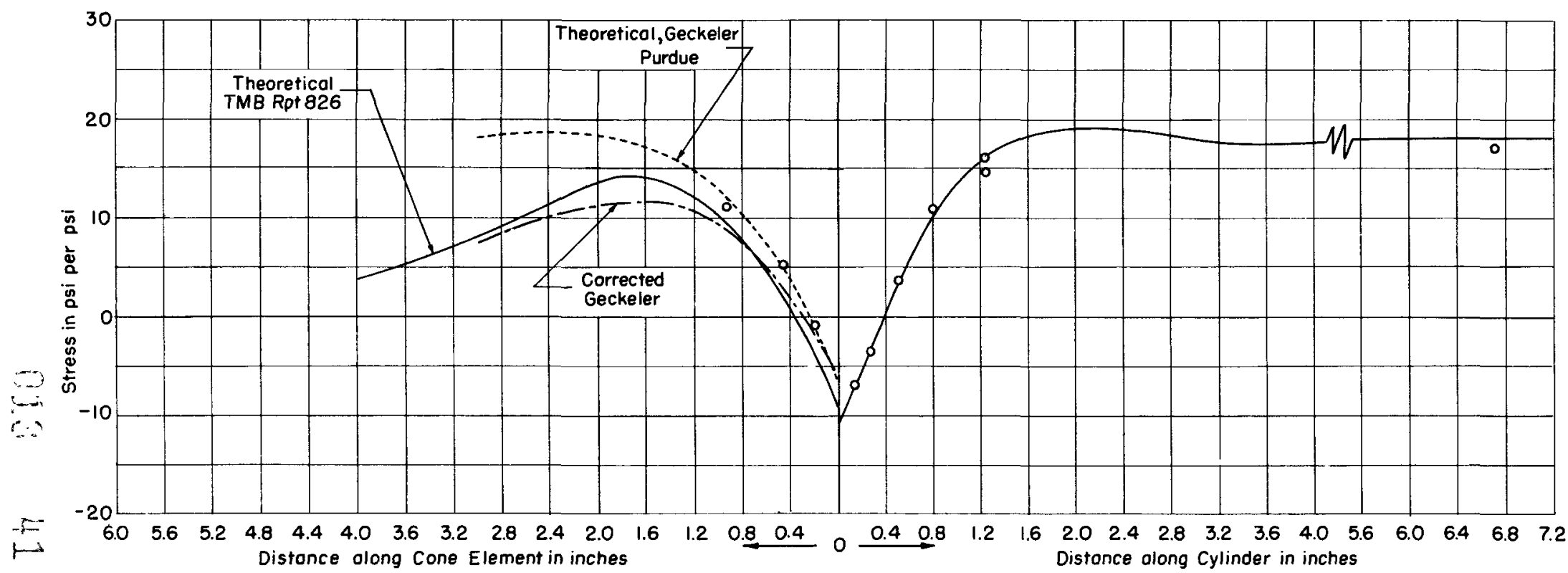

Figure 40 - External Circumferential Stresses in Purdue University Model 3 for Internal Hydrostatic Pressure of 1 psi

Inadvertently, a cylindrical membrane term was used in the Geckeler curves computed by Purdue University. The corrected Geckeler curves contain a conical membrane term. 


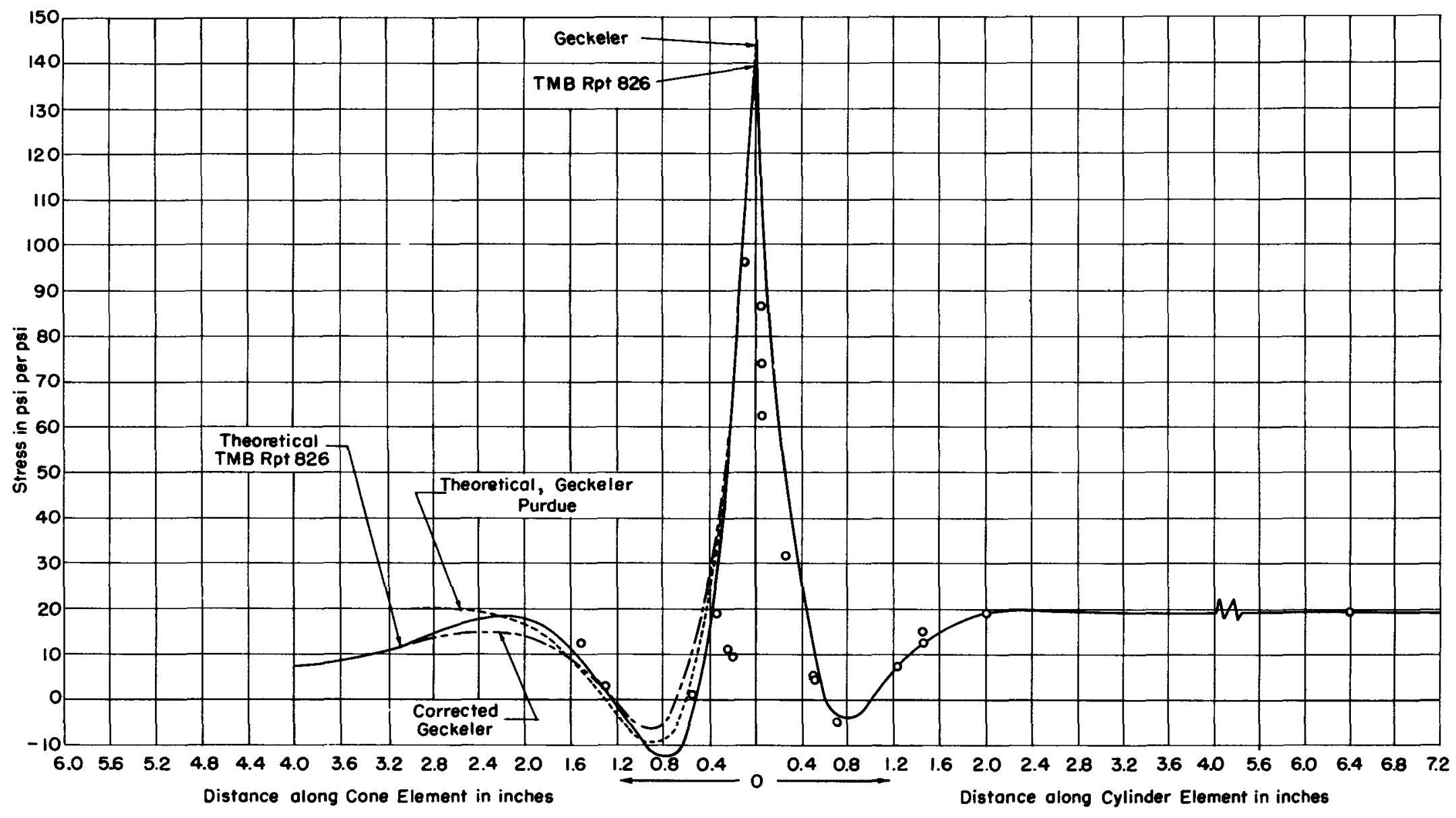

Figure 41 - Internal Longitudinal Stresses in Purdue University Model 2 for Internal Hydrostatic Pressure of 1 psi

Inadvertently, a cylindrical membrane term was usea in the Geckeler curves computed by Purdue University. The corrected Geckeler curves contain a conical membrane term. 


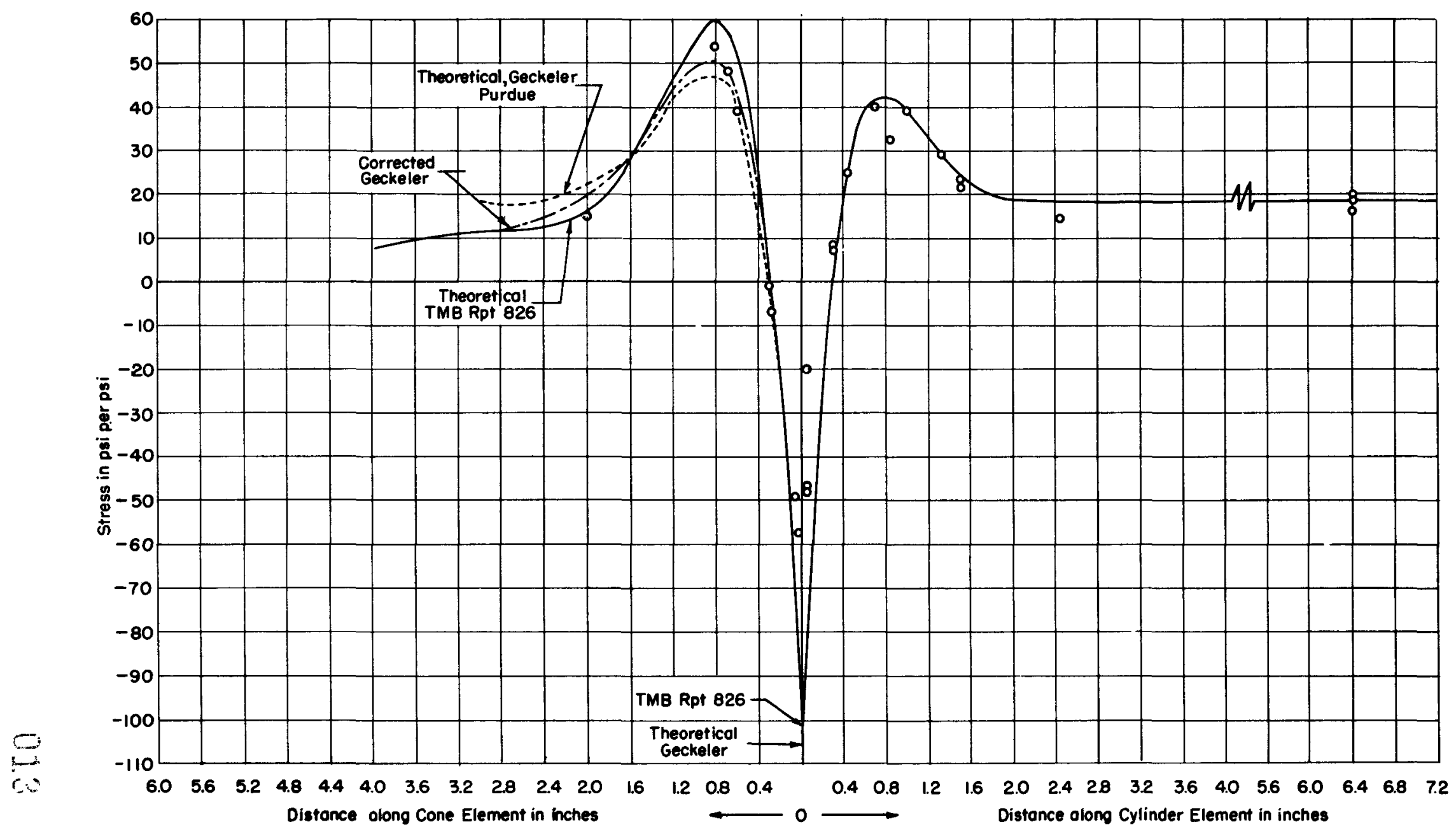

Figure 42 - External Longitudinal Stresses in Purdue University Model 2 for Internal Hydrostatic Pressure of 1 psi Inadvertently, a cylindrical membrane term was used in the Geckeler curves computed by Purdue University. The corrected Geckeler curves contain a conical membrane term. 


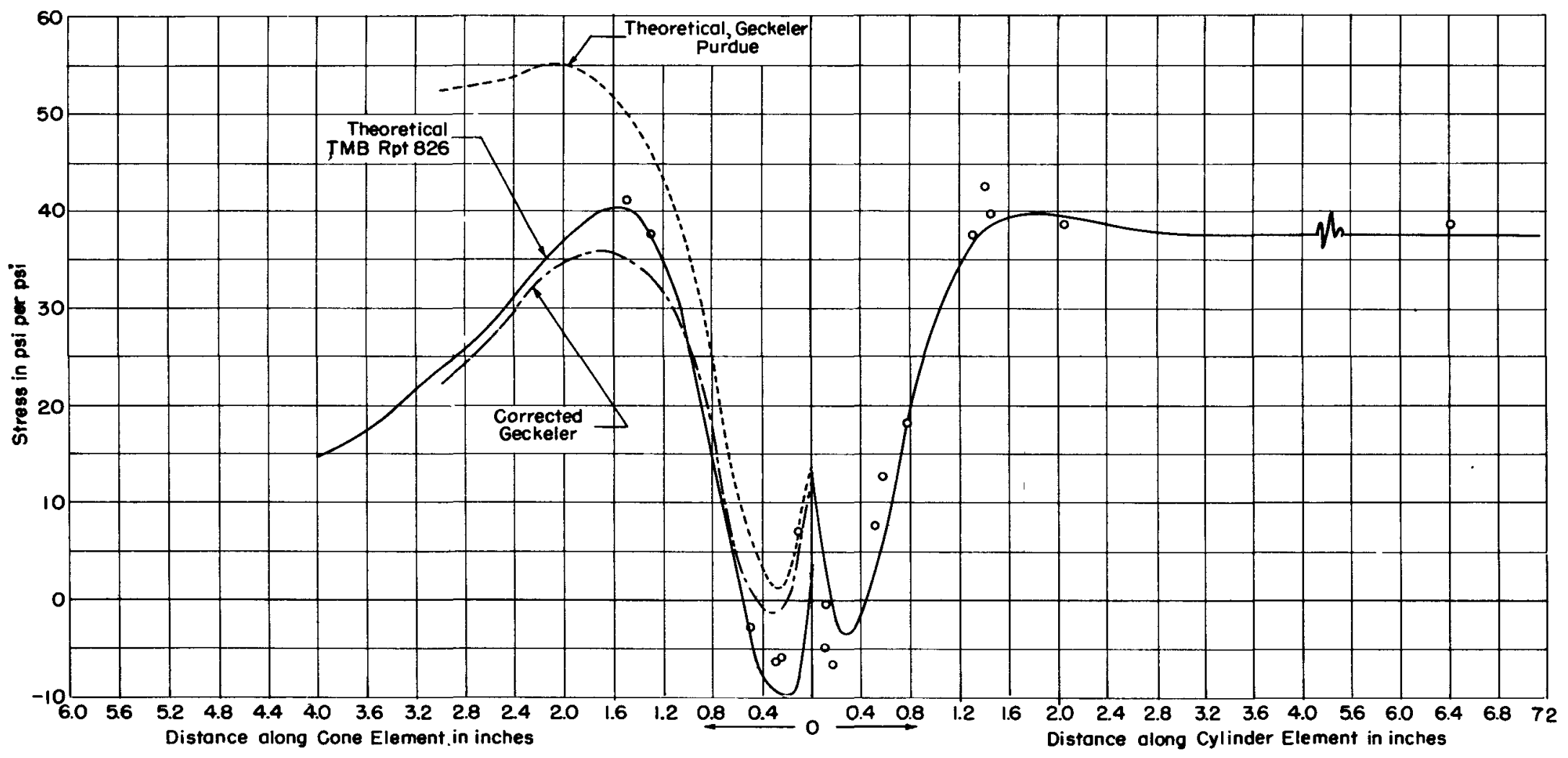

Figure 43 - Internal Circumferential Stresses in Purdue University Model 2 for Internal Hydrostatic Pressure of 1 psi Inadvertently, a cylindrical membrane term was used in the Geckeler curves computed by Purdue University. The corrected Geckeler curves contain a conical membrane term. 


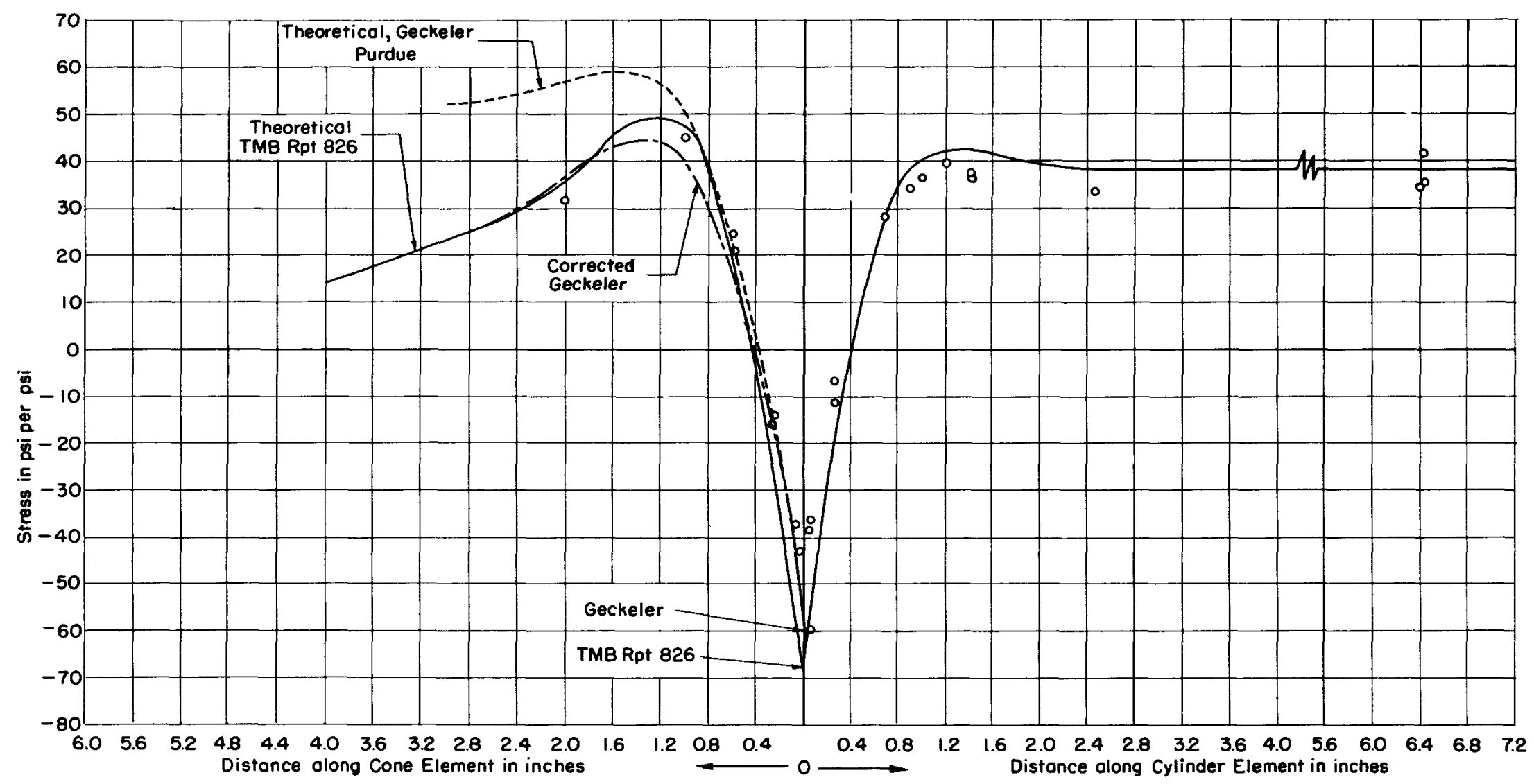

Figure 44 - External Circumferential Stresses in Purdue University Model 2 for Internal Hydrostatic Pressure of 1 psi Inadvertently, a cylindrical membrane term was used in the Geckeler curves computed by Purdue University. The corrected Geckeler curves contain a conical membrane term. 


\section{DISCUSSION}

\section{COMPARISON OF EX PERIMENTAL RESULTS WITH THEORY}

From Figures 10 through 35 it is evident that the TMB tests are in good agreement with the Wenk-Taylor theory. ${ }^{2}$ They agree equally well with the Geckeler curves drawn in Figures 13 through 17 , the difference between the two theoretical curves being small in these cases. The agreement with the Wenk-Taylor theory is especially good for Model CC-16 (Figures 28 and 29), for the external strains in Model CC-10 (Figures 15 and 17) and Model CC-11 (Figures 18 and 19), and for Models CC-20 and CC-21 (Figures 30 through 35) except over limited ranges. The largest disagreements occurred in the circumferential strains; this may have been due to the use of approximate edge coefficients in the theoretical calculations (see page 60).

The Purdue results shown in Figures 37 through 44 also agree about equally well with both Wenk-Taylor and the Geckeler approximate theories; the difference between the two theo* retical results is again small.

\section{FEATURES OF THE THEORETICAL STRAINS}

The maximum theoretical external stresses and strains, as calculated from the WenkTaylor theory, are collected in Table 2 for models with equally thick cone and cylinder and in Table 3 for the models with unequal thicknesses.

From the numbers in the tables, or by inspection of the curves in Figures 10 through 35, the following general conclusions can be inferred:

1. General Comparison. At the intersection of cone and cylinder, the external stresses and strains are all compressive in models with $\alpha=30 \mathrm{deg}$ or $60 \mathrm{deg}$, the longitudinal ones being larger than the circumferential because of bending of the shell. When $\alpha$ is $5 \mathrm{deg}$, however, both stress and strain are tensile except for the longitudinal strain, which is slightly compressive; the circumferential stresses and strains are larger than the longitudinal because of membrane stretching.

At a sufficient distance from the intersection, on the other hand, the external stresses and strains are necessarily all tensile.

\section{Longitudinal Strains.}

a. The maximum external longitudinal strain occurs at the intersection and in the cylinder, when $\alpha$ is $30 \mathrm{deg}$ or $60 \mathrm{deg}$, except in Model CC-21 (Figure 34), where the maximum occurs in the thinner cone $(h / H<1)$. For $\alpha=5 \mathrm{deg}$, there is little difference between cone and cylinder at the intersection, and numerically larger stresses and strains occur elsewhere.

b. In Model CC-20, with a thicker cone $(h / H>1)$, the calculated internal longitudinal stresses and strains exceed the external at the intersection in both cone and cylinder. At a distance, greater external stresses and strains occur in both components. 


\section{TABLE 2}

Maximum Theoretical External Stresses and Strains, for $h / H=1$, per psi of Internal Pressure

Tensile stress is positive.

\begin{tabular}{|c|r|r|r|r|r|r|r|r|r|r|r|r|r|}
\hline \multirow{2}{*}{ Location } & \multirow{4}{*}{$\alpha$} & \multicolumn{4}{|c|}{$h / 2 R=0.00391$} & \multicolumn{3}{|c|}{$h / 2 R=0.00617$} & \multicolumn{3}{|c|}{$h / 2 R=0.01042$} \\
\cline { 3 - 14 } & & \multicolumn{1}{|c|}{$\sigma_{\phi}$} & \multicolumn{1}{c|}{$\sigma_{x}$} & $\epsilon_{\phi}$ & $\epsilon_{x}$ & \multicolumn{1}{c|}{$\sigma_{\phi}$} & $\sigma_{x}$ & $\epsilon_{\phi}$ & $\epsilon_{x}$ & $\sigma_{\phi}$ & $\sigma_{x}$ & $\epsilon_{\phi}$ & $\epsilon_{x}$ \\
\hline At Intersection & 60 & -919.2 & -1163.4 & -19.0 & -29.6 & -416.4 & -520.0 & -8.7 & -13.2 & -261.4 & -330.0 & -5.4 & -8.5 \\
of & 30 & -285.5 & -418.1 & -5.3 & -11.1 & -109.8 & -185.9 & -1.8 & -5.1 & -42.2 & -75.9 & -0.6 & -2.1 \\
Cone & 5 & 57.6 & 2.2 & 1.9 & -0.5 & 50.0 & 2.1 & 1.7 & -0.4 & 39.3 & 4.7 & 1.3 & -0.2 \\
\hline At Intersection & 60 & -881.2 & -1205.4 & -17.4 & -31.4 & -385.1 & -523.3 & -7.6 & -13.6 & -220.8 & -365.4 & -3.8 & -10.0 \\
of & 30 & -275.9 & -418.3 & -5.0 & -11.1 & -109.7 & -185.9 & -1.8 & -5.1 & -39.0 & -75.9 & -0.6 & -2.1 \\
Cylinder & 5 & 57.9 & 2.3 & 1.9 & -0.5 & 51.0 & 2.3 & 1.7 & -0.4 & 39.4 & 4.7 & 1.3 & -0.2 \\
\hline Away from & 60 & 284.8 & 440.5 & 6.9 & 13.4 & 158.6 & 233.2 & 3.7 & 7.0 & 110.5 & 152.4 & 2.7 & 4.7 \\
Intersection & 30 & 162.1 & 182.9 & 4.3 & 5.0 & 89.4 & 85.1 & 2.4 & 2.4 & 51.4 & 50.7 & 1.4 & 1.3 \\
in Cone & 5 & 108.5 & 66.4 & 3.1 & 1.2 & 83.4 & 50.1 & 2.4 & 0.9 & 57.9 & 33.2 & 1.7 & 0.5 \\
\hline Away from & 60 & 183.1 & 304.8 & 4.7 & 9.5 & 100.5 & 149.7 & 2.6 & 4.8 & 69.7 & 90.9 & 1.9 & 2.7 \\
Intersection & 30 & 152.1 & 163.9 & 4.1 & 4.5 & 88.0 & 85.0 & 2.4 & 2.2 & 50.7 & 44.1 & 1.4 & 1.2 \\
in Cylinder & 5 & 108.9 & 66.4 & 3.1 & 1.2 & 86.0 & 50.3 & 2.5 & 0.9 & 58.8 & 33.2 & 1.7 & 0.5 \\
\hline
\end{tabular}

TABLE 3

Maximum Theoretical External Stresses and Strains, for $h / H \neq 1$, per psi of Internal Pressure

Tensile stress is positive.

\begin{tabular}{|c|c|c|c|c|c|c|c|c|c|}
\hline \multirow{2}{*}{ Location } & \multirow{2}{*}{ Shell } & \multicolumn{4}{|c|}{$\begin{array}{c}\text { Model CC-20* } \\
h / 2 R=0.00617 \\
h / H=1.605\end{array}$} & \multicolumn{4}{|c|}{$\begin{array}{c}\text { Model CC-21 } \\
h / 2 R=0.00548 \\
h / H=0.623\end{array}$} \\
\hline & & $\sigma_{\phi}$ & $\sigma_{x}$ & $\epsilon_{\phi}$ & $\epsilon_{x}$ & $\sigma_{\phi}$ & $\sigma_{x}$ & $\epsilon \phi$ & $\epsilon_{x}$ \\
\hline \multirow{2}{*}{$\begin{array}{c}\text { At the } \\
\text { Intersection }\end{array}$} & Cone & $\begin{array}{l}-137.4 \\
-28.1\end{array}$ & $\begin{array}{r}-143.9 \\
221.5\end{array}$ & $\begin{array}{l}-3.2 \\
-3.2\end{array}$ & $\begin{array}{r}-3.4 \\
7.7\end{array}$ & -138.6 & -259.2 & -2.0 & -7.3 \\
\hline & Cylinder & $\begin{array}{r}-212.8 \\
70.4\end{array}$ & $\begin{array}{r}-409.3 \\
534.7\end{array}$ & $\begin{array}{l}-3.2 \\
-3.2 \\
\end{array}$ & $\begin{array}{r}-11.5 \\
17.1 \\
\end{array}$ & -81.4 & -89.3 & -1.8 & -2.2 \\
\hline \multirow{2}{*}{$\begin{array}{l}\text { Away from } \\
\text { the } \\
\text { Intersection }\end{array}$} & Cone & $\begin{array}{l}96.2 \\
82.3 \\
\end{array}$ & $\begin{array}{r}113.6 \\
39.7 \\
\end{array}$ & $\begin{array}{l}2.5 \\
2.5 \\
\end{array}$ & $\begin{array}{r}3.2 \\
-\quad 1.3 \\
\end{array}$ & 104.8 & 110.7 & 2.9 & 2.9 \\
\hline & Cylinder & $\begin{array}{l}141.6 \\
131.4\end{array}$ & $\begin{array}{r}138.5 \\
65.9\end{array}$ & $\begin{array}{l}3.8 \\
3.8\end{array}$ & $\begin{array}{r}3.6 \\
-1.2\end{array}$ & 67.1 & 70.4 & 1.8 & 1.9 \\
\hline
\end{tabular}


c. Away from the intersection, the maximum stress and strain usually occur, in both cylinder and cone, at a distance of $0.16 R$ to $0.26 R$ from the intersection (where $R$ is the radius of the cylinder), the maximum stress and maximum strain not necessarily occurring at the same point.

3. Circumferential Strains. External circumferential strains at the intersection were, of course, equal in cone and cylinder (provided the exact edge coefficients are used); the stresses are also nearly equal when $h=H$, whereas greater circumferential stresses occur in the thinner component when $h$ and $H$ are unequal.

Away from the intersection, the maximum external circumferential stress and strain are found within $0.1 R$ to $0.5 R$ of the intersection, the two maxima not necessarily coinciding. The maximum stress is found in the cone for $\alpha=30 \mathrm{deg}$ or $60 \mathrm{deg}$, but for $\alpha=5 \mathrm{deg}$ the maximum in the cylinder slightly exceeds the maximum in the cone.

\section{THE EXPERIMENTAL DEVIATIONS}

The deviations between observed and calculated strain sensitivities show no marked consistent bias. The experimental points lie about equally above and below the theoretical curves.

In order to see whether the deviations vary systematically with cone angle $\alpha$ or thickness $h$, deviations were collected for all models having $h=H$, taken at two selected points on both cone and cylinder. The deviations were determined as close to the intersection of cone and cylinder as experimental values were known, and also in the neighborhood of the maximum at a distance from the intersection. Both longitudinal and circumferential external strain sensitivities were included.

These deviations were arranged by values of $\alpha$ and of $h / 2 R$ in four squares, of which a typical one is shown in Table 4. The deviations near the intersection were nearly all positive, indicating a slight tendency here for the experimental strains to be numerically smaller than the theoretical. Furthermore, all plots showed a slight tendency for the deviations to increase with increasing $\alpha$ or decreasing $h$. The deviations vary so much, however, that the significance of the features noted remains dubious. This negative conclusion was supported by a chi-test ${ }^{11}$ made as if all deviations had reference to independent observations of the same quantity.

It may be remarked that, on retesting certain models after 9 to 18 months, no substantial change in the strain data was observed. The major sources of error probably lay in theoretical approximations or in imperfections due to fabrication techniques; these will now be discussed. 


\section{TABLE 4}

Average Deviation of Experimental from Theoretical Longitudinal

Strain Sensitivities Close by the Intersection

Strain sensitivities are given in microinches per inch per psi internal pressure.

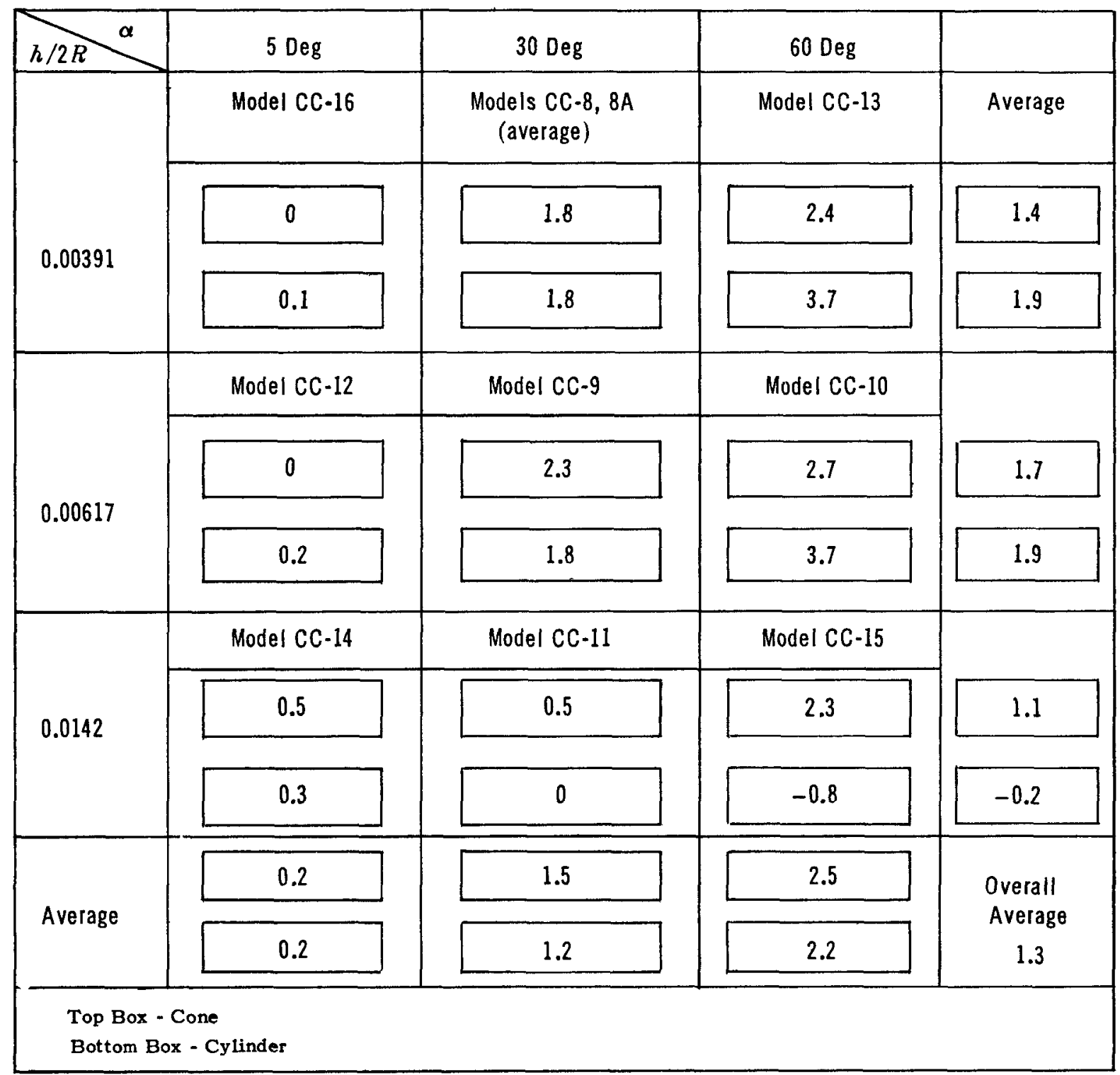




\section{FACTORS AFFECTING STRAIN RESULTS}

\section{The Experimental Precision}

Pressures were read to 1 percent, strains to $5 \mu \mathrm{in} / \mathrm{in}$. In calculating strain sensitivities, a pressure range of $50 \mathrm{lb}$ was employed. The reading error in the sensitivities should thus not exceed $5 / 50$ or 0.1 at most. In addition, there might be an error of 2 percent due to an error of this magnitude in the strains. A glance at the figures will show that instrumental errors of this sort will not suffice to explain the observed differences between experimental and theoretical results.

\section{Theoretical Approximations}

Approximations made in the derivation of Report 826 theory which affect stress magnitudes in the cone are:

1. Use of approximate differential equation;

2. Use of approximate stress-resultant equations;

3. Neglect of longitudinal displacement $u$ when computing the displacement normal to the axis $\bar{w}$ due to bending; and

4. Use of approximate edge coefficients in calculating edge forces.

Items 1, 2, and 3 above are discussed in Report 826. ${ }^{2}$ The approximate expressions for the edge coefficients $a$ and $d$ on page 10 of Reference 2 were employed here. Use of these simplified coefficients results in slightly less computation, but the theoretical circumferential strains in the cone and cylinder at the intersection are caused to differ, whereas in reality they must be equal. This difference becomes more pronounced as the half-apex angle increases. The difference with $\alpha=5 \mathrm{deg}$ is small (Figure 25); when $\alpha=30 \mathrm{deg}$, it may be small (Figure 19) or it may be appreciable. In Model CC-10, with $\alpha=60 \mathrm{deg}$ (Figure 17), the calculated circumferential strain was $-8.7 \mu \mathrm{in} / \mathrm{in}$. in the cone and $-7.6 \mu \mathrm{in} / \mathrm{in}$. in the cylinder, a difference of about 13 percent. A later calculation with use of the exact coefficients $a$ and $d$ on page 10 of Reference 2 gave a strain in both elements of -7.9 . Thus, here the use of the approximate edge coefficients caused a maximum error of 10 percent.

Estimates are given on page 9 of Reference 12 of the maximum total error resulting from all the approximations made in the Wenk-Taylor theory. The numbers given there agree closely with the following formula (if Poisson's ratio $\nu=0.3$ ):

$$
\text { Maximum error at the intersection }=105 \sqrt{\frac{h}{2 R} \sin \alpha \tan \alpha} \text { (in percent) }
$$

At other points on the cone, $R$ is to be replaced by $x \sin \alpha$ where $x$ is the distance from the apex. Maximum errors at the intersection calculated from this formula for Models CC-8 to CC-16 vary from 0.6 to 12 percent. 


\section{Effects of Imperfections in the Models}

Three major defects encountered in any one model are lack of

1. Circularity.

2. Rectilinearity of generators.

3. Constant thickness at or close to the intersection.

All three defects are attributable to the fabrication of rolled and welded shells into a composite structure.

That initial deviations around the circumference and axially along a cylindrical shell increase the stresses under hydrostatic loading is well known.12,13 Reference 13 states that, in a thin circular ring, an initial deviation equal to $1 / 100$ of the radius may increase the maximum fiber stress due to circumferential bending 4 to 7 times over the circumferential membrane stress. The initial deviation of Model CC-21 presented in Table 5 in Appendix A was greater than $1 / 100$ of the radius. Such large initial deviations in a conical shell may very likely cause a far larger increase in the maximum fiber stress due to bending.

This nonsymmetric bending of the shell can be studied in regions away from the intersections where almost pure membrane action should result in stresses and strains equal on both sides of the shell. In Figure 32, for example, the strains in the internal fibers follow the trend of the theoretical curve but nearly all lie above it; the external strains, similarly, all lie below the theoretical curve in the region of membrane stress.* Averaging the internal and external strains to eliminate circumferential bending places the membrane strains in close proximity to the theoretical curve. Unfortunately, the original deviations on Model CC-20 are unknown. The initial circumferential irregularities preceding the second test were not excessive, being within the tolerances discussed in Appendix A. The longitudinal generators, as may be seen from Figures 54 and 55 in Appendix A, were almost straight.

The longitudinal strains in Model CC-20, on the other hand, both internal and external, agree closely with the theoretical strains.

The original theoretical calculations were made on the basis of uniform thickness, taken as the average measured thickness of the sheet steel prior to rolling. The thickness variation close by the intersection does not vary monotonically, however. In fact, due to the irregularity of hand grinding, it may vary in a random manner, and the randomness of thickness would be very difficult to compare with the strain.

Strains recorded on different generators, at 0,120 , and $240 \mathrm{deg}$, but at equal distances from the intersection, differed in magnitude. This spread in values is presumably due to a stiffening effect from an excess or lack of weld material, which increases or decreases the local bending when the shell is pressurized.

\footnotetext{
*Departures from circularity were apparently in an oval mode. Results would not have shown such marked effects of nonsymmetric behavior if the imperfections in shape were more localized.
} 
Excess weld material acting as a stiffener may contribute to the low compressive strain at the intersection. Conversely, a deficiency of material at the juncture may induce high compressive strain. The resultant strain depends upon whether the bending or membrane action is the major contributor to the strains.

An attempt was made actually to correlate initial out-of-roundness with the experimental strains, but with only limited success. Figures 45 to 50 in Appendix A show that only the circumferential strain followed (in many locations) the deviation pattern of the original circumferential circularity. An effect of thickness variation upon strain is unrecognizable.

More consistent results could undoubtedly have been obtained with machined instead of welded models. The cost would have been very much greater, however, and it is believed that the accuracy obtained with the welded models was sufficient, not only to validate the TMB Report 826 theory, but also to indicate the locations of maximum stresses and strains. The inconsistencies caused by the initial imperfections in this series of models may themselves be useful in estimating variations in elastic strains in welded pressure vessels due to normal imperfections in workmanship.

\section{CONCLUSIONS}

1. The test results indicate substantial agreement with the Wenk-Taylor elastic theory described in TMB Report 826, in spite of irregularities in fabrication of the models. It may be concluded that the theory is an adequate representation, within engineering accuracy, of the discontinuity stresses arising at the intersection of a conical and cylindrical shell.

2. As the half apex angle $\alpha$ of the cone increases, there is a pronounced divergence between both the Geckeler and TMB approximate analyses and the accurate Love-Meissner analysis, but for cones with smaller apex angles there is very little difference between the theories.

\section{ACKNOWLEDGMENTS}

Experimental verification of the theory was part of the program of analysis on conical shells under the supervision of Dr. E. Wenk, Jr., and Dr. C.E. Taylor, who planned the program and made many valuable suggestions. Experimental work was begun by Mr. J.L. Bigio and continued by the author. Assistance in the computations was furnished by Miss T.M. Morrow.

After the author's departure from the Model Basin, while the report was still in draft stage, considerable revision was made by members of the TMB staff; Dr. E.H. Kennard undertook the preparation of the final draft. 


\section{APPENDIX A \\ MODEL IMPERFECTIONS}

\section{OUT-OF-ROUNDNESS}

The initial out-of-roundness and the allowable out-of-roundness of the intersection of the cone and cylinder are compared for five models in Table 5. The actual out-of-roundness was determined from circularity measurements on the inside of the shells. Measurements on the internal surface were chosen in preference to those on the external surface since measurements on the outside would include also the thickness deviations due to the grinding at the intersection. The actual deviation was taken as the difference in inches between the two extreme eccentric points of shell deviations; Figures 45 through 50 .

\section{TABLE 5}

Initial and Allowable Out-of-Roundness of Cone and Cylinder at the Intersection

\begin{tabular}{|c|c|c|c|c|c|c|c|}
\hline \multirow{2}{*}{ Model } & $\alpha$ & $\begin{array}{c}\text { Shell } \\
\text { Thickness } \\
\text { in. }\end{array}$ & $\begin{array}{c}\text { Actual Out- } \\
\text { of-Roundness } \\
\text { in. }\end{array}$ & $\begin{array}{c}\text { Allowable } \\
\text { Deviation } \\
\text { ASME* }\end{array}$ & $\begin{array}{c}\text { Shell } \\
\text { Thickness } \\
\text { in. }\end{array}$ & $\begin{array}{c}\text { Actual Out- } \\
\text { of-Roundness } \\
\text { in. }\end{array}$ & $\begin{array}{c}\text { Allowable } \\
\text { Deviation } \\
\text { ASME* }\end{array}$ \\
\hline CC-8 & 30 & 0.060 & 0.060 & 0.08 & 0.060 & 0.065 & 0.08 \\
CC-8A & 30 & 0.060 & 0.054 & 0.08 & 0.060 & 0.043 & 0.08 \\
CC-10 & 60 & 0.096 & 0.050 & 0.076 & 0.096 & 0.033 & 0.076 \\
CC-20 & 30 & 0.067 & 0.061 & 0.076 & 0.097 & 0.032 & 0.076 \\
CC-21 & 30 & 0.097 & 0.076 & 0.057 & 0.067 & 0.047 & 0.057 \\
\hline \multicolumn{7}{|l}{ *A1lowable deviation is 1 percent of the radius (Section UG-80, Boiler Code, 1952). } \\
\hline
\end{tabular}

The actual measured out-of-roundness is compared with two widely accepted criteria for allowable out-of-roundness in Table 5. The first, commonly used in submarine fabrication, is that the allowable deviation from circularity is equal to the shell thickness. $\dagger$ All the models, with the exception of the cylinder of Model CC-8, were well within this tolerance. The second criterion is used in the fabrication of commercial unfired pressure vessels and may be found in the ASME Boiler Code, Section UG-80, 1952; the allowable out-of-roundness is 1 percent of the difference between minimum and maximum diameters divided by the nominal diameter at the cross section. The cone of Model CC-21 was the only shell that did not fall within this latter

\footnotetext{
† In the fabrication of cylindrical models which are to be tested under external hydrostatic pressure, the deviation allowed at the Model Basin has been one-half the shell thickness. As the cylicone models are tested exclusively under internal pressure, this allowable out-of-roundness seems unduly rigid for these models.
} 
limit. As all the cylicone models were fabricated by identical procedures, the out-of-roundness of the five models shown probably indicates that the out-of-roundnesses of all the models were within recognized tolerances.

In Figures 45 through 50 the strain sensitivities of Models CC-8A, CC-10, and CC-21 are shown for comparison with shell thickness and circumferential initial circularity at points equidistant from the intersection on both cone and cylinder. Initial circumferential deviations of cone and cylinder at these points have a two-lobe formation, and the deviation curves of cone and cylinder of any one model are very similar. Circumferential strain sensitivities of all three models have directional inclines resembling the initial circularity of its shell.

\section{GENERATOR RECTILINEARITY}

Longitudinal profiles were measured along the 0-, 120-, and 240-deg generators on both cone and cylinder and also on the seam, to determine generator rectilinearity. In Figures 51 through 55 are shown comparisons of longitudinal profiles of the cone on Models CC-8 and CC-8A, two separate generators of the cone and cylinder of Model CC-10, and generators of the second test of Model CC-20. In general, it was noted that the initial deviation of any one generator was never larger than the shell thickness. The directions of the deviations indicated a tendency of the models to bulge outward.

\section{THICKNESS MEASUREMENTS}

Thickness measurements along the generators of Models CC-10, CC-20 (second test), and CC-8A are illustrated in Figures 56 through 60 . Thickness measurements at points $3 / 32$ or $1 / 4 \mathrm{in.}$ from the intersection on cone and cylinder for Models CC-8A and CC-10 are shown in Figures 45 through 48.

Measurements of points close to the intersection of Model CC-10 (Figures 56 and 57) show that on the 0 - and 120-deg lines, the conical shell thicknesses along the generator were greater for the first than for the second test. On the 240-deg line, and also away from the intersection on the 0 - and 120-deg lines, the thickness at equidistant points varied at most by 3 percent. On the cylindrical shell generators, thicknesses at equidistant points were practically equivalent in the first and second tests, with variations of up to 3 percent.

The thickness variations along the generators of Model CC-20 (second test), Figures 58 and 59 , showed remarkable similarity due to the technique employed in grinding off the excess weld material at the intersection. All generators on the cone were undercut near the intersection; the corresponding generators on the cylinder were thicker near the intersection but otherwise quite uniform.

Thicknesses on the 0-deg line on both cone and cylinder of Model CC-8A are shown in Figure 60. The material close to the intersection on both cone and cylinder is thicker than the original shell, whereas beyond about $3 / 4 \mathrm{in}$. from the intersection the effect of grinding has diminished so that essentially the true shell thickness exists. 


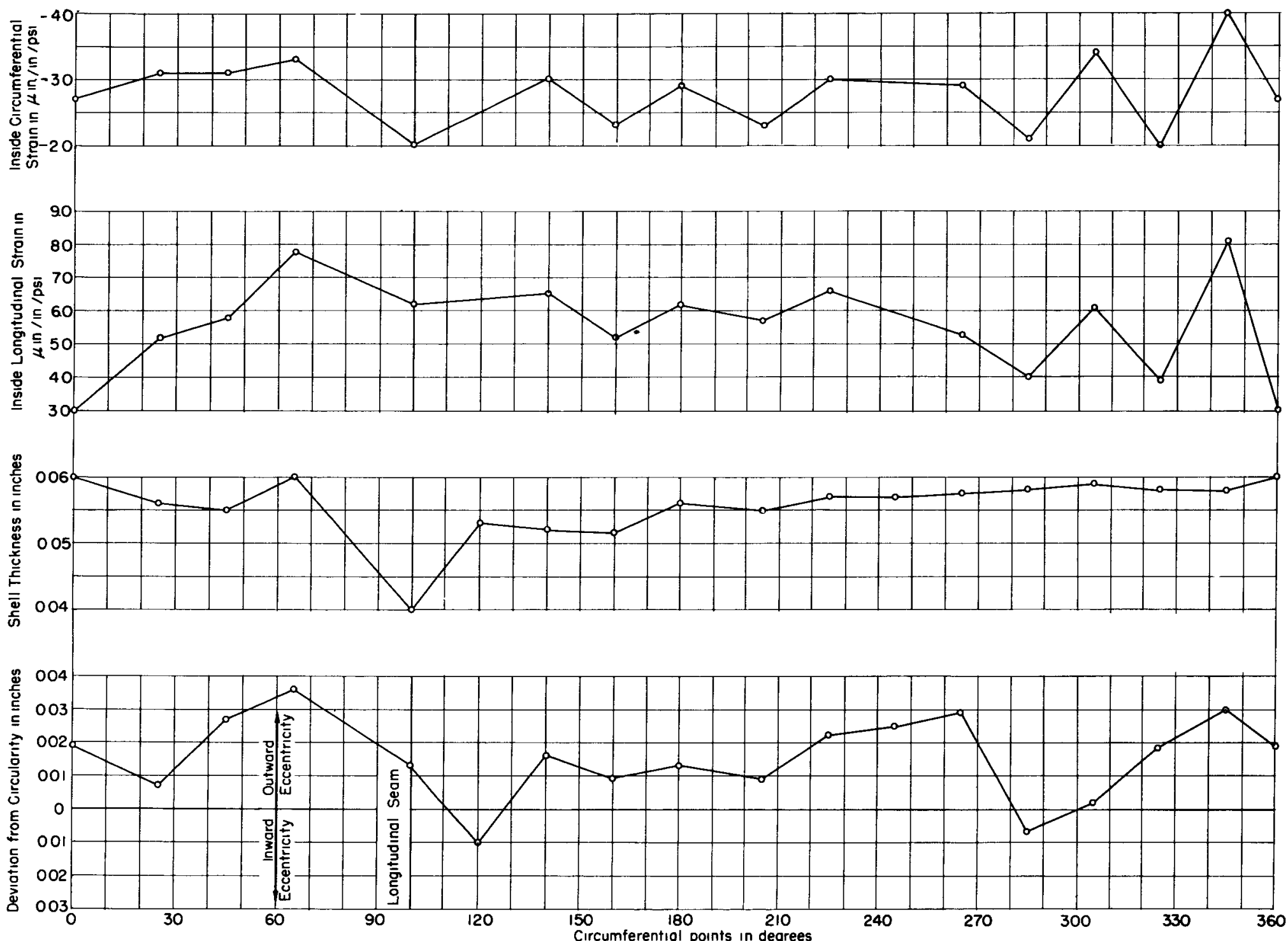

Figure 45 - Circumferential Circularity and Thickness Measurements Compared to Strain Sensitivities at Points $1 / 4$ Inch from the Intersection on the Cone of Model CC-8A 


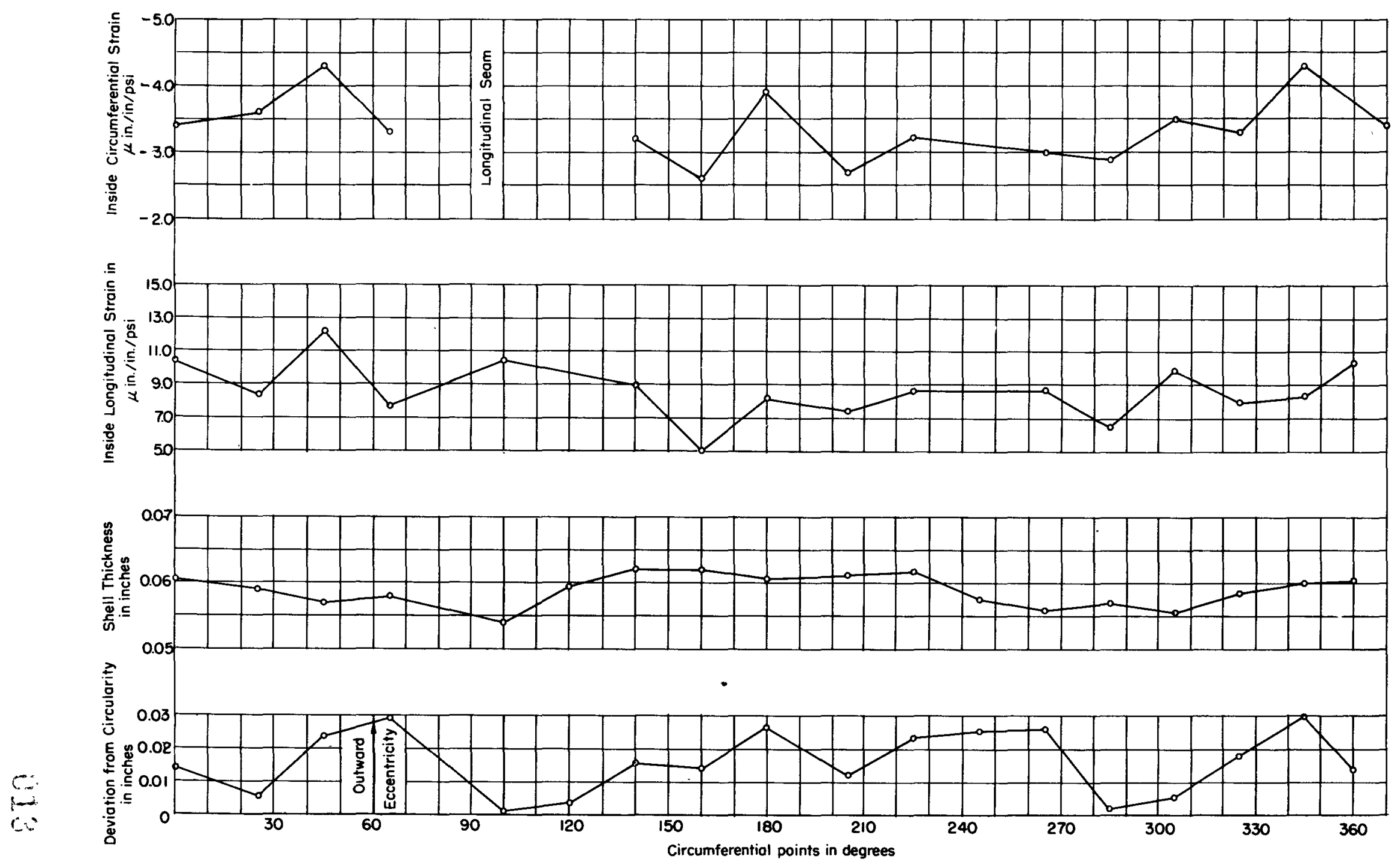




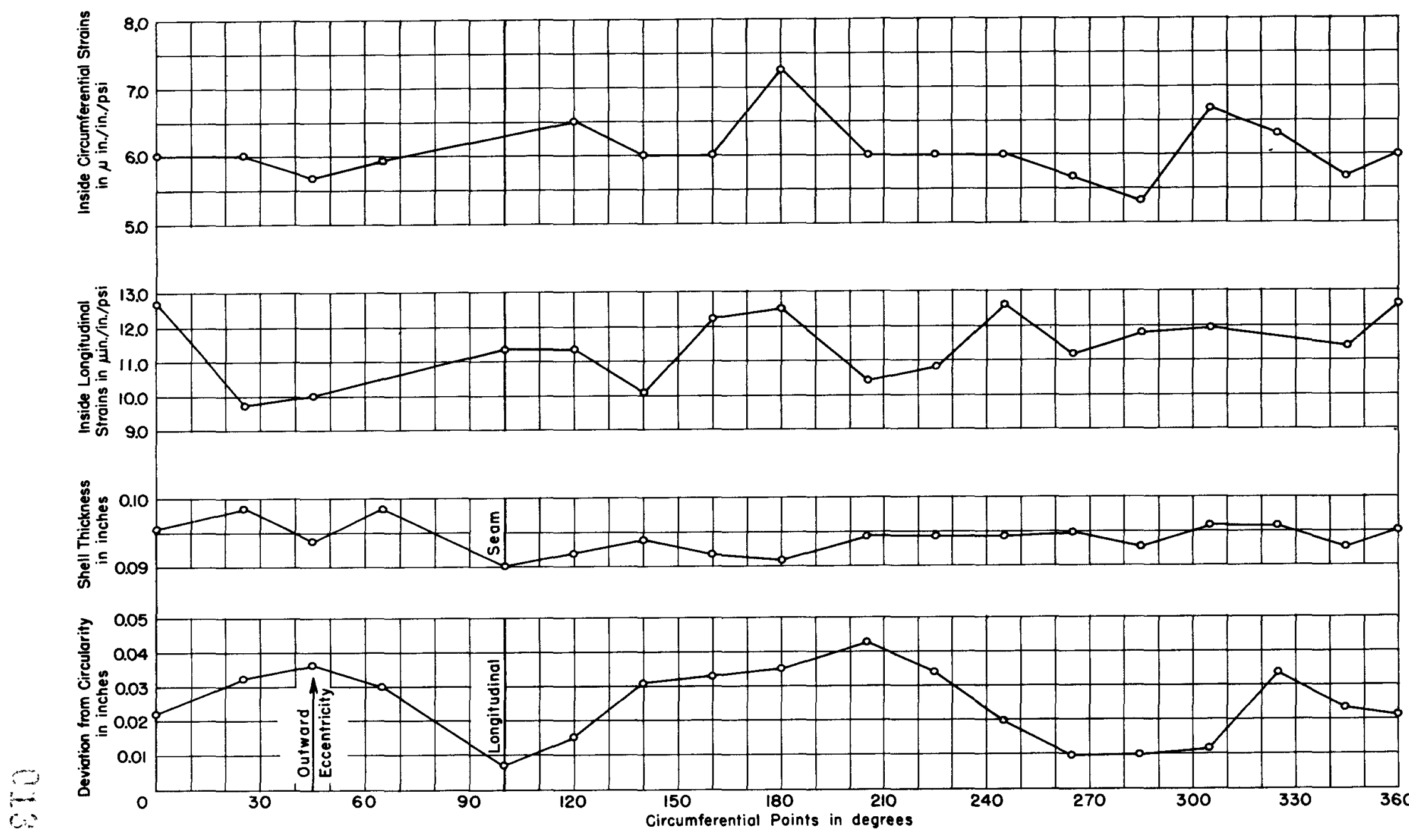

Figure 47 - Circumferential Circularity and Thickness Measurements Compared to Strain Sensitivities at Points 1/4 Inch from the Intersection on the Cone of Model CC-10 (Second Test) 


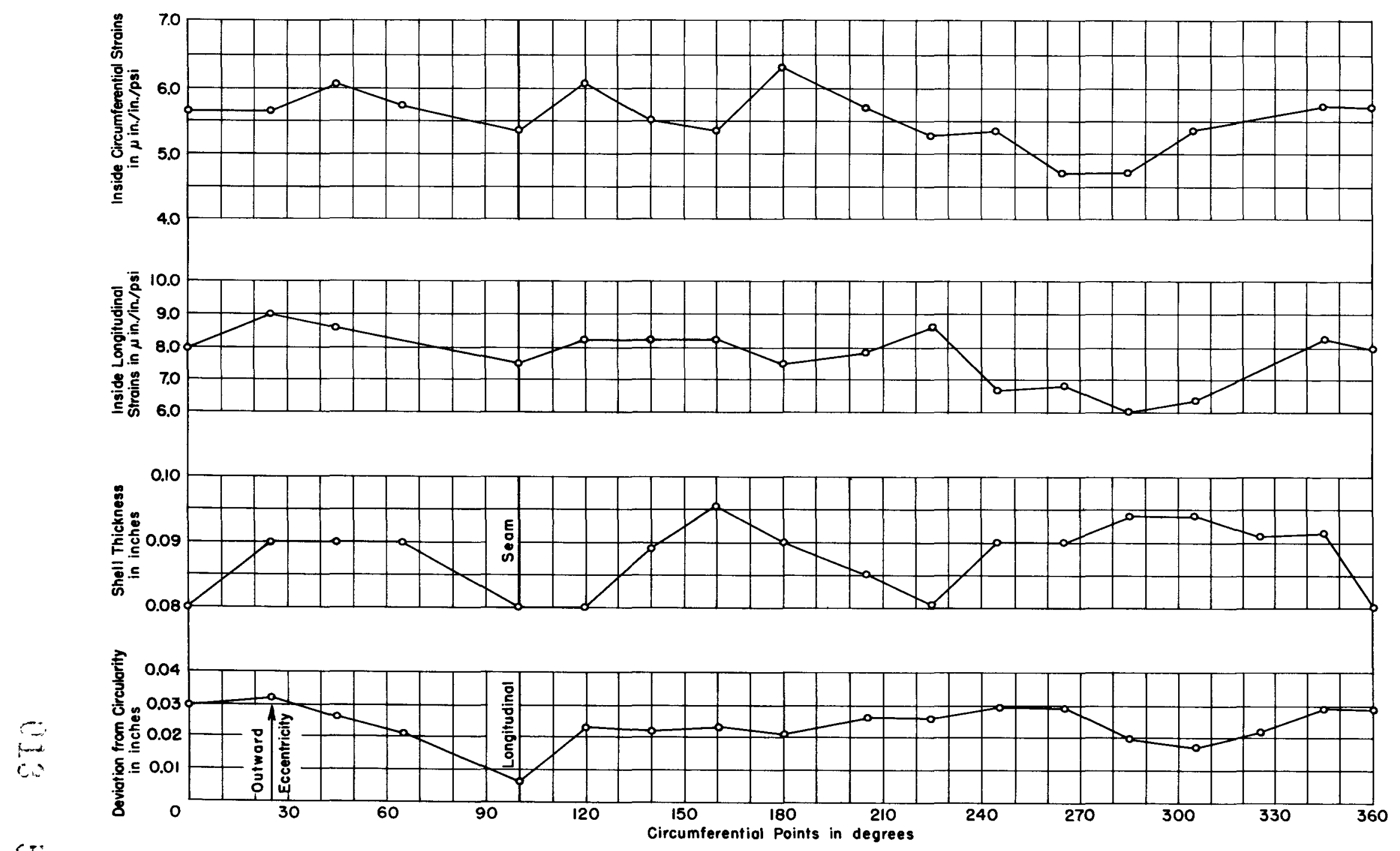

Figure 48 - Circumferential Circularity and Thickness Measurements Compared to Strain Sensitivities at Points 1/4 Inch from the Intersection on the Cylinder of Model CC-10 (Second Test) 


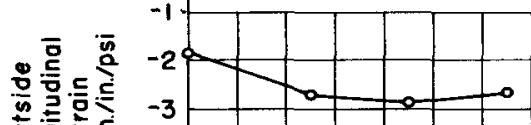

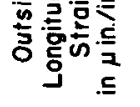
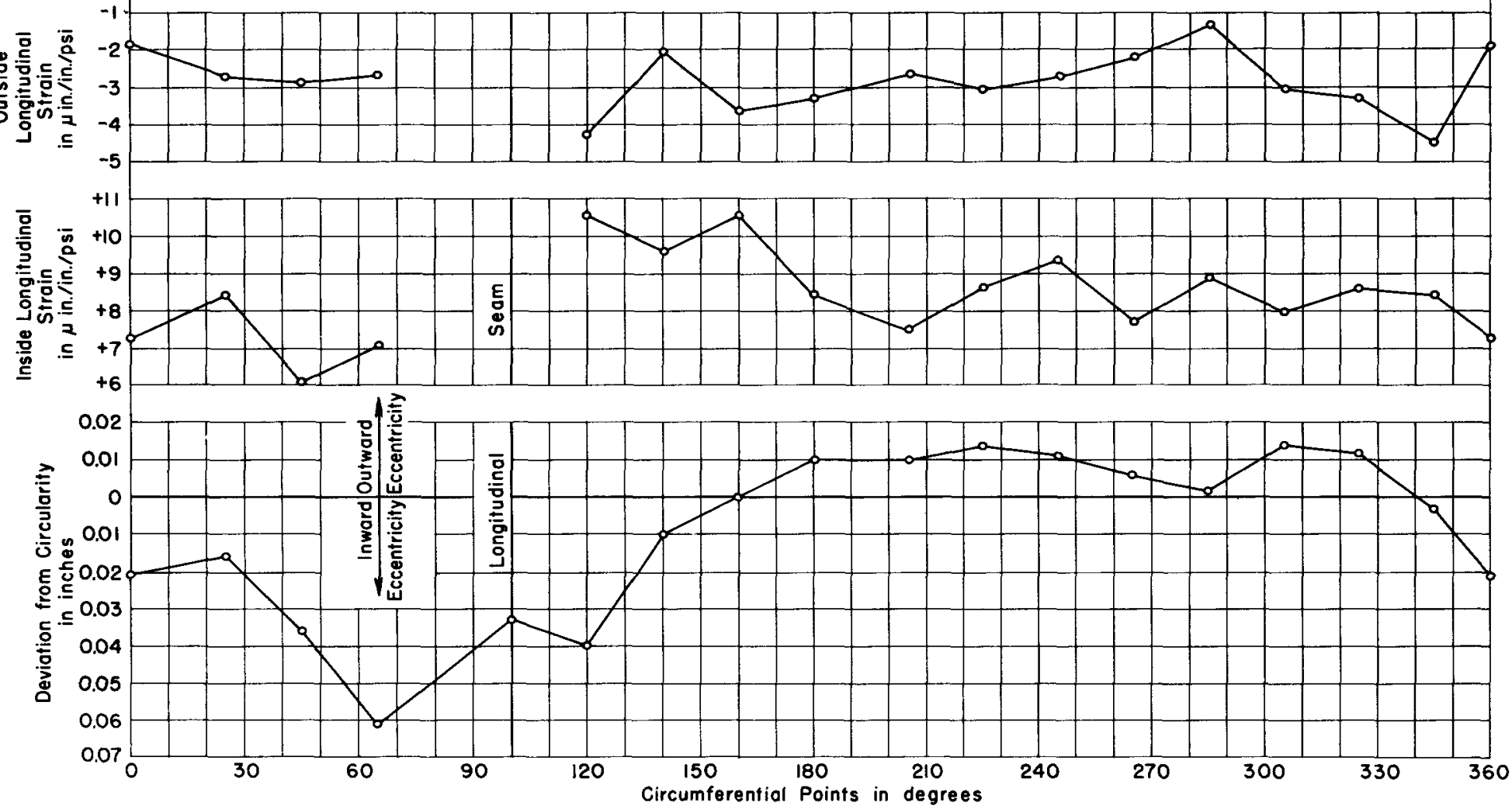

Figure 49 - Circumferential Circularity Measurements Compared to Strain Sensitivities at Points $3 / 32$ Inch from the Intersection on the Cone of Model CC-21 


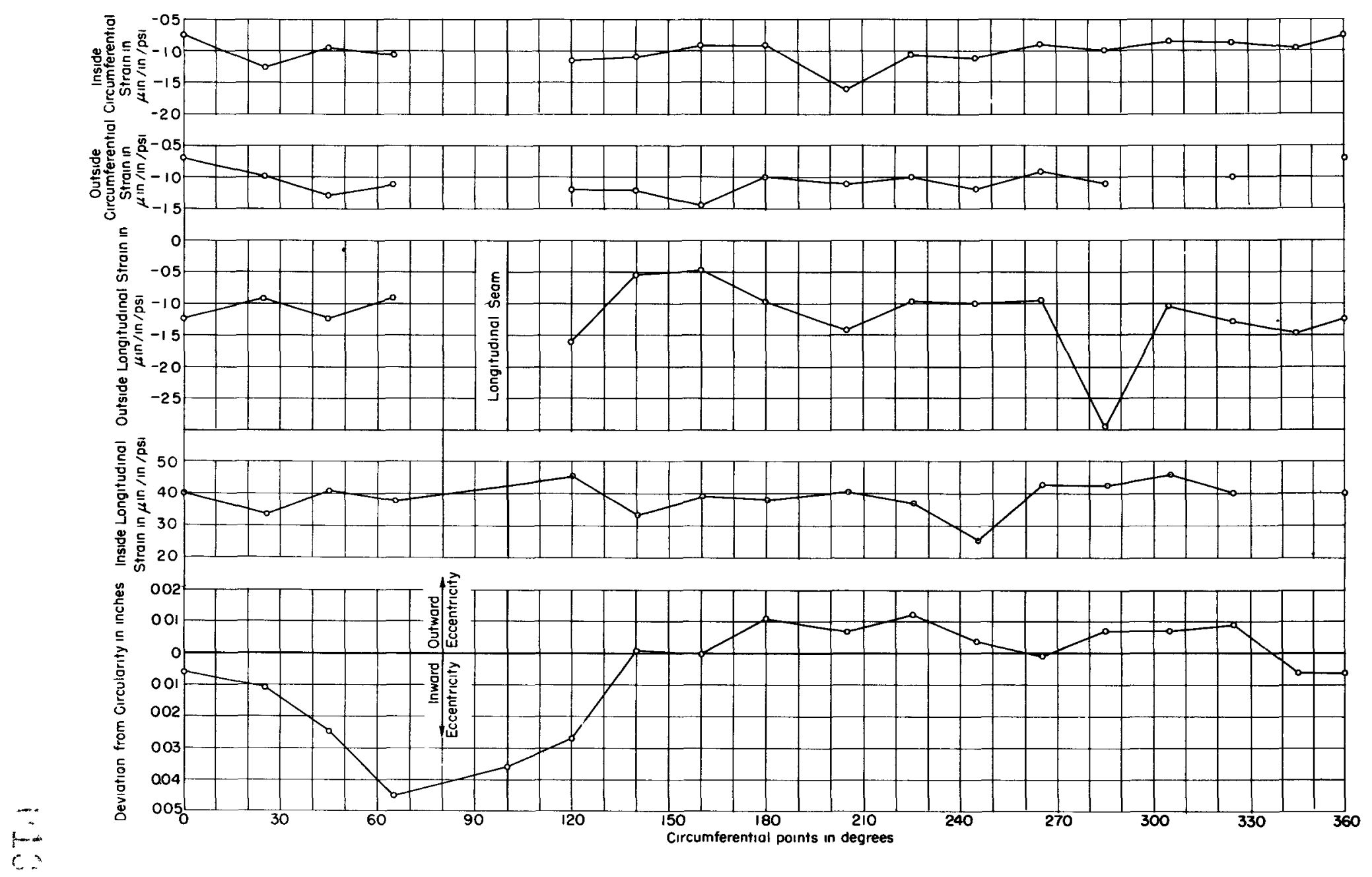

Figure 50 - Circumferential Circularity Measurements Compared to Strain Sensitivities at Points

$\infty$ $3 / 32$ Inch from the Intersection on the Cylinder of Model CC-21 


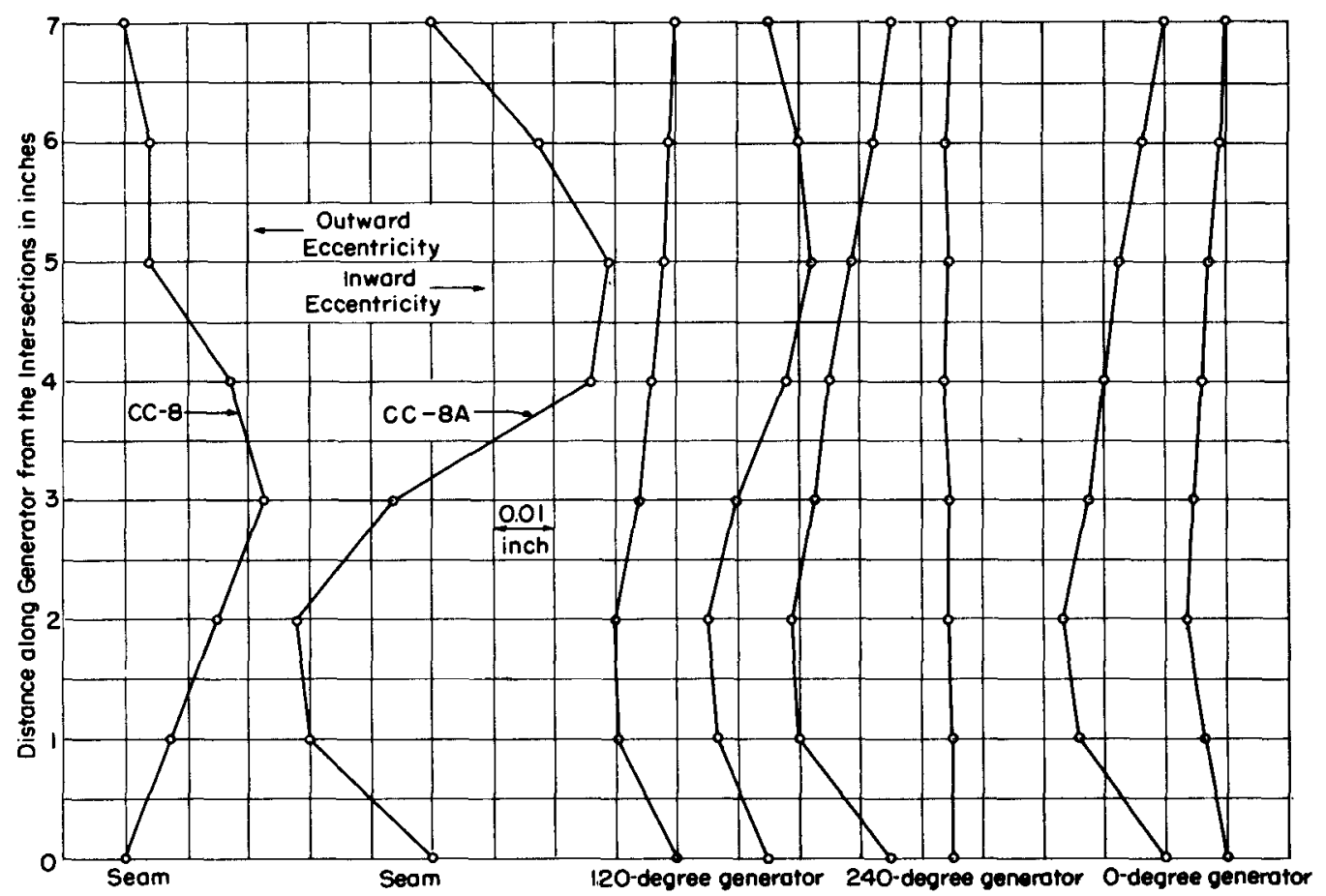

Figure 51 - Longitudinal Profiles of Generators on Cone of Models CC-8 and CC-8A

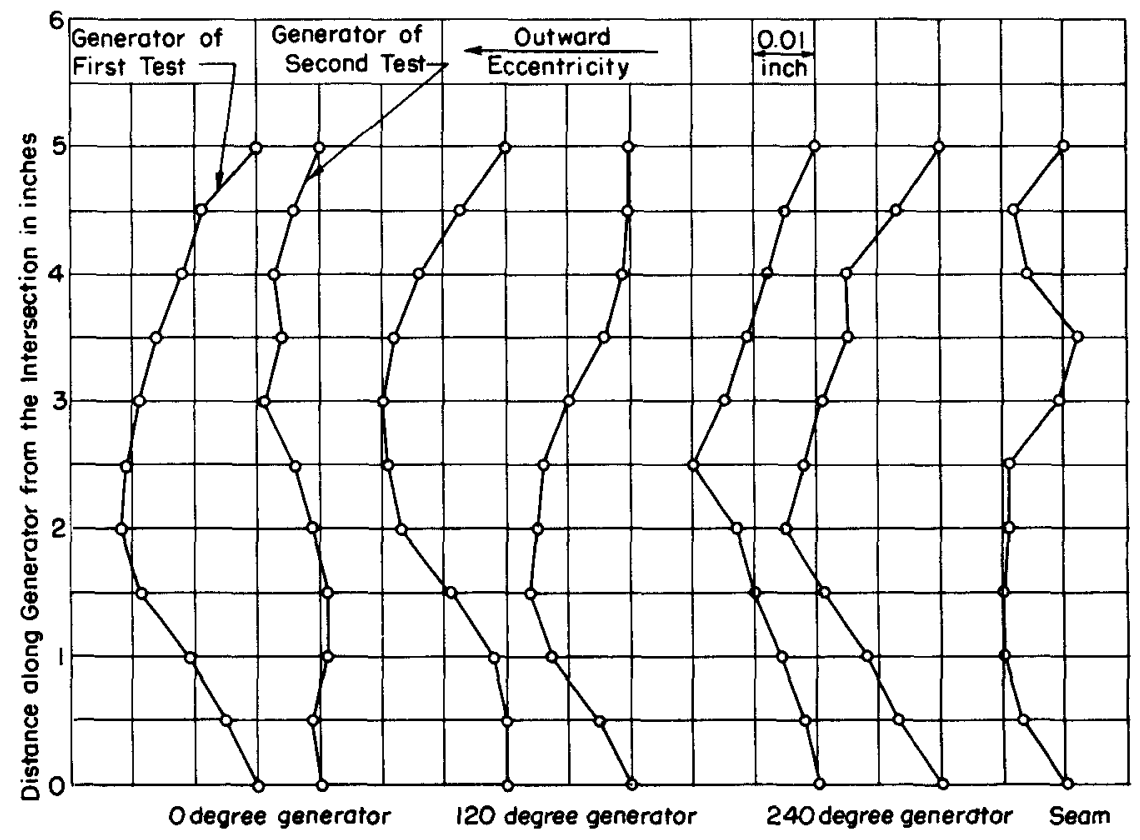

Figure 52 - Longitudinal Profiles of Generators on Cone of Model CC-10

$$
\text { 1) } 61
$$




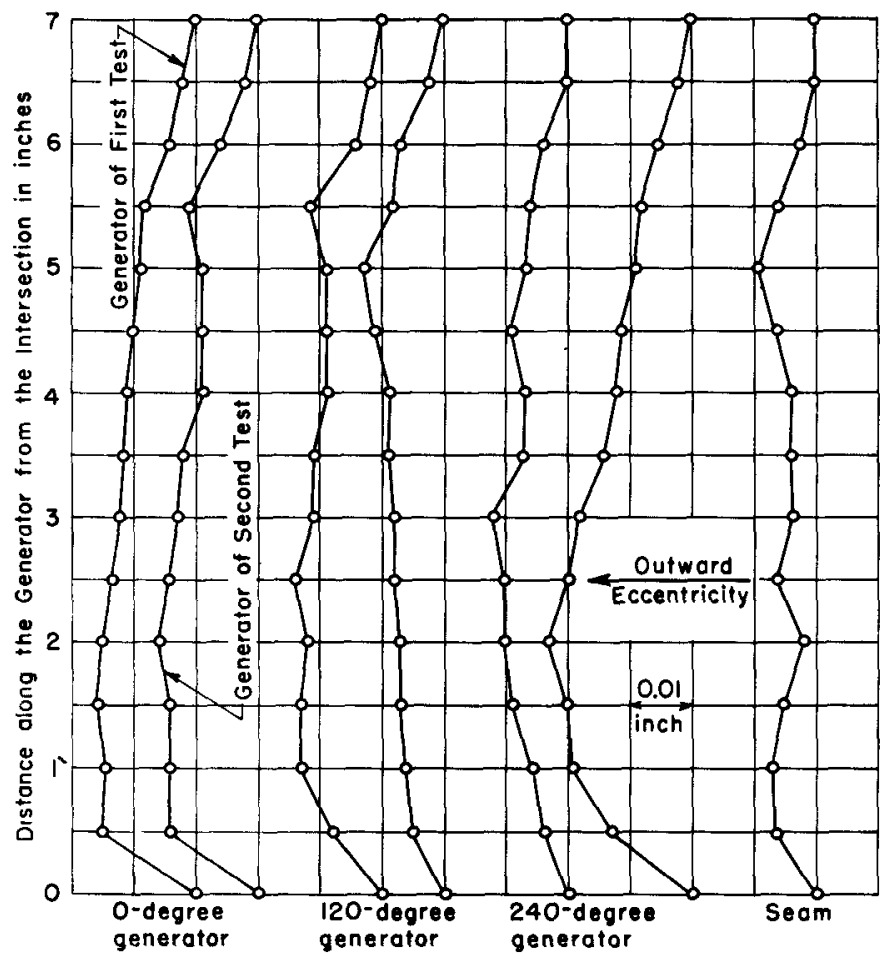

Figure 53 - Longitudinal Profiles of Generators on Cylinder of Model CC-10

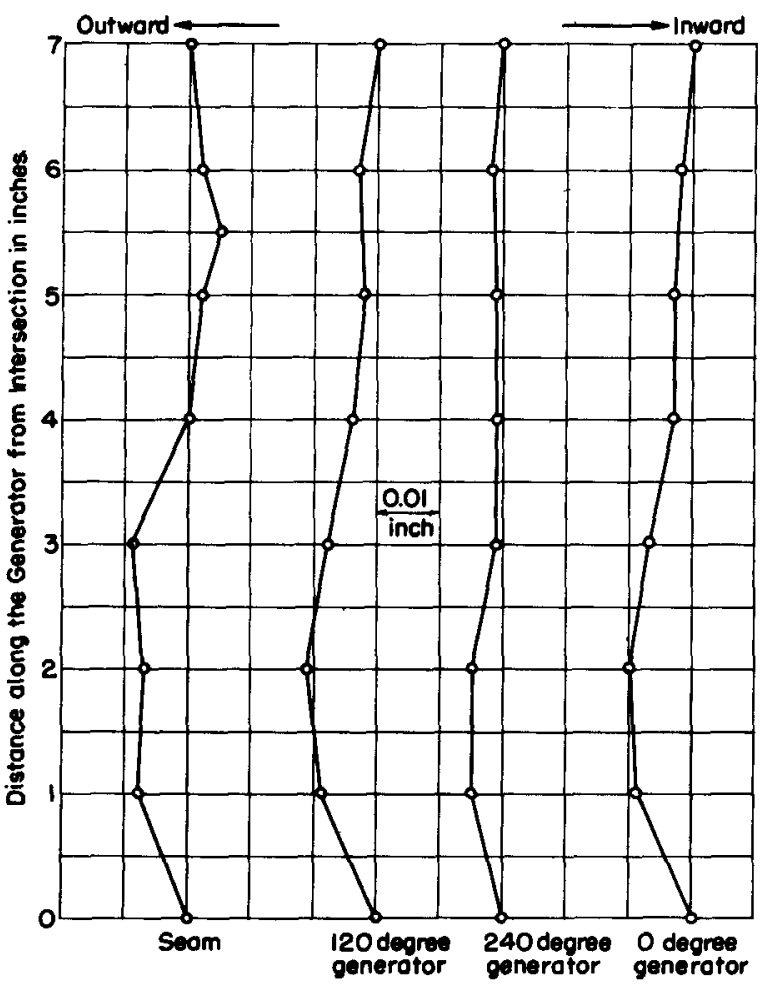

Figure 54 - Longitudinal Profiles of Generators on Cone of Model CC-20 (Second Test) 


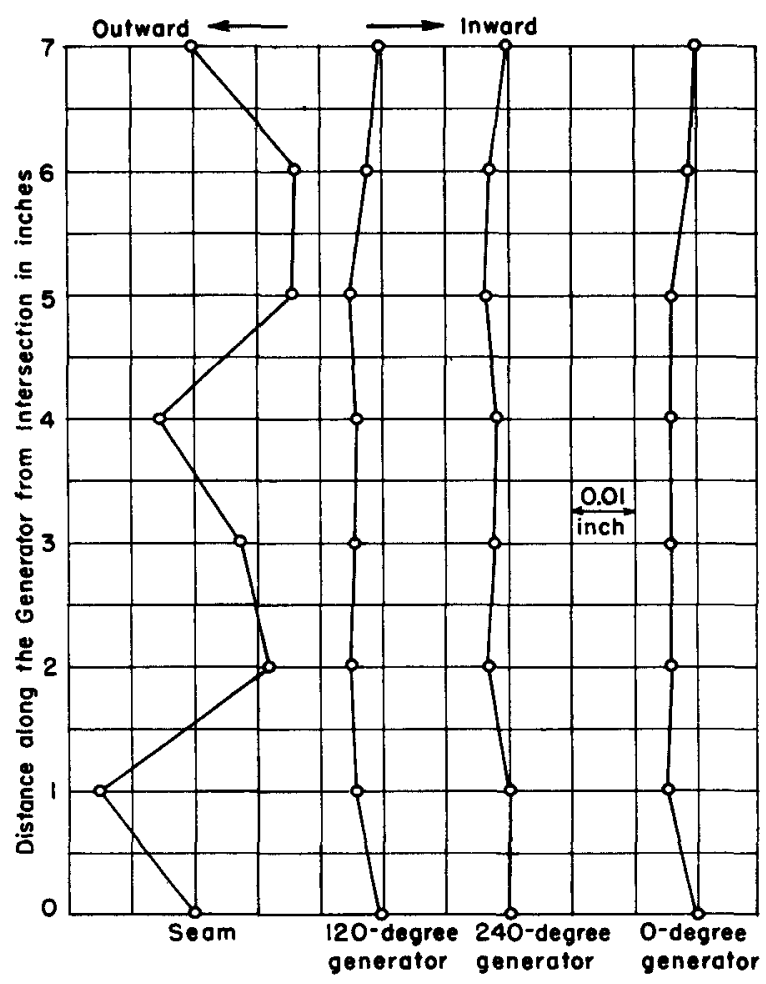

Figure 55 - Longitudinal Profiles of Generators on Cylinder of Model CC-20 (Second Test)

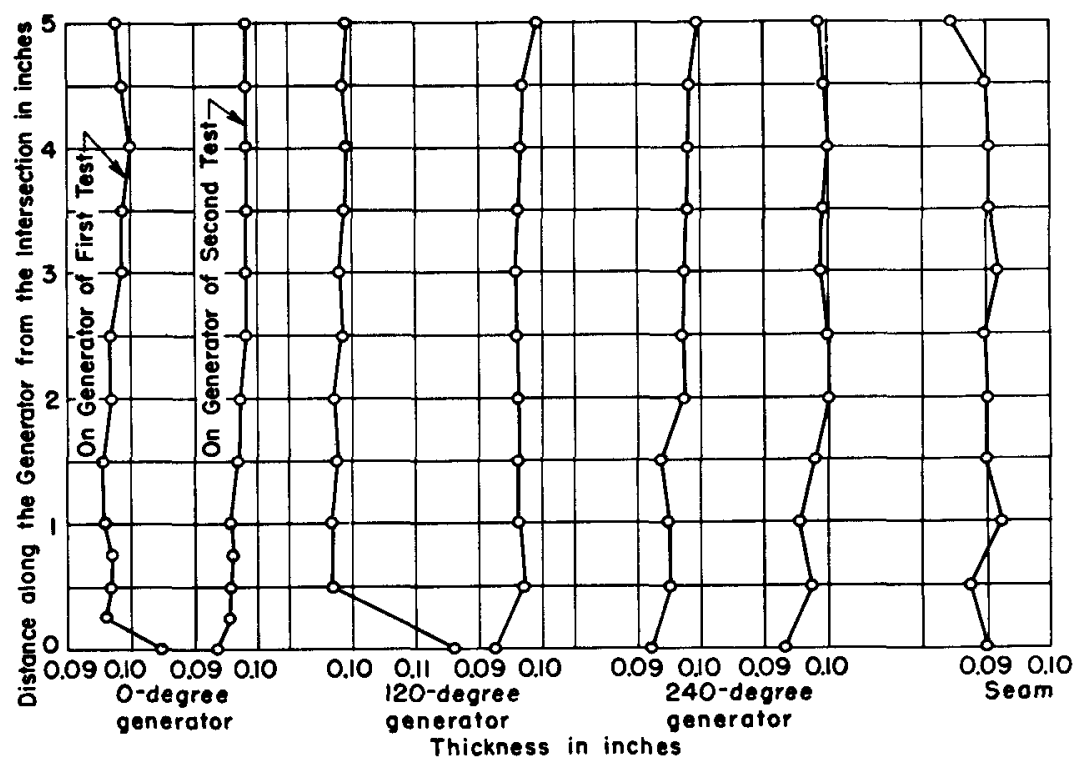

Figure 56 - Thickness Measurements on Generators of Cone of Model CC-10

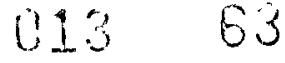




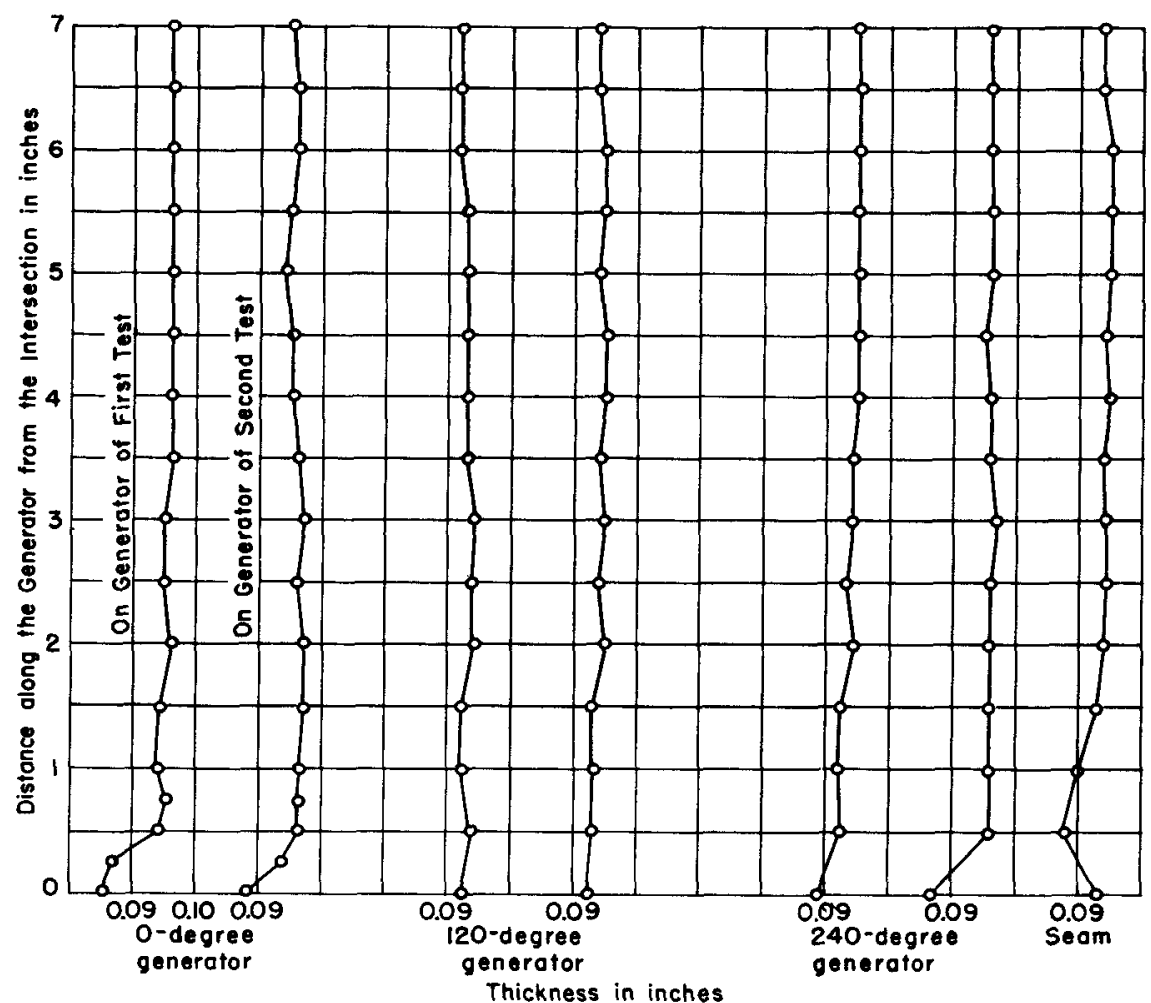

Figure 57 - Thickness Measurements on Generators of Cylinder of Model CC-10

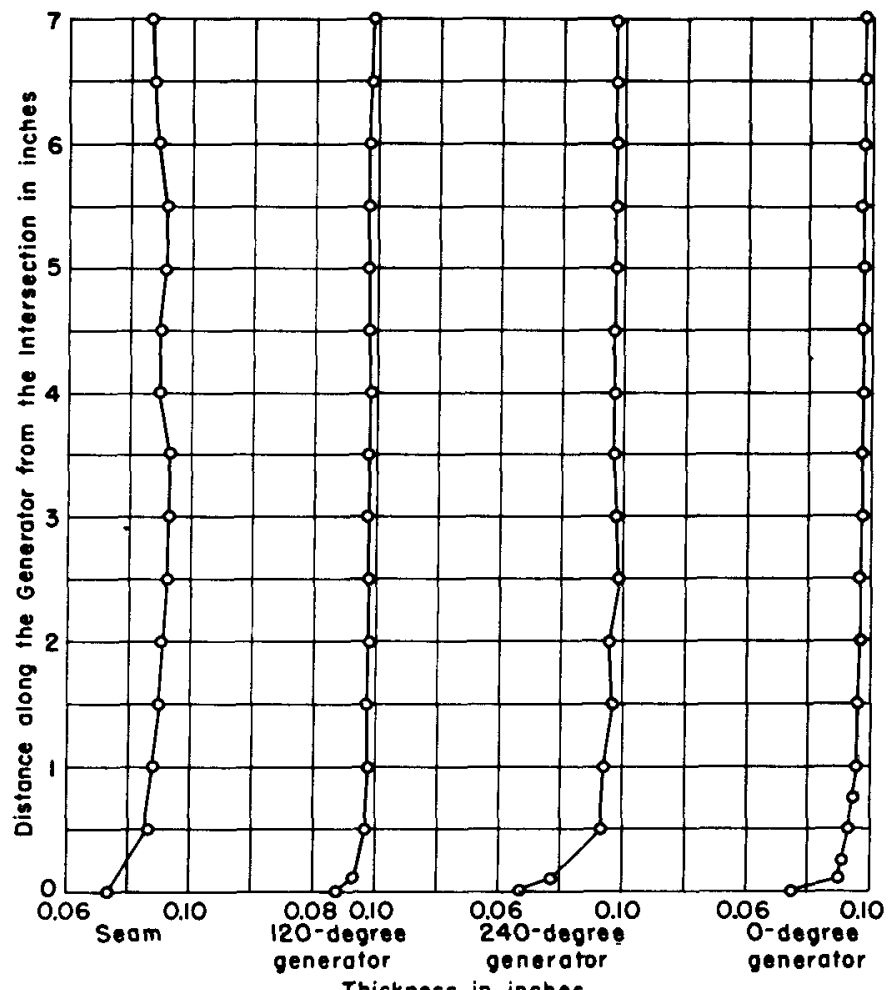

Figure 58 - Thickness Measurements on Generators of Cone of Model CC-20 (Second Test) 


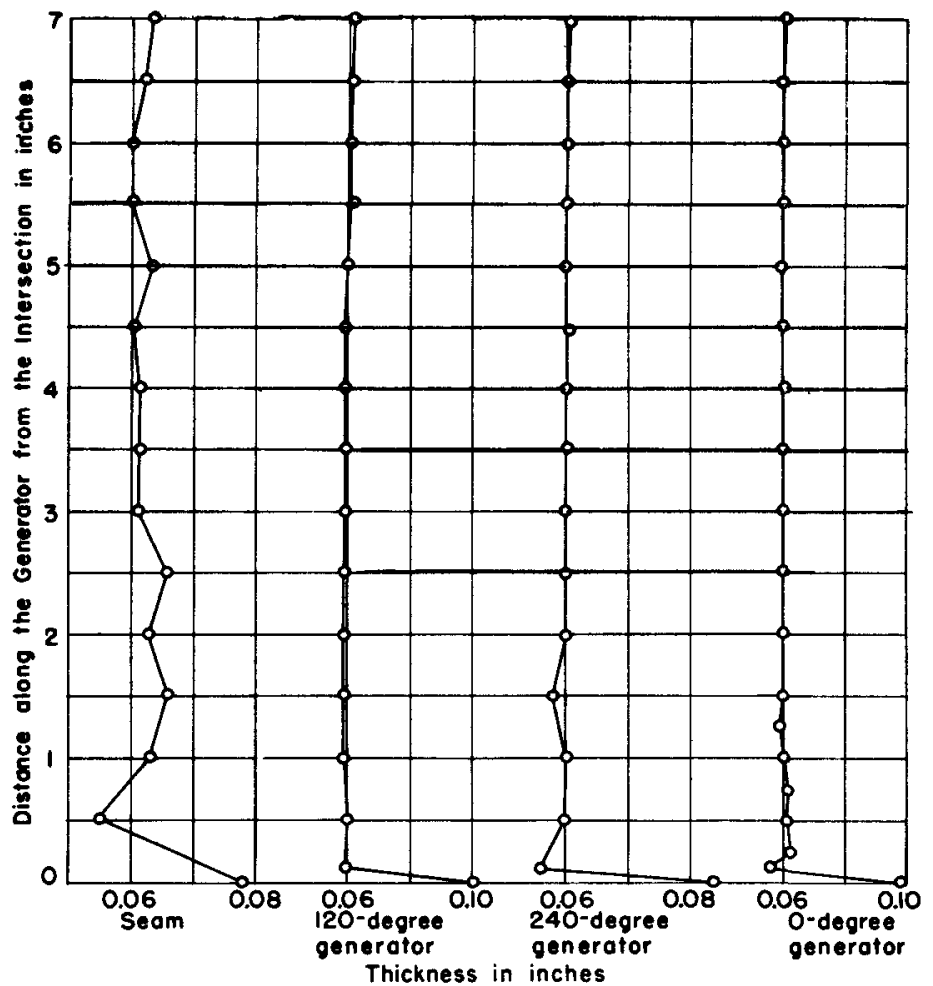

Figure 59 - Thickness Measurements on Generators of Cylinder of Model CC-20 (Second Test)

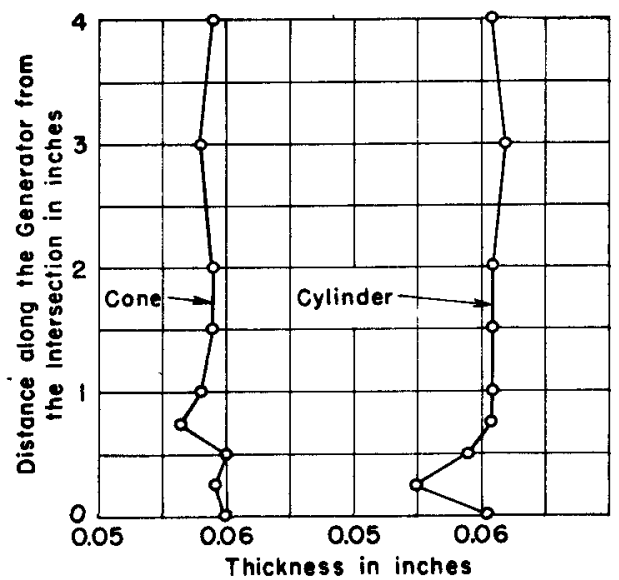

Figure 60 - Thickness Measurements on 0-Degree Generator of Cone and Cylinder of Model CC-8A 


\section{APPENDIX B \\ THEORETICAL CALCULATIONS}

Theoretical distributions of stress and strain were calculated for all models, including the Purdue models, ${ }^{5}$ using the approximate Wenk-Taylor theory ${ }^{2}$ for the cone and Timoshenko's equations ${ }^{14}$ for the cylinder. Young's modulus and Poisson's ratio were taken as $30 \times 10^{6}$ and 0.3 , respectively. The approximate edge coefficients $a$ and $d$ on page 10 of Reference 2 were employed except in a few special calculations to be described later. For comparison, calculations were also made for two models by the approximate method of Geckeler, sometimes called the equivalent-cylinder method. Finally, maximum stresses at the intersection of cone and cylinder in these models were also calculated from the general equations of E. Meissner ${ }^{10}$ as extended by F. Dubois. ${ }^{15 *}$

\section{COMPARISON OF THE THEORIES}

Two models with $h=H$ and nominal $h=0.00617$ were selected for a close comparison of the theories, namely, CC-9 with $\alpha=30 \mathrm{deg}$ and CC-10 with $\alpha=60 \mathrm{deg}$. The exact expressions for the edge coefficients as given on page 10 of Report 826 were employed in these calculations. The resulting edge moments $M_{0}$ in the cone at the intersection, as calculated by TMB Report 826 and Geckeler, agreed within 3 percent, and the edge forces $H_{0}$ within 1 percent.

Stresses and strains at the intersection of cone and cylinder, as calculated from three different theories, are listed in Tables 6 and 7. It will be noted that, for the model with $\alpha=30 \mathrm{deg}$, stresses calculated by the method of TMB Report 826 differed only by 1 to 3 percent from the values calculated by the exact Love-Meissner theory, the Geckeler values differing by 3 to 5 percent. For the model with $\alpha=60 \mathrm{deg}$, however, Geckeler's method comes closer, agreeing within 2 percent, whereas the TMB Report 826 values are off 3 to 4 percent. The strain sensitivities show differences, as between TMB Report 826 and Geckeler, with a maximum of 9 percent between the largest values (13.8 versus 15.1). All these differences are satisfactorily small.

\section{STRESS INDEX FACTORS}

The general nature of the calculated results can be exhibited graphically by plotting stress index factors, or the maximum stress in the cone at the intersection divided by the ordinary hoop stress in the cylinder, $p R /(2 h)$. This is done for all TMB models with $h=H$ in Figures 61 and 62.

\footnotetext{
*Numerical data for the use of Dubois' equations were given by Watts and Burrows, ${ }^{16}$ and Watts and Lang. 17
} 
It will be noted that the stress index factors become numerically large as the cone angle $\alpha$ becomes large, but decrease numerically as $h / 2 R$ increases, except when $\alpha$ is small. The index factors should depend on $h$ only through the ratio $h / 2 R$.

The results show graphically the small differences between results computed by the various available theories.

\section{TABLE 6}

Comparison of Maximum External Stresses in Cone at Intersection of Models CC-9 and CC-10

\begin{tabular}{|c|c|c|c|c|}
\hline \multirow{2}{*}{ Model } & \multirow{2}{*}{ Stress } & TMB Report 826 & Geckeler & $\begin{array}{c}\text { Love-Meissner } \\
\text { Exact }\end{array}$ \\
\cline { 3 - 5 } & & -185.9 & -189.1 & -179.3 \\
CC-9 & $\sigma_{x}$ & -109.8 & -113.1 & -110.8 \\
$\alpha=30 \mathrm{deg}$ & $\sigma_{\phi}$ & -520.0 & -530.0 & -541.6 \\
CC-10 & $\sigma_{x}$ & -416.4 & -390.9 & -389.9 \\
\hline
\end{tabular}

\section{TABLE 7}

Maximum Theoretical External Strain Sensitivities in Cone of Models CC-9 and CC-10

\begin{tabular}{|l|c|c|c|c|c|}
\hline \multirow{2}{*}{ Model } & \multirow{2}{*}{$\alpha$} & \multicolumn{2}{|c|}{$\begin{array}{c}\text { Max. Circum. Strain } \\
\mu \mathrm{in} / \mathrm{in} / \mathrm{psi}\end{array}$} & \multicolumn{2}{c|}{$\begin{array}{c}\text { Max. Longit. Strain } \\
\mu \mathrm{in} / \mathrm{in} / \mathrm{psi}\end{array}$} \\
\cline { 3 - 6 } & $\operatorname{deg}$ & Geckeler & TMB Report 826 & Geckeler & TMB Report 826 \\
\hline CC-9 & 30 & $+2.2^{*}$ & $+2.5^{*}$ & -5.1 & -5.1 \\
CC-10 & 60 & -7.4 & -7.7 & -15.1 & -13.8 \\
\hline \multicolumn{3}{|c}{ *Away from the intersection. Others at intersection. } \\
\hline
\end{tabular}




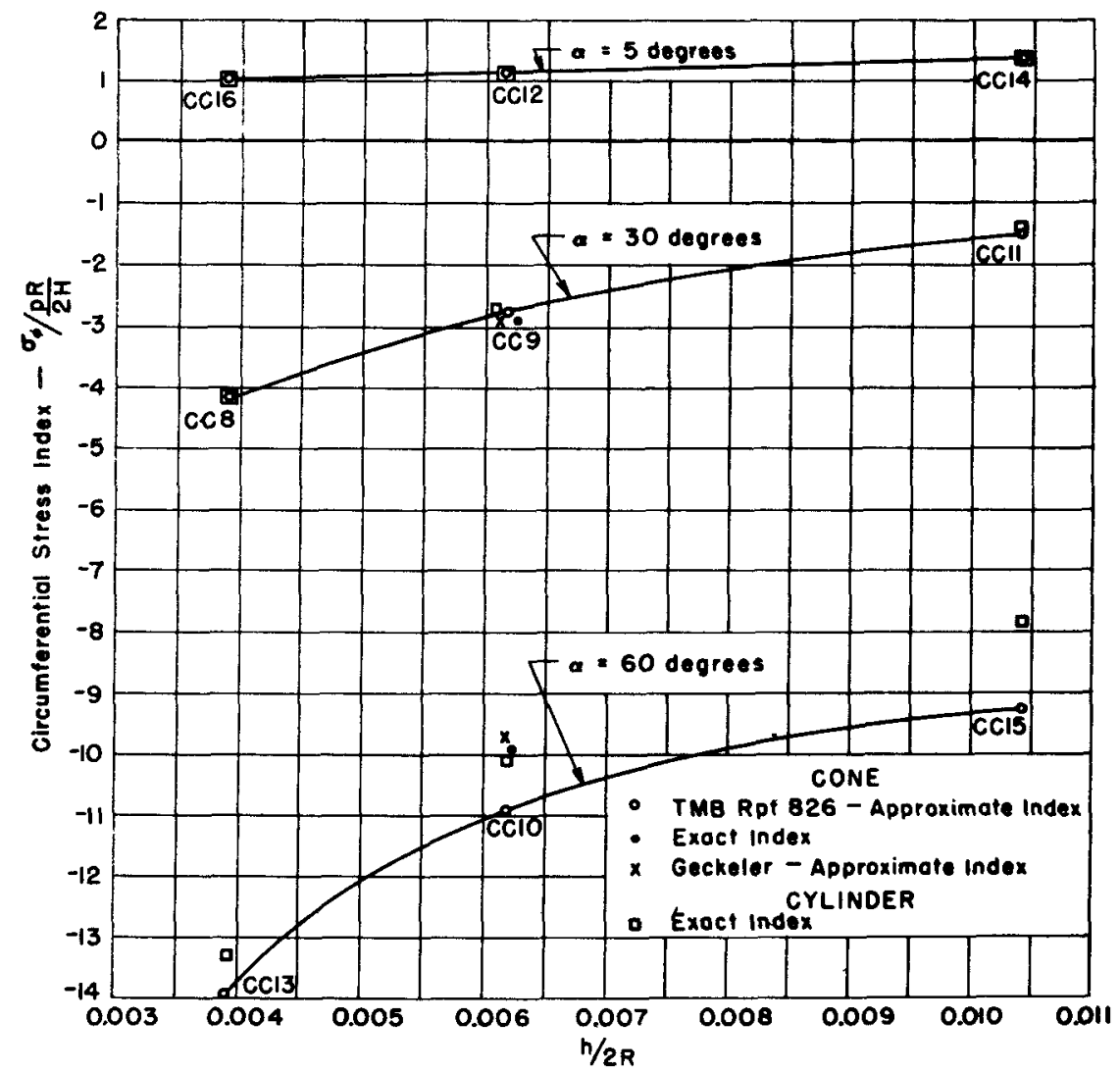

Figure 61 - Maximum Theoretical Circumferential Stress Indexes in Conical and Cylindrical Shell at-the Intersection (External Fiber) $h / H=1$ 


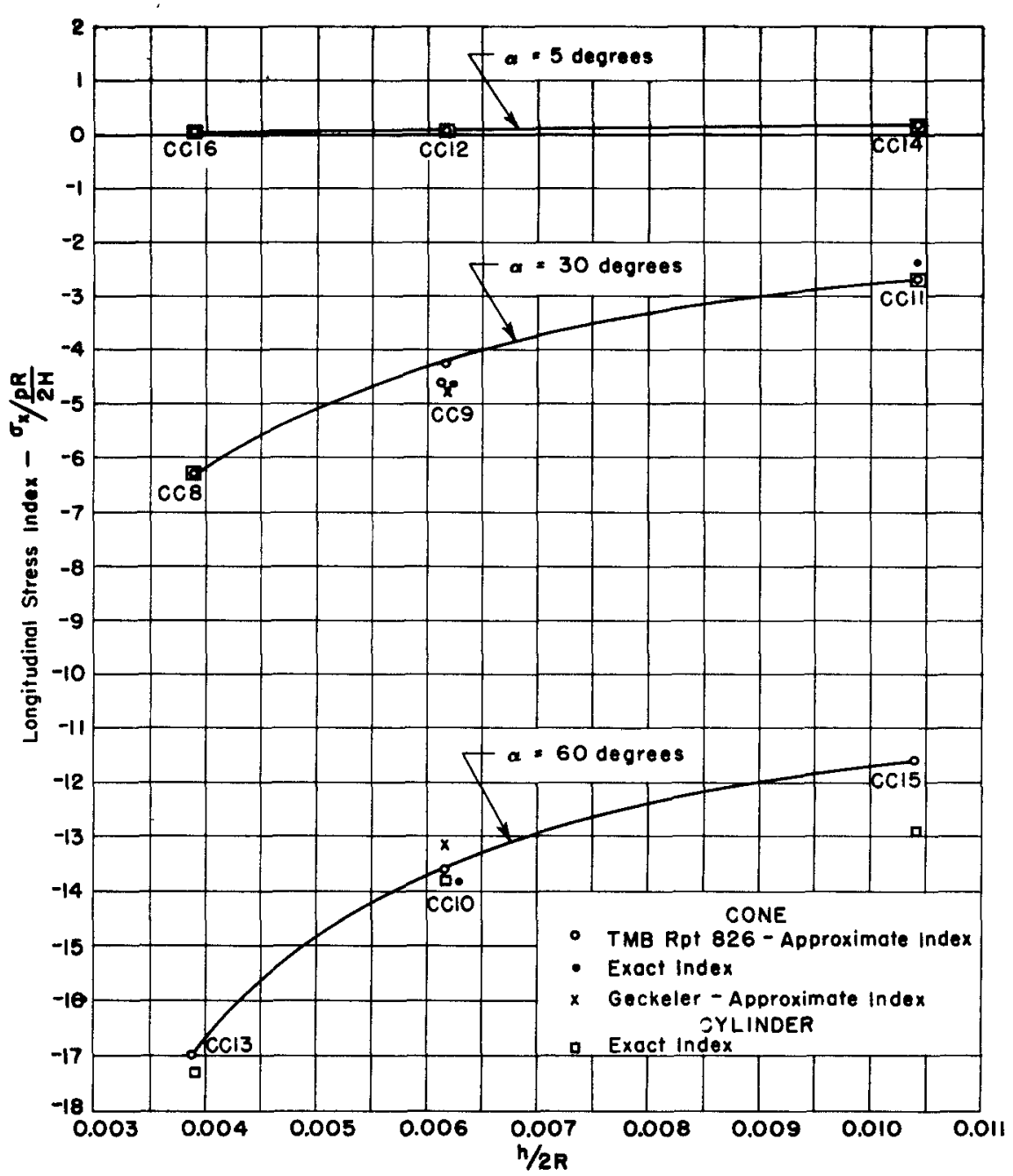

Figure 62 - Maximum Theoretical Longitudinal Stress Indexes in Conical and Cylindrical Shell at the Intersection (External Fiber) $h / H=1$ 


\section{REFERENCES}

1. Research and Development Project Card, NS 731-038, dated 31 Mar 1952.

2. Wenk, E., Jr. and Taylor, C.E., "Analysis of Stresses at the Reinforced Intersection of Conical and Cylindrical Shells," David Taylor Model Basin Report 826 (Mar 1953).

3. Taylor, C.E. and Wenk, E., Jr., "Analysis of Stresses in the Conical Elements of Shell Structures," Paper submitted to Second National Congress of Applied Mechanics, Ann Arbor, Michigan (1954). Also David Taylor Model Basin Report 981 (in preparation).

4. Kooistra, L.F. and Blaser, R.U., "Experimental Technique in Pressure-Vessel Testing," Transactions, ASME, Vol. 72, No. 5 (Jul 1950), pp. 579-589.

5. O'Brien, H.L., et al, "Design Correlations for Cylindrical Pressure Vessels with Conical or Toriconical Heads," The Welding Journal, Vol. 29, No. 7 (Jul 1950), pp. 336s-342s.

6. Design Division, Pressure Vessel Research Project, "Final Report," Purdue University (Aug 31, 1952).

7. Smith, L.W., "An Investigation of Discontinuity Stresses in Pressure Vessels by Means of Three-Dimensional Photo-Elasticity," Doctoral Thesis, Purdue University (Aug 1952).

8. Geckeler, J., "Uber die Festigkeit achsensymmetrischer Schalen," Forsch. Ing. Wes., Berlin, Vol. 276, (1926), p. 21.

9. Wetterstrom, E., "Discontinuity Stresses in Pressure Vessels," Master's Thesis, Purdue University (1947).

10. Meissner, E., "Uber Elastizitat und Festigkeit dunner Schalen," Viert. Natur. Gesellschaft, Vol. 60 (1915), pp. 23-47.

11. Villars, D.S., "Statistical Design and Analysis of Experiments for Developmental Research," Wm. C. Brown Company, Dubuque, Iowa (1951), pp. 226-229.

12. Sturm, R.G., "A Study of the Collapsing Pressure of Thin-Walled Cylinders," University of Illinois Bulletin No. 12 (Nov 1941). For further information see Bodner, S.R. and Berks, W., Pibal Report 210, Polytechnic Institute of Brooklyn (Dec 1952).

13. Wu, T.S., et al, "Effect of Small Initial Irregularities on the Stresses in Cylindrical Shells," Structural Research Series No. 50, University of Illinois (Apr 1953).

14. Timoshenko, S., "Theory of Plates and Shells," McGraw-Hill Book Company, Inc., New York (1940), pp. 389-395 and 409.

15. Dubois, F., "Uber die Festigkeit der Kegelschale," Doctorate Dissertation, Zurich (1917).

16. Watts, G.W. and Burrows, W.R., "The Basic Elastic Theory of Vessel Heads under Internal Pressure," Journal of Applied Mechanics, Vol. 16 (1949), pp. 55-73.

17. Watts, G.W. and Lang, H.A., "Stresses in a Pressure Vessel with a Conical Head," Transactions, ASME, Vol. 74, No. 3 (Jun 1952), pp. 315-326. Also corrections to the above letter from authors, dated Mar 16, 1953. 